\title{
MITTELFRÄNKISCH-NIEDERFRÄNKISCHE STUDIEN.
}

\section{Das ripuarisch-niederfränkische übergangsgebiet.}

1.

Man hat sich daran gewöhnt, die Benrather linie als grenze zwischen mittelfränkisch und niederfränkisch, und die zwischen Benrather und Ürdinger linie gelegene zone als übergangsgebiet zu betrachten.1) Diese auf der lautverschiebung beruhende einteilung stützt sich vor allem darauf, daß nördlich der Benrather linie noch zahlreiche verschobene formen mit mehr oder minder festem grenzverlauf begegnen. In einem schmalen streifen am linken Rheinufer lassen sich diese verschiebungen sogar bis Hohenbudberg-Traar, also bis zur Ürdinger linie beobachten ${ }^{2}$ ); und auf dem rechten Rheinufer gehen sie vereinzelt noch über die Ürdinger linie hinaus. ${ }^{3}$ ) Nun aber können nach DDG. I §59 und DDG. V § 258 die linksrheinischen teile der beiden linien vom standpunkt des localforschers nicht mehr als hauptsprachgrenzen gelten. Ebensowenig kommt ihnen aber eine über die mittelalterliche territorialgeschichte hinausreichende bedeutung zu. Bremers versuch, die Ürdinger linie mit der ausdehnung der salischen oder

1) So z. b. Behaghel, Geschichte der deutschen sprache $^{3} \$ \S 34.35$; anders J. Franck, Afrk. gramm. s. 2.

2) Ramisch, Studien zur niederrbeinischen dialektgeographie, Marburg 1908 in DDG. (= Deutsche dialektgeographie hsg. von F. Wrede) I $\$ 16$; vgl. auch Frings, Studien zur dialektgeographie des Niederrheins zwischen Düsseldorf und Aachen, Marburg $1913=$ DDG. V § $161 \mathrm{ff}$.

3) Lobbes, Nordbergische dialektgeographie, Marburg 1914 in ING. VIII § 22; Jeihener, Cronenberger wörterbuch, Marburg $1908=--1) \mathrm{DG}$. II § 82 . 
hattuarischen Franken zusammenzubringen (Grdr. III2 887. 894), erscheint nach Ramischs untersuchungen DDG. I $\$ 63 \mathrm{ff}$. hinfiillig; und die alte vorstellung von einem unmittelbaren zusammenhang zwischen der Benrather linie und der nordgrenze des ehemaligen 'ducatus Ribuariensis' ist Beitr. 39, $362 \mathrm{ff}$. zerstört worden. Für eine teilstrecke der Ürdinger linie links des Rheins fehlt überhaupt jeder historische anhaltspunkt; für den in unmittelbarer nähe des Rheins gelegenen teil und für die Bemrather linie links des Rheins aber ist die enge abhängigkeit von der mittelalterlichen territorialgeschichte durch die genannten untersuchungen erwiesen. Ähnlich liegen die verhältnisse in dem bergischen gebiete rechts des Rheins. Auch hier erscheinen alle versuche, die Ürdinger linie mit der grenze des salischen oder hattuarischen stammgebietes zusammenzubringen, nach Lobbes, DDG. VIII §§ 118-121 vergeblich. Vielmehr ist die grundlage für die nächst dem Rheine gelegenen teile der Ürdinger und der Benrather linie nach Lobbes, DDG. VIII $\$ 87$ ff. und Leihener, DDG. II $\S \S 118 \mathrm{f}$. $124 \mathrm{ff}$. in der geschichte der mittelalterlichen territorien $\mathbf{z u}$ suchen. Für den rest der beiden linien bis zu ihrer vereinigung bei Wermelskirchen, namentlich also für den südostverlauf der Ürdinger linie, läßt sich nach den untersuchungen der genannten forscher nichts sicheres feststellen : nur die spätmittelalterliche kleinpolitische geschichte vermag hier einige unbefriedigende anhaltspunkte zu bieten. Durch diesen mangel an geschlossener historischer bedeutung scheint der wert der lautverschiebungslinien als sprachlicher einteilungsprincipien stark erschüttert; falls sie nicht eine besondere fülle anderer sprachlicher grenzen auf sich vereinen, müssen sie hinter linien, die gleichzeitig starke historische und sprachliche scheiden bilden, zurücktreten. So hat Ramisch, DDG. I $\$ 59$ die ou/o $\chi$ 'euch'-grenze, die mit der gutturalisierungslinie von $\boldsymbol{n}+$ dental (hōnt/hork 'hund') und der scheide zwischen erhaltener und vocalisierter spirans in der verbindung cht (naxx/nout, nęit 'nacht') 1) im allgemeinen zusammenfällt, als hauptsprachscheide gegenüber der sprachlich und historisch unbedeutenden Ürdinger linie gefordert; so ist DDG. V § 258 die $z e g a / z \bar{a} \gamma \partial-$

1) Vgl. auch die DDG. I beigegebenen pauscn. 
linie als normallinie aufgestellt worden, weil ihr die Benrather linie sprachlich und historisch unterlegen schien. So hat sich aber auch anderseits auf dem rechten Rheinufer die Ürdinger linie in den gebieten von Leihener und Lobbes trotz ihrer stellenweisen historischen unzulänglichkeit und trotz einer kleinen, unten erwähnten abweichung als hauptsprachscheide gehalten, weil sie eine masse anderer sprachgrenzen auf sich vereinigt. ${ }^{1}$ ) Die Benrather linie steht hier der Ürdinger linie vollends nach. ${ }^{2}$ ) Als sicheres ergebnis dieser über die localforschung hinausblickenden betrachtung scheint darnach festzustehen, daß die Benrather linie in zukunft nicht mehr als einschneidende dialektgrenze, also auch nicht mehr als ripuarisch-niederfränkische grenze gelten kann. Im übrigen aber scheint uns die niederrheinische dialektforschung mit ihren beiden neuen sprachscheiden links des Rheins und ihrem conservativen festhalten an dem rechtsrheinischen teil der Ürdinger linie in eine schlimme anarchie gestürzt zu haben. Wie lassen sich nun die drei linien zu einem neuen einteilungsprincip verknüpfen und in welchem verhältnis würde die neubegrenzung zu der alten gruppierung nach lautverschiebungslinien stehen? Wie ordnen sich endlich dem neuen einteilungsprincip die tausend stücke unter, in die die jüngste forschung die niederrheinischen mundarten zerschlagen hat?

Mit diesen fragen sind im grunde zwei andere eng rerknüpft: was ist niederfränkisch? was ist ripuarisch? Es ist längst bekannt, daß die tenuisverschiebungen aus mannigfachen gründen schon seit dem 13. jh. über ihre normallinie nach norden hinausstreben. ${ }^{3}$ ) Es steht nichts im wege anzunelımen, daß dieselbe nordwärtsstrebende bewegung auch anderen ripuarischen erscheinungen innewolnt oder innegewohnt hat. Die stadien und grenzen dieser ripuarischen eroberung sind schwer zu entwirren; und jeder in dieser richtung zu unternehmende versuch wird sich zumächst mit. der frage abfinden müssen, welche erscheinungen fïr das

1) Vgl. z. b. die zusammenstellungen bei Leihener, DI)(7. II $\$$ 9) und die abwägung der hauptlinien ebda. \$109; vgl. auch Lobbes, II)( $\S \S 77.82$.

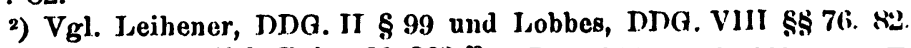

8) Vgl. namentlich Beitr. 39, $362 \mathrm{ff}$. 
niederfrïkische charakteristisch sind und welche siidliche ausdehnung diese erscheinungen noch heute besitzen. Je klarer die eigenheiten des unberührten niederfränkischen sprachgebietes erkannt sind, um so leichter wird es sein, in dem gebiete der ripuarischen eroberung eingeborenes und eingeflossenes nach inhalt, zeit und umfang zu scheiden.

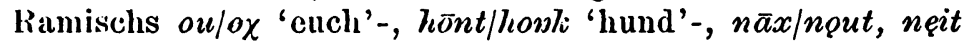
'nacht'-linie, die nach den beiden letzten erscheinungen treffend gutturalisierung's - oder vocalisierungslinie genannt wird, trifft nördlich der bereits erwähnten Strecke Traar-Hohenbudberg oder cinfacher nördlich Ürdingen mit der im übrigen einige kilometer südlich verlaufenden $e k / e \chi$-linie zusammen. ${ }^{1}$ Damit ergibt sich aber ein zwangloser anschluß an die rechtsrheinische normallinie bei Lobbes und Leilhener, die durch die Ürdinger linie gebildet wird; hierbei soll allerdings nicht verschwiegen werden, daß unmittelbar am rechten Rheinufer eine kleine differenz zwischen Ürdinger linie und rechtsrheinischer normallinie dadurch entsteht, daß die $c \chi$-orte Angerhausen und Wanheim nach Lobbes, DDG. VIII §§ 77. 92. 93 aus sprachlichen und historischen gründen dem norden zugewiesen werden müssen. Doch ist die abweichung so unbedeutend, daß wir Ürdinger linie und rechtsrheinische normallinie unbedenklich gleichsetzen können. So wäre denn für das weite niederfränkische gebiet von der holländischen bis zur westfälischen grenze, von Herongen nördlich Kaldenkirchen im westen über Ürdingen a. Rhein bis Wermelskirchen im osten eine historisch oder sprachlich fest begrïndete südgrenze gewonnen. Man könnte sie die niederfränkische normalgrenze nennen. Sprachliche erscheinungen, die über das gesamte niederfränkische gebiet verbreitet sind und an dieser weiten grenze halt machen, sind darnach ohne zweifel als echtes niederfränkisches sprachgut $\mathrm{zu}$ betrachten. Ideal genommen dürften diese erscheinungen auch mit keiner einzigen ortschaft von der niederfränkischen normalgrenze abspringen.

1) Hier und in folgenden setze ich vorars, daß die karten der in betracht kommenden hefte von Wredes DDG. dem leser vorliegen. Für das verhältnis der Ürdinger linie zu den übrigen sprachscheiden vgl. auch die der arbeit von Ramisch, DDG. I beigegebenen pausen, namentlich I. II. 
Die wirklichkeit sieht freilich anders aus. Zunächst ist die zahl der erscheinungen, die die ganze nordecke der Rheinprovinz beherrschen und außerdem der niederfränkischen normalgrenze von westen bis osten treu bleiben, äußerst gering; und eine ideale linie entwickelt keine von ihnen. Man würde es schon in den kauf nehmen, daß Ramischs ou ${ }^{1) / 0 \chi-g r e n z e}$ bei Wachtendonk und Gelinter dadurch ins schwanken gerät, daß diese beiden ortschaften neben dem regulären nördlichen ou auch das südliche $\theta \%$ verwenden ${ }^{2}$, zumal sich für diese abweichung eine historische begründung bietet ${ }^{3}$ ) und außerdem ou gegenüber $o \chi$ die höflichkeitsform (nhd. 'Ihuen' gegenüber 'Euch') vertritt. Aber auf der rechten Rheinseite tritt statt ou der alte dual inj ein, der auch für Mülheim a.d. Ruhr belegt ist. ${ }^{4}$ ) Die linie $i \eta j k$, enjk, $\theta n k / \chi^{5}$ ) geht zwar eine strecke mit der niederfränkischen normalgrenze zusammen, läßt dann aber zwischen sich und ihr einen breiten streifen mit der dualform liegen; erst südlich von Wermelskirchen treffen beide linien wieder zusammen. Durch dieses südwestliche hinübergreifen der dualform ist es nicht möglich, in einer linie

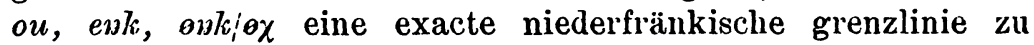
gewinnen; eine kleine abweichung unmittelbar am rechten Rheinufer, wodurch die nördlich der normallinie gelegenen ortschaften Wanheim und Angerhausen dem ox-gebiet zufallen, hätte man wie die linksrheinische unregelmäßigkeit bei Wachtendonk auf grund der besonderen historischen verhältnisse ${ }^{6}$ ) übersehen können.

Auch andere einzelerscheinungen, die auf der linken Rheinseite hoffnungsvoll einsetzen, versagen auf der rechten. Die 'muhme, tante, alte frau' lautet nordlich der gutturalisierungslinie $m \bar{\theta}: \ell$ und $m \theta^{\cdot} y$., das mit nl. moci, mnl. moeye, moye,

1) Zu linksrheinisch ou vgl. auch Hanenberg, Studien z.ur nicderrheinischen dialektgeographie zwischen Nymegen und ïrdingen, Malburg 1914 in DDG. VIII $\$ 242$.

2) Ramisch, DJUG. I $\$ 40$.

ग) Ramisch, DDG. I $\$ 59$.

4) Vgl. Maurmann, Grammatik der mundart, vou Miilhein a. d. Buhr, J,eipzig 1898, \$221; yu, das dem linksrheinischen ou lantgesetglich cuts]pricht, gilt auch hier nur als hïflichkeitsform.

s) Jeihener, DDG. II $\$ 87,4$; Lobbes, DD(1. VIII $\$ 61$.

") Loblses, DDG. VIII \$\$ 92.93. 
nınd. môie auf ahd. muoja zurïckweist, südlich jedoch mī:n,

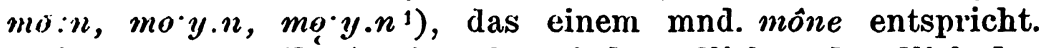
Auf der rechten Rheinseite aber sind nördlich und südlich der niederfräukischen normalgrenze nur die - $n$-formen $\mathrm{zu}$ belegen: (ronenberg mȳon, Wermelskirchen, Mülheim a.d. Ruhr my̆: $n^{2}$ ). Fiir 'hier' erscheinen nördlich der gutturalisierung'slinie ' $h i \cdot \partial . r$ und $h \bar{\imath}$ :, deren $i$-laute auf altes $\bar{e}$ zurückweisen (in demselben gebiete ri:p 'rief', brī:f 'brief'); südlich aber begegnen bis $z$ dem wiederum auf altes $\bar{c}$ weisenden rip. $h \bar{e}:{ }^{3}$ ) die formen

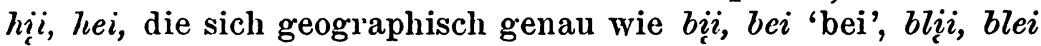
'blei' verteilen und dadurch ihre herkunft von einem ehemaligen $h \bar{\imath}(r)$ bezeugen. $\left.{ }^{4}\right)$ Wie sich zu dieser linksrheinischen $\bar{e} / \bar{\imath}-$ grenze das rechtsrheinische $h \bar{\imath}$ : in Mülheim a.d. Ruhr ${ }^{5}$ ) sowie die $h e \cdot i ., h \bar{\imath} ;, h \bar{\imath} \partial$ in Leiheners gebiet verhalten ${ }^{6}$ ), läßt sich nicht sicher beurteilen. Die arbeit von Lobbes, die die scheidung der WVupertaler formen nach ihrer $\bar{e}$ - oder $\bar{\imath}$-quelle durch eine vergleichende dialektgeographische betrachtung hätte bringen müssen, läßt uns bei diesem ebenso wichtigen wie schwierigen problem leider im stich.

Erst die wat/jęt 'etwas'-linie, die sich ebenfalls mit der gutturalisierungslinie deckt $^{7}$ ), kommt einer idealgrenze in etwa nahe. Kleine abweichungen und schwankungen an der holländischen grenze, bei denen namentlich wiederum Wachtendonk und Gelinter beteiligt sind, sowie die hier vorkommende compromißbildung węt, ferner die tatsache, daß auch in diesem falle Angerhausen und Wanheim südliches jęt aufweisen, und endlich eine nicht unbedeutende südöstliche ausbiegung bei Velbert, Neviges ${ }^{8}$ ), alles das kann nicht sonderlich stören, zumal sich die unregelmäßigkeiten meistens

1) Ramisch, DDG. I $\S 34,3$; DDG. V § 61.

2) Leihener, DDG. II im wörterbuch; Hasenclever, Der dialekt der gemeinde Wermelskirchen, diss. Marburg 1904, s. 88; Maurmann § 69. $\S 112 b$.

3) Münch, Grammatik der ripuarisch-fränkischen mundart, Bonn 1904,

4) Ramisch, DDG. I § 38 anm.; DDG. V § 242 I aum. 1.

5) Maurmann $\S \S 66.69$.

$\left.{ }^{6}\right) \mathrm{DDG}$. II $\S \S 26.74$ anm.

7) Ramisch, DDG. I $\$ 22 \mathrm{k}$; jęt $=$ ahd. iowicht.

8) Lobbes, DDG. VIII $\S 49$ anm. 3. 
historisch begründen lassen. 1) Damit ist in wat ein sicheres niederfränkisches charakteristikum (vgl. auch nl. wat 'etwas') mit normaler südgrenze gewonnen. Es befriedigt nicht ganz, weil es nur eine einzelerscheinung darstellt. Aber wertvoll ist es im zusammenhang mit den beiden niederfränkischen eigenheiten, die ganze wortgruppen beherrschen: dem conservativen festhalten der dentalen nasalis in der ursprünglichen verbindung $n+$ dental und der gutturalen spirans in der ursprünglichen verbindung cht. Ramischs vocalisierungs- und gutturalisierungslinie, die nur dadurch voneinander abweichen, daß Wachtendonk und Gelinter die gutturalisierung von $n$ + dental durchgeführt, die verbindung cht jedoch bewahrt haben ${ }^{2}$ ), setzen sich östlich des Rheins in der Ürdinger linie fort. Sieht man über zwei kleine abweichungen, die Angerhausen und Wanheim zum vocalisierungsgebiet, und das nördlich der Ürdinger linie gelegene Kettwig zum gutturalisierungsgebiet schlagen ${ }^{3}$ ), hinweg, so gehen die drei linien bis an die stelle zusammen, wo die Ürdinger linie nach südosten in der richtung Wermelskirchen abbiegt. Die gutturalisierunglinie weist nun zunächst die nordöstlich der Ürdinger linie gelegene ortschaft Vosnacken dem gutturalisierungsgebiete $\mathrm{zu}$, eine erscheinung, die sich durch historische verhältnisse begreifen läßt ${ }^{4}$, die aber besonders bedeutungsvoll dadurch erscheint, $\mathrm{da} B$ nunmehr die gutturalisierungslinie sich an die westfälische -et-linie anlehnt und, von gelegentlichen südwestlichen abbiegungen abgesehen, ilhr auch im ganzen treu bleibt. Allerdings soll es nicht verschwiegen werden, daß Lobbes, der eine für alle beispiele geltende linie aufstellt, und Leihener, der nur 'winter' und 'andern' untersucht ${ }^{5}$ ), insofern voneinander abweichen, als Leihener eine viel stärkere anlehnung an die -et-linie als Lobbes verzeichnet, nach der linienführung von Lobbes also noch einige ortschaften, wie z. b. Ost-Barmen, von

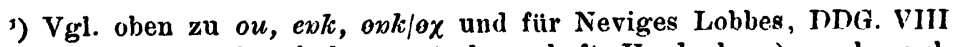
$\S 103$ (grenzen der bergischen unterherrschaft Hardenberg); vgl. auch Maurmann §228 vat, Leibener, DDG. II wörterbuch gęt.

2) Vgl. panse I bei Ramisch, DDG. I.

3) Nach den grenzangaben bei Lobbes, DDr. VIII $\$ \$ 31.48$.

) Lobbes, DDG. VIII $\S 106$.

๖) Leihener, DDG. II \$§ 83. 97. 
der gut turalisierung verschont bleiben. Diese differenz zwischen zwei gewissenhaften forschern beruht nicht etwa auf falscher beobactitung des einen oder andern; sie wird vielmehr in den dialektischen schwankungen des streifens zwischen Ürdinger und -et-linie begründet sein, einer erscheinung, die für die lösung der ripuarisch-niederfränkischen grenzfrage wichtige anhaltspunkte bietet. Auch die vocalisierungslinie weist Vosnacken dem suidwesten zu; auch sie folgt von hier an der -et-linie, so daß z. b. Elberfeld, Barmen trotz ihrer lage östlich der Ürdinger linie dem vocalisierungsgebiete zufallen. Aber sie weicht von der gutturalisierungslinie darin bedeutsam $a b$, daß sie sich südlich der genannten städte wiederum mit der Ürdinger linie vereinigt. ${ }^{1}$ ) Auch in diesem falle stimmen Leihener und Lobbes aus dem genannten grunde nicht ganz überein. Lobbes' für alle beispiele gültige linie deckt sich nur mit Leiheners 'tochter'-grenze; im übrigen aber weist Lobbes gegen Leihener Ost-Barmen dem cht-gebiete zu.

Somit wären zwei für ganze wortgruppen geltende erscheinungen, die uns auf dem niederfränkischen gebiete der nördlichen rheinprovinz wohl bezeugt sind2), mit mehr oder minder großen abweichungen an der niederfränkischen normalgrenze festgelegt. Aber anch diese beiden erscheinungen sind untereinander von verschiedenem wert. Schon die tatsache, daß Wachtendonk und Gelinter sich gegen die südlichen $\theta \chi$ und jęt sträuben und conservativ an dem ndfrk. $\operatorname{ch}(t)$ festhalten, dagegen die gutturalisierung durchführen, erweist die verbindung cht als ein besonders widerstandskräftiges charakteristicum; und ihr oben auseinandergelegtes verhältnis zur -et- und ek/ex-linie vermag diese erkenntnis nur zu stützen. Auch die von Lobbes, DDG. VIII $§ 50$ anm. 2 für Vosnacken

1) Vgl. Leihener, DDG. II §§ 34. 71. 72. 95. 96; Lobbes, DDG. VIII § 48.

2) Für die erhaltung der dentalen nasalis in der verbindung $\boldsymbol{n}+$ dental vgl. auch Meynen, Über die mundart von Homberg-Niederrhein, diss. Leipzig 1911, s. 24; Hanenberg, DDG. VIII $\S \S 141.237$; Neuse, Studien zur niederrheinischen dialektgeographie in den kreisen Rees, Dinslaken, Hamborn, Mülheim, Duisburg, in DDG. VIII §§ 206. 358; Maurmann §§ 96. 113. 160; für die erhaltung der gutturalen spirans in der verbindung cht Hanenberg §§ 13. 27. 57. 78. 88. 91. 117. 190. 228. 240; Neuse §§ 211. 237. 361; Maurmann $\S 150$; Koch, Die laute der Werdener mundart, disș. Münster 1879, §§ 37. 42 . 
nachgewiesenen nāt 'nacht', gəbrāt 'gebracht' gehören unter diesen gesichtspunkt. Sie sind keineswegs mit den DDG. V $\S \S 222.228$ nachgewiesenen gleichlautenden ripuarischen formen, die durch dehnung und ch-schwund entstanden sind, zu vergleichen. Für ihre entstehung sind überhaupt keine lautphysiologischen momente, wie Lobbes annimmt, entscheidend gewesen. Vielmehr ist die von Lobbes richtig erkannte grenzstellung allein verantwortlich zu machen: während in allen anderen fällen die südwestlichen vocalisierten formen an die -et-linie vordrangen, ist aus dem widerstrebenden -acht und dem vorwärtsrückenden -ęit das - $\bar{a} t$ durch mechanische addition entstanden, ein sicherer beweis, daß an dieser stelle ehedem Ürdinger und vocalisierungslinie zusammengegangen sind. Somit wäre von den augenblicklichen mundartlichen verhältnissen aus betrachtet das gebiet der erhaltenen spirans in der verbindung cht als niederfränkisches sprachgebiet und demnach die vocalisierungslinie als die der niederfränkischen normallinie am ehesten entsprechende sprachgrenze zu betrachten. Sprachliche erscheinungen, deren ausdehnung zum gebiete der erhaltenen gutturalen spirans enge geographische beziehungen aufweisen, sind darnach als niederfränkische eigenarten zu werten.

Diese vorzugsstellung der vocalisierungslinie läßt sich noch durch eine letzte beobachtung fest begründen. Südlich der linksrheinischen vocalisierungslinie herrscht im anlaut die stimmhaft palatale spirans $j$, im inlaut stimmhaft palatales $j$ oder stimmhaft gutturales $\gamma$ ( $j$ nach palatalem vocal und $l$ oder $r, \gamma$ nach gutturalem vocal), im auslaut stimmlos palatales $\chi$ oder gutturales $x$. Nördlich der vocalisierungslinie erscheint jedoch anlautend und auslautend stimmlos gutturales $x$, inlautend stimmhaft gutturales $\gamma$, und diese gutturallante greifen im äußersten westen an der holländischen grenze stellenweise auch in das vocalisierungsgebiet hinïber - eine unebenheit, die vorläufig ïbersehen werden soll.1) Merkwürdigerweise belegt nun Hanenberg für Kalkar im anlant. gegenüber Ramischs stimmlos gutturaler spirans $x$ die stimm-

1) Ramisch, DDG. I $\$ 19$; vgl. anch DDA. V $\$ 170$ und din dort licigebrachten weiteren belege. 
haft gutturale spirans $\gamma$, und im auslaut scheidet er wie in Ramisches palataldistrict $\chi$ und $x$. Neuse, DDG. VIII $\S 2$ benutzt für die ma. von Aldenrade nördlich Ruhrort, Meiderich die spirantenzeichen $g$ und $\chi$ ohne bestimmte qualitätsangabe: seine spiranten werden am harten oder weichen gaumen erzeugt in sehr stark wechselnder klangfarbe. Doch kennt er $\$ 366$ für den anlaut eine rechtsrheinische grenze zwischen stimmhafter ${ }^{1}$ ) und stimmloser spirans, die Ruhrort, Meiderich, Hamborn, Sterkrade zum norden, Duisburg, Duissern, Speldorf, Mïlheim, Styrum zum süden schlägt. Das stimmt denn auch mit den angaben Maurmanns $\$ 124$ und den beobachtungen Lobbes', DDG. VIII § 24 überein, wonach nördlich der Ürdinger linie dieselben verhältnisse wie in Ramischs gutturalisierungsgebiet herrschen. Hält man hierzu noch die angaben Meynens für Homberg b. Mörs S. 11, wonach im anlaut und inlaut stimmhafte, augenscheinlich gutturale spirans, im auslaut die postpalatale oder vordervelare stimmlose spirans herrschen, so ergäbe sich für die niederrheinische spirantenarticulation nördlich der vocalisierungslinie das folgende bild: die nur südlich der vocalisierungslinie auftretende präpalatale articulation ist dem norden fremd. Hier herrscht in unmittelbarer nähe der vocalisierungslinie (Ramisch, Maurmann, Lobbes) eine ausgesprochen velare, im übrigen norden (Meynen, Hanenberg, Neuse) aber eine palatal-velare grenzarticulation. Dieser nordsüdlichen abstufung palatal-velar | velar | palatal entspricht geographisch die abstufung stimmhaft | stimmlos / stimmhaft für den anlaut, so daß die velarzone gleichzeitig das gebiet der stimmlosen anlautenden spirans ist. Da die spirantenlinie somit auf bergischem boden keine wesentlichen abbiegungen zur -et-linie zeigt2), so könnte sie noch eher als die vocalisierungslinie geeignet erscheinen, als niederfränkische normalscheide zu dienen. Hiergegen sprechen jedoch die grenzmundarten von Cronenberg, Remscheid und Ronsdorf südwestlich der Ürdinger linie. Schon Leihener hatte DDG. II $\$ 18$ für den postpalatalen als auch den velaren stimmhaften reibelaut

1) Vgl. auch § 223 .

2) Der verschlußlaut $g$ in Elberfeld ist wohl kaum als grenzlaut anzusprechen, wie Lobbes, DDG. VIII § 25 meint. 
dasselbe zeichen gewählt $(g)$; dessen lautwert hatte er in festen gegensatz zum präpalatalen reibelaut $j=$ germ. $j$ gestellt; und mit $\chi$ hatte er aus praktischen gründen gleichfalls sowohl den stimmlosen palatalen als auch den stimmlosen velaren reibelaut bezeichnet, da beider articulationsstellen in seiner ma. nicht weit auseinander liegen. Durch Lobbes' beobachtungen DDG. VIII $\S 25$ wissen wir jetzt, daß die stimmhafte anlautende spirans in dem genannten gebiete ihre velare natur mit dem osten, ihre stimmhaftigkeit dagegen mit dem westen gemein hat, daß ferner die verhältnisse des in- und auslautes denen der maa. außerhalb der rechtsrheinischen normallinie entsprechen. Wir bewegen uns also auf einem compromißgebiet, in dem der westen den osten $\mathbf{z u}$ überflügeln droht. Die stimmhaftigkeit der anlautenden spirans ist der erste erfolg; und der von Leihener im gegensatz zu Lobbes angedeutete palatale einschlag scheint einen weiteren eroberungszug anzudeuten. Solange dieser kein festes verhältnis zur niederfränkischen normallinie gewonnen hat, kann die spirantenlinie nicht als charakteristische niederfränkische sprachscheide angesprochen werden. Wertvoll erscheint sie nur dadurch, daß sie die bedeutung der vocalisierungslinie kräftig unterstreicht. Übrigens ist es kein zufall, daß die beiden linien so enge geographische beziehungen miteinander aufweisen. Nördlich der vocalisierungslinie hat die stimmlose spirans in der verbindung $c h(t)$ denselben lautwert wie die auslautende $g$-spirans, d. h. einen vorwiegend velaren charakter, auch nach palatalvocal. Im vocalisierungsgebiet erscheint jedoch in den sporadischen fällen erhaltener ch-spirans eine palatale und eine velare articulation je nach dem charakter des vorhergehenden vocals, was ebenfalls mit den lautwerten der auslautenden $g$-spirans übereinstimmt. Mit recht hat, daher schon Ramisch, DDG. I $§ 19$ vermutet, daß die erhaltung der spirans in der verbindung cht in der vorwiegend velaren (gutturalen), die vocalisierung jedoch in der vorwiegend palatalen spirantenarticulation der entsprechenden gebiete begründet ist. $\left.{ }^{1}\right)$

Niederfränkisches sprachmaterial läßt sich nummehr iiber

3) Vgl. auch DDG. V \& 223 . 
die bereits herausgehobenen einzelheiten hinaus durch ständigen vergleich mit der geographischen ausdehnung des cht-gebietes und der vocalisierungslinie leicht erkennen.

Aus dem gebiete des vocalismus kommt die entwicklung von westgerm. $\bar{c}, \bar{o}$ und dem in den rheinischen maa. mit westgerm. $\bar{c}$ zusammengehenden $e o$ in betracht. Ramisch belegt DDG. I §§ 34. 38 für das gebiet von Geldern und Mörs einen $\bar{i}: \bar{\imath}:$; $\bar{y}:$-laut ${ }^{1}$ ), dessen südgrenze sich mit der gutturalisierungslinie von $n+$ dental vergleichen läßt. Auch sonst sind uns $\bar{\imath}-, \bar{u}$-, $\bar{y}$-entsprechungen in dem linksrheinischen nordwestzipfel der Rheinprovinz wohl bezeugt. ${ }^{2}$ ) Diesen nfrk. $\bar{\imath}: \bar{u}: ; \bar{y}: ; \bar{\imath}-, \bar{u}-, \bar{y}$ lauten schließen sich nach süden sowohl monophthongische $\bar{e}$; $\bar{o}:, \bar{\theta}:$ als diphthongische $e^{\cdot} i, o^{\cdot} u ., \theta^{\cdot} y$. an. Ramischs vermutung, daß die am Rhein um Krefeld und Ürdingen zwischen den nördlichen und südlichen monophthongen auftretenden diphthonge compromißbildungen sein könnten, ist DDG. V $\S \S 140$. 142. 158. 328 dahin berichtigt, $\mathrm{daB}$ in diesen fällen secundüre entwicklungen aus alten $\bar{e}:, \bar{o}:, \bar{\theta}:$ vorliegen. Die damit gewonnene linksrheinische $\bar{\imath}: \bar{u}:, \bar{y}: \mid \bar{e}: ; \bar{o}:, \bar{\theta}:-$ linie deckt sich nur im äußersten westen an der holländischen grenze mit der vocalisierungslinie. Im übrigen aber weisen die nördlichsten vocalisierungsorte $\bar{\imath}: \bar{u}: ; \bar{y}$ :-laute auf, die somit über die niederfränkische normallinie nach süden hinübergreifen. Solche südliche vorsprünge begegnen namentlich in fällen, wo die $\bar{\imath}, \bar{u}$ und $\bar{y}$-qualitäten im hiatus oder im auslaut stehen. So weist Ramisch, DDG. I § 29 anm. 2 südlich der vocalisierungslinie formen wie blya 'blühen', bryə 'brühen' nach; so sind DDG. V $\S \S 142,2.143,1.2 .248,4$ in einem am Rhein

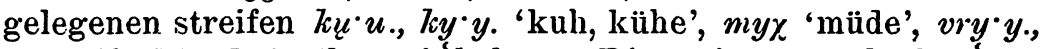

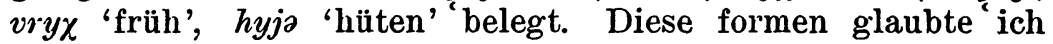
a. a. o. so verstehen zu müssen, daß die $u, y$-qualitäten den ihnen ursprünglich zustehenden bereich erweitert, mit andern worten über ihr niederfränkisches heimatsgebiet hinaus in den $\bar{o}: \bar{\theta}:$-district hineingewandert wären. Eine stütze für diese,erklärung schienen die vielfach $\mathrm{zu}$ beobachtenden geographischen

1) Letzteren für den umlaut von westgerm. $\bar{o}$.

2) Vgl. Hanenberg, DDG. VIII §§ 72. 79. 110. 209. 212. 219; Meynen s. 19. 20; Geerling, Die klevische volksmundart, Wesel 1841, s. 25. 31. 32 . 
besonderheiten von hiatus- und auslautsbildungen $\mathrm{zu}$ bieten.

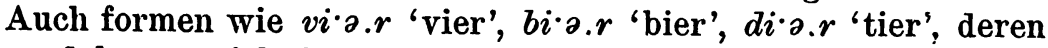
ausdehnung sich der der $u, y$-fälle vergleichen läßt (DDG. $\mathrm{V}$ $\S 158 \mathrm{a}$ ), schienen diese auffassung $\mathrm{zu}$ bestätigen. Sie hält jedoch nicht stand, wenn man die hiatus- und auslautfälle mit einer sonderentwicklung von westgerm. $\bar{o}$ in einer gruppe einsilbiger, auf $k$ schließender wörter vergleicht. In diesen fällen erscheint nämlich südlich Geldern ein gebiet mit kurzem $u$ (buk 'buch', duk 'tuch' u.s. w.), das über das mittelstück der linksrheinischen vocalisierungslinie so weit nach süden hinausreicht, daß ihm selbst einige orte, die sonst zum $\bar{o}$ :-gebiet gehören, zufallen. Umgekehrt aber zeigen die $\bar{u}$ :-orte in unmittelbarer nähe des Rheins ein $\bar{o}$ :, also ein $b \bar{o}: k$ 'buch' gegenüber einem hier zu erwartenden $b \bar{u}: k$. Und endlich erscheint in mehreren zwischen dem $b u k$ - und dem $b \bar{o}: k$-gebiet gelegenen ortschaften, z. b. in Krefeld, die compromißbildung $u+\bar{o}:=0$, also bok.1) Diese wirren geographischen verhältnisse hat schon Ramisch DDG. I $§ 35$ zu lösen versucht. Er erschließt für das ganze gebiet, das heute den typus buk aufweist, die priorität der $\bar{u}$ :-entsprechung für westgerm. $\bar{o}$ überhaupt; die $\bar{o}$ :-formen hätten dann die $\bar{u}$ :-formen verdrängt, d. h. statt blü:t 'blut' wäre blō:t eingetreten; die $u$-formen seien erhalten geblieben, weil die kürzung von $\bar{u}:>\imath$ schon vor dem allgemeinen ersatz der $\bar{u}:-$ durch die $\bar{o}:$-formen eingetreten war. Es hätte also eine verschiebung der lautgrenze $\bar{u}: / \bar{o}$ : in südnördlicher richtung stattgefunden. Den umgekehrten vorgang nimmt Ramisch für den typus $b \bar{o}: k$ im $\bar{u}$ :-gebiet an; hier wäre mit der priorität der $\bar{o}$ :-entsprechung für westgerm. $\bar{o}$ überhaupt zu rechnen; die $\bar{u}:$-formen hätten die $\bar{o}:$-formen verdrängt. d. h. statt blō:t 'blut' wäre blü:t eingetreten; warum ein blü:t zwar ein blō:t verdrängen konnte, nicht aber statt $b \bar{o}: k$ ein $b \bar{u}: l k$ eintrat, erkläre sich daraus, daß bei dem eindringen der $\bar{u}$ :-formen aus dem norden dort die kürzung von $\bar{u}:>\boldsymbol{u}$ in buk schon vollzogen war, als im süden noch $b \bar{o}: k$ galt; eine form $b u k$ aber konnte ein $b \bar{o}: k$ nicht so leicht verdrängen, wie ein $b l \bar{u} . t$ an die stelle von blō.t treten konnte. In ummittel-

1) Ähnliches weist Ramisch, DDG. I $\$ 34$ nnm. 2 und s. 34 fuBnote 3 auch für die zweisilbigen 'rufen' und 'suchen' nach. 
barer nähe des lRheins hätte also eine verschiebung der lautgrenze $\pi: / \ddot{o}$ : in nordsüdlicher richtung stattgefunden. Ramischs anschauung von der südnördlichen verschiebung der ii:/o:-grenze wird man bedingungslos beipflichten. Es liegt aber kein grund vor, unmittelbar östlich von dieser verschiebung den umgekehrten proceß anzunehmen. Gerade das an der schwelle der $b u k$ - und $b \bar{o}: k$-gebiete auftretende compromiß bol beweist durch die vocalqualität $o$, daß die $\bar{o}:-$ formen auf das $\iota$-gebiet übergeflossen sind. So hat denn auch unmittelbar am Rhein der typus $b \bar{o}: \bar{k}$ von altem $\bar{u}$ :-gebiet besitz genommen und sich dabei bis zur niederfränkischen normallinie, der vocalisierungslinie, ausgedehnt. So sind denn auch die hiatus- und auslautsfälle mit $\iota, y$-qualität nicht etwa im sinne Ramischs und der DDG. $V$ vertretenen anschaungen als niederfränkische eindringlinge, sondern wie die kurzen $u<$ westgerm. $\bar{o}$ als relicte eines im übrigen von $o$, $\theta$-qualitäten eroberten ehemaligen $u, y$-gebietes zu fassen. Dieser eroberungszug der rip. $\bar{o}:, \bar{\theta}:$-entsprechungen von westgerm. $\bar{o}$ stellt sich in unmittelbare parallele $\mathrm{zu}$ der längst bekannten tendenz lautverschobener formen, das gebiet zwischen der Benrather und der Ürdinger linie zu durchdringen; und es dürfte kein zufall sein, daß die nördlichsten abweichungen von der Benrather linie an der zu eingang erwähnten strecke Hohenbudberg-Traar mit der nordgrenze des typus $b \bar{o}: k$ zusammentreffen; lautverschobene ripuarische formen und rip. $\bar{o}$ :, $\bar{\theta}$ : aus westgerm. $\bar{o}$ haben altes niederfränkisches sprachgebiet in unmittelbarer nähe des Rheins bis zur vocalisierungslinie besetzt. Die ortschaften Wachtendonk und Gelinter rechtfertigen diese auffassung. Sie liegen nördlich der vocalisierungslinie, weisen aber vielfach südliche formen auf; an dieser stelle ist die sonst so feste niederfränkische normallinie besonders erfolgreich von südlichen eindringlingen durchbrochen worden. Wenn in diesen ortschaften nun nach Ramischs zeugnis für westgerm. $\bar{e}$, eo und $\bar{o}$ gegenüber den sonst geschlossenen nfrk. $\bar{\imath}:, \bar{\imath}:, \bar{y}:$-lauten offene $\bar{\imath}:, \bar{u}:, \bar{y}:$ erscheinen, die als compromi $\beta$ zwischen nfrk. $\bar{\imath}:, \bar{u}:, \bar{y}:$ und rip. $\bar{e}:, \bar{o}:, \bar{\theta}:$ erklärt werden müssen, so ist damit ein letzter gewichtiger beweis für die nordwärtsstrebende tendenz der rip. $\bar{o}:, \bar{\theta}$ : und ebenso des rip. $\bar{e}$ : erbracht. Man könnte schon an dieser stelle der 
untersuchung die allgemeine folgerung ziehen, daß alle sprachformen des übergangsgebietes, die auch nördlich der vocalisierungslinie gelten, altes bodenständiges niederfränkisches sprachgut darstellen; die vocalisierungslinie erschiene dann als ein letzter wall, den das niederfränkische aus noch näher zu bestimmenden ursachen dem nordwärts dringenden ripuarischen entgegengestellt hat.

Rechtsrheinisch bietet sich auf den ersten blick ein undurchdringlicher wirrwar dar. Die rip. $\bar{e}:, \bar{o}:, \bar{\theta}:$-laute umfassen nur einen schmalen streifen am Rhein entlang mit Düsseldorf im mittelpunkt. Nach Lobbes, DDG. VIII $\S 36$ reichen sie bis zu einer linie Angermund-Ratingen-Gerresheim; die auf der linken Rheinseite in consequentem westostverlauf dahinziehende nordgrenze der $\bar{e}: \bar{o}:, \bar{\theta}:$ biegt also unmittelbar nach überschreiten des Rheins in südlicher richtung ab. Der ganze nordosten der Rheinprovinz weist im übrigen lange $i, u$ und $y$-qualitäten auf, die sich quantitativ und accentuell vielfach voneinander unterscheiden. $\left.{ }^{1}\right)$ In den ostrand der nördlichen Rheinprovinz greifen längs der -e(n)/-etgrenze an manchen stellen westfälische $\bar{e}, \bar{o}, \bar{\theta}$-laute hinein, ohne daß die beiden sprachgrenzen sich etwa ort für ort deckten. Die scheide zwischen $\bar{q}: \bar{\imath}: \bar{y}:-$ und $\bar{e}, \bar{o}, \bar{\theta}$-entsprechungen von westgerm. $\bar{e}, e o, \bar{o}$ läuft zwischen MülheimRuhr und Werden durch. ${ }^{2}$ ) Südlich Werden reichen die $\bar{e}, \bar{o}$, $\bar{\theta}$-laute bis zur Ürdinger linie in die Rheinprovinz hinein. $e i, q u$, $\theta y$-diphthonge, die sporadisch an der grenzlinie auftauchen, sind durch junge diphthongierung aus $\bar{e}, \bar{o}, \bar{\theta}$ entstanden; dies erhellt namentlich aus der geographischen gruppierung im gebiete Leiheners; denn die $\bar{\imath} \cdot e ., \bar{\imath} \cdot a ., \bar{e}$, ęi- und $\bar{u} \cdot e ., \bar{u} \cdot a$. , $\bar{o}, \bar{\sigma} \cdot a ., \quad q u$-entsprechungen (einschließlich umlaut) von westgerm. $\bar{e}, e o, \bar{o}$ scheiden sich an der Ürdinger linie so, daß die $i, u$-laute dem westen, die $e, o$-laute und ihre diphthongischen sprößlinge dem osten zufallen. ${ }^{3}$ ) In welchem verhältnis stehen nun die ripuarischen $\bar{c}: \bar{o}$ : und die westfälischen $\bar{\sigma}, \bar{o}$ zu einander? Die immer wieder auftauchende ansicht, die rip. $\bar{c} \therefore$ :

1) Vgl. Neuse, DDG. VIII $\$ \$ 90 \mathrm{ff} .95 \mathrm{ff} .102 \mathrm{ff} .152 \mathrm{ff} .3012 .3114 .335$. 337; Maurnann $\$ \$ 66$. 68 f. 82; Hascnclever $\$ \$ 38.40 .44$.

2) Koch-Werden belegt $\$ \$ 15,2.20$ lange $c$, $\delta$-laute.

3) Vgl. Neuse a. a. o.; Leihener, DDG. 11 \$ $\$ 90$. 
wären aus alten diphthongen entstanden, wobei ihr accent ein letzter reflex elıemaliger diphthongischer aussprache sein soll, hofle ich demnächst zu widerlegen. Gerade der ihnen seit voralthochdeutscher zeit eigentümliche accent, für den DDG. V $\$ \$ 9.312$ fi. die bezeichnung 'schärfung' vorgeschlagen und begründet worden ist, hat die teilnahme an dem althochdeutschen diphthongierungsproceß verhindert, dafür aber stellenweise die schon oben erwähnten $e^{\bullet} i$,, $o^{\cdot} u$. erzeugt. Daß westgerm. eo mit westgerm. $\bar{e}$ vollständig zusammengefallen ist, erklärt sich nicht etwa aus einer gemeinsamen ehemaligen diphthongstufe, sondern aus einem alten monophthongierungsproceß $e o>\bar{e}$. Derselbe proceß ist auch für die an die nordöstliche Rheinprovinz angrenzenden westfälisch-sächsischen maa. anzusetzen. Die dort begegnenden jungen diphthonge von der form $e i$, $q u$ beruhen auf überdehnung und zweigipfligkeit, sind also aus einem accentprincip entstanden, dessen eigenheiten zu den charakteristischen merkmalen der schärfung (DDG. V $\S 319)$ in directem gegensatz stehen. Aus der gleichen überdehnungs - und zweigipfligkeitstendenz sind die Leihenerschen $\bar{\imath} \cdot e ., \bar{o} \cdot a ., \bar{u} \cdot e . \mathrm{zu}$ erklären. Infolge einer vermischung von schärfung und zweigipfligkeit, die sich aus der grenzgestellung der Wuppertaler maa. erklärt, hat Leihener das schärfungszeichen : zu unrecht auf diese laute übertragen. ${ }^{1)}$ Sie wären also richtiger $\bar{\imath} \partial, \bar{o} a, \bar{u} \partial$ zu schreiben. Von diesen drei diphthongen erweist sich $\bar{o} a$ durch seine geographische stellung östlich der Ürdinger linie und seine qualität als ein jüngstes, in dem ersten stadium stehendes diphthongierungsproduct ${ }^{2}$ ), das wohl noch jünger als die benachbarten $e^{i}, q u$ ist. Seine qualität aber bietet einen wertvollen hinweis auf die vorstufe der westlichen $\bar{\imath} \partial, \bar{u} \partial$. Sie gehören gewiß einem ältesten, auf überdehnung und zweigipfligkeit beruhenden diphthongierungsproce $\beta$ an, der nach zeit und resultat von dem entsprechenden althochdeutschen vorgang kaum $\mathrm{zu}$ trennen ist; denn es ist wohl zu beachten, daß der $ə$-laut in den genannten diphthongen imallgemeinen die qualität des dem ersten bestandteil entsprechenden

1) Vgl. DDG. V § 317.

2) Hierauf weist auch Lobbes' polemik DDG. VIII s. 27 fußn. 2 gegen Leihener, nach der der diphthongierungsproce $B>\bar{\delta} a$ in Elberfeld nicht regelmäßig eintritt. 
offenen lautes besitzt. Soweit sich reine $\bar{\imath}, \bar{u}$-monophthonge nachweisen lassen, wären sie den entsprechenden endresultaten der althochdeutschen diphthongierung zu vergleichen. Ob auch im $i, u$-gebiet westgerm. eo eine monophthongierungsstufe $\bar{e}$ durchlaufen ist, läßt sich nicht mit sicherheit sagen; hier kann auch die gemeindeutsche entwicklung vorliegen.

Innerhalb der nördlichen Rheinprovinz und der benachbarten westfälisch-sächsischen maa. ergibt sich also folgende gruppierung: das niederfränkische hat den aus einer ältesten überdehnungs - und zweigipfligkeitstendenz hervorgegangenen diphthongierungs- und secundären monophthongierungsproce $B$ alter $\bar{e}, \bar{o}$ in gemeindeutschem sinne durchgeführt; die schärfung hat im ripuarischen die alten $\bar{e}, \bar{o}$ schon in der vorliterarischen zeit des althochdeutschen von dem gemeindeutschen proceß abgeschnürt; im westfälischniedersächsischen zeigen sich erst in jüngerer zeit diphthongierungstendenzen, die stellenweise an den althochdeutschen vorgang anklingen (Leiheners $\bar{o} a$ ).

In diese gruppierung wollen sich einmal die $\bar{\imath}:, \bar{u}:, \bar{y}:$ und $\bar{\imath}:, \bar{u}: \bar{y}:$, die das ganze an den $\bar{e}:, \bar{o}:, \bar{\theta}:$-district anschließende randgebiet beherrschen, sowie die bei Leihener (s. oben) und Lobbes DDG. VIII $\$ \S 14.36$ zwischen diesem randgebiet und den $\bar{\imath} \partial, \bar{u} \partial, \bar{y} \partial$-entsprechungen belegten $\bar{\imath} \cdot \curvearrowright$., $\bar{u} \cdot$ ə., $\bar{y} \cdot \partial$. nicht recht einfügen. Für die letzteren lautwerte wäre wohl die schreibung $i \cdot \partial ., u^{\cdot} \cdot ., y \cdot \partial$. vorzuziehen, da der erste component tatsächlich nur den wert einer halblänge besitzt; auch der gegensatz kurz- und langdiphthong, in dem die $i \cdot \partial ., u \cdot \partial ., y \cdot \partial$. und $\bar{\imath} \partial, \bar{u} \partial, \bar{y} \partial$, abgesehen von ihrer accentuellen verschiedenheit, zueinander stehen, gewänne so einen treffenderen ausdruck. Die $i \cdot \partial ., u \cdot \partial ., y \cdot \partial$. sind gegenüber den linksrheinischen und den im westlichen rechtsrheinischen auftretenden $\bar{\imath}:, \bar{u}:, \bar{y}: ; \bar{\imath}:, \bar{u}:, \bar{y}:$ so zu werten, daß sie eine zweigipflige schwächungsstufé der im princip eingipfligen schärfung darstellen, mit andern worten einen übergang von geschärften $\bar{\imath}: \bar{u}: ; \bar{y}: ; \bar{\imath}:, \overline{\boldsymbol{u}}: ; \bar{y}:$ zu den auf einer ïberdehmungsund zweigipfligkeitstendenz beruhenden $\bar{\imath}, \bar{x}$, $\bar{y}$ ə bilden. A ber auch die $\bar{\imath}:, \bar{u}:, \bar{y}: ; \bar{q}:, \bar{u}:, \bar{y}:$ tragen ihren accent nicht von alters her. An anderer stelle wird noch nachgewiesen werden, daß die schärfung im großen und ganzen das gebiet des hentigen 
mittelfränkischen, also des ripuarischen und moselfränkischen, sowie das sïdliche niederfränkische unmittelbar nördlich der ïrdinger linie bis zu der stelle unfaßt, wo die Ürdinger linie nach siiden abbiegt und gleichzeitig sprach- und accentgrenze wird. In diesen niederfränkischen district ist aber der accent durch dieselbe nordwärtsstrebende bewegung getragen worden, die auch die rip. $\bar{e} ;, \bar{o}:, \bar{v}$ : über ihr altes gebiet hinausgetrieben hat; nur erleben wir hier das eigentümliche schauspiel, daß der eroberungszug des südlichen lautwertes halt macht, der accent aber noch weiter vordringt und niederfränkische lautwerte überwältigt, die seinem wesen ursprünglich fremd sind; auf bergischem boden lehnt sich die accentgrenze sogar an die niederfränkische normalgrenze an, während die lautwerte $\bar{e}$; $\bar{o}:, \bar{\theta}:$ gleich hinter Düsseldorf stehen geblieben sind. Damit wäre die erklärung der $\bar{\imath}:, \bar{u}:, \bar{y}: ; \bar{c}:, \bar{u}:, \bar{y}: ; i \cdot \partial ., u \cdot \partial ., y \cdot \partial$. in einem compromiß zwischen niederfränkischem lautwert und ripuarischer accentuierung $\mathrm{zu}$ suchen.

Nachdem nunmehr für drei so verschiedene sprachliche dinge wie lautverschiebung, entsprechung von westgerm. $\bar{e}$, $e o, \bar{o}$ und rheinische accentuierung oder schärfung - von gelegentlich erwähnten einzelheiten abgesehen - feststeht, daß sie ihr altes gebiet in nördlicher richtung erweitert haben, drängt sich die frage auf, ob die niederfıänkische normalgrenze . licht überhaupt relativ jung ist; ob nicht alle erscheinungen, die sich an ihr heute mehr oder minder restlos scheiden, ehedem an einer einheltlichen südlicheren linie halt machten; ob die abweichungen z. b. der grenze zwischen $e, o, \theta-$ und $i, \imath, y$ werten für westgerm. $\bar{e}, e o, \bar{o}$ von der jungen normalgrenze etwa darauf beruhen, daß die $e, o, \theta$-werte ihr nördliches endziel nicht erreicht haben. Sollte die heute minderwertige Benrather linie vielleicht jene alte einheitliche niederfränkisch-ripuarische sprachscheide sein, die infolge irgendwelcher jüngerer territorialverschiebungen gesprengt wurde? Hat sich dann vielleicht das niederfränkische dem nach norden vordringenden ripuarischen sprachstrom an einem festen historischen wall entgegengestemmt, der in der heutigen, jüngeren niederfränkischen normalgrenze hervortritt? Und deuten dann die vielen erscheinungen, die das gebiet zwischen der alten und jungen niederfränkischen grenze heute von westen nach osteng durch- 
schneiden und zuweilen nur an kleinen teilstrecken bis zu der letzteren vordringen, auf schwächere südnördliche vorstöße des ripuarischen hin, die an einer freien entfaltung nach norden durch secundäre territoriale besonderheiten verhindert wurden? Es sei nur darauf hingewiesen, in welch neues licht durch die beantwortung dieser fragen der viel umstrittene zusammenhang zwischen den lautverschiebungslinien, der Benrather und der Ürdinger linie, tritt. Ist es nicht sonderbar, daß die nördlichsten ausläufer der ripuarischen mouillierung (hont $>$ homk 'hund') und der rheinischen lautverschiebung ( $e k>e \chi$ 'ich'), sowie das gros der mouillierungslinien (win $>$ wiv 'wein', brūn $>$ bruss 'braun', tīt $>$ tsik 'zeit', krūt $>k r u k$ 'kraut') und die Benrather linie in ihrer geographischen ausdehnung miteinander eng verwandt sind? 1)

Aber suchen wir für diese gesichtspunkte zunächst eine sichere grundlage zu gewinnen, indem wir mit hilfe des durch die vocalisierungslinie gebotenen kriteriums die niederfränkischripuarischén grenzlinien aufzeigen.

\section{2.}

Auf der linken Rheinseite teilen die $e l k / e \chi$ 'ich'-, die $\bar{o} k_{l}^{\prime} \bar{o} x$ 'auch'-, die wei/wer 'wir'- und die $x e i$ (jei)/er 'ihr'-linie ${ }^{2}$ ) das schicksal der $\bar{u}: / \bar{o}:-$ grenze. Die ek/ex-linie, mit der die $\bar{o} k / \bar{o} x-$ linie zusammenfällt, zieht von der reichsgrenze aus einige kilometer südlich der vocalisierungslinie dahin und vereinigt sich mit ihr erst an der oft genannten strecke Traar-Hohenbudberg unmittelbar nördlich Ürdingen. Die beiden anderen linien setzen an derselben stelle der reichsgrenze wie die $e k / e \chi$-linie ein, biegen auf ihrem mittellauf zwischeu reichsgrenze und Rhein bedeutend weiter nach süden ab, kehren

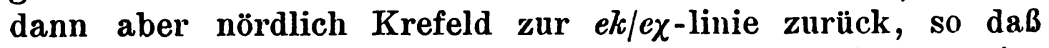
an der strecke Traar-Hohenbudberg die drei linien gemein-

1) Vgl. auch DDG. V § 209.

2) Vgl. Ramisch, DDG. I $\$ \$ 17.39$ sowie pausblat. I; DГ, V. V $\$ 256$, wo auch die neben wer, er begegnenden ver, wĩar, viar, iar und wogr, vọ", or nachgewiesen sind; vgl. auch Hanenberg, DIOG. VIII $\$ 242$. Dic laliodentale spirans $v$ statt der regulären bilabialen $w$ erklärt sich ans anlehnung an einen dentalen auslant in fillen wic hant wer, sent wer. 
schaftlich dem Rhein zust reben. Immerhin sind die abweichungen

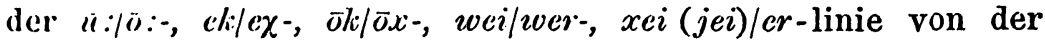
vocalisierungslinie nicht allzu bedeutend. Die fünf linien ließen sich gegenüber den im ersten teil herausgehobenen grenzen, die im allgemeinen mit der niederfränkischen normalgrenze zusammenfallen, zu einer zweiten liniengruppe zusammenfassen, zumal alle sich in unmittelbarer nähe des Rheins mit der normallinie vereinigen, oder, wie die geographische entwicklung des typus $b \bar{\delta}: k$ 'buch' zeigt, zu vereinigen suchen. Dabei ist es wichtig, daß die südliche ausbuchtung der wei/wer-und $x e i$ (jei)/er-linie mit der südlichen ausdehnung des buk 'buch'districtes im großen und ganzen übereinstimmt, während die auf compromiß zwischen $b u k$ und $b \bar{o}: k$ beruhenden $b o k$ teilweise außerhalb des wei- und $x e i$ (jei)-gebietes bleiben. Durch diese geographische verwandtschaft zwischen buk- und wei, $x c i$ (jei)-gebiet ergibt sich nämlich einmal ein neuer beweis dafür, daß die formen vom typus $b u k$ relicte eines alten niederfränkischen $u$-gebietes sind, daß also die $\bar{u}: / \bar{o}:-$ grenze eine verschiebung nach norden erfahren hat. Andererseits werden wir annehmen müssen, daß die wei, $x e i$ (jei) ehemals auch in dem einem heutigen bok-vorausliegenden buk-gebiet gegolten haben, daß also mit der verschiebung der $\bar{u}: / \bar{o}:-$ grenze eine in gleicher richtung verlaufende veränderung der vei/wer-,

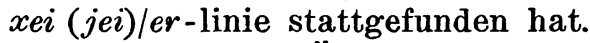

Zwischen der Ürdinger und Benrather linie ist nun DDG. V $\S \S 209.252 .258$ eine grenzlinie nachgewiesen worden, die die Benrather linie an sprachscheidender kraft bedeutend übertrifft, und die für das gebiet südlich der Ürdinger linie als normallinie zu gelten hat: die $z e q g \partial / z \bar{a} \gamma \partial$-linie. Sie unterscheidet sich von den benachbarten rheinischen sprachscheiden dadurch, daß sie das linke Rheinufer nicht etwa von westen nach osten, sondern von südwesten nach nordosten durchquert. Stellt man sich das gebiet zwischen Ürdinger und Benrather linie als viereck vor, in dem die reichsgrenze und der Rhein, die dritte und vierte seitenlinio bilden, so erscheint die $z \varepsilon g \partial / z \bar{a} \gamma \partial-$ linie ungefähr als diagonale verbindung des südwest- und nordostpunktes. Als besonderheit ist außerdem noch $\mathbf{z u}$ erwähnen, daß sie zunächst die äußerste, ins Limburgische hineinspringende nordwestecke des regierungsbezirkes Aachen ab- 
schneidet, ein stückchen an der reichsgrenze entlangläuft, und dann wieder ins reich zurückkehrt. Ihre bedeutung beruht nicht etwa darauf, daß sich jede ihrer kleinsten teilstrecken als ein wuchtiger sprachlicher einschnitt für eine reihe der verschiedensten sprachlichen erscheinungen erweist; auf ihrem lauf von Viersen bis zum Rhein sondern sich sogar eine reihe von linien, die bis dahin mit ihr zusammengegangen sind, ab, um eigene, kräftige nebenlinien zu bilden. Aber auf der weiten strecke von Gangelt an der holländischen grenze bis Viersen bilden ihre teilstrecken vielfach die stärksten sprachlichen scheiden des übergangsgebietes; vor allem aber decken

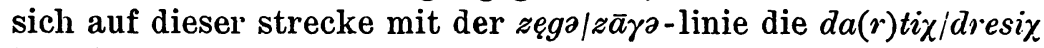
'dreißig'- und die męrat/māt 'markt'-linie; und zieht man einige junge schwankungen am äußersten südwestverlauf $a b$, so wäre auch noch die $r$-linie (nördl. $r$-erhaltung gegenüber südl. $r$ ausfall vor dentalis) und die hobə, hębə, habə/hān, han, hāvə 'haben'-linie hinzuzufügen.' ${ }^{1}$ Von diesen grenzen lassen sich östlich Viersen die $d a(r) t i \chi / d r e s i \chi$ - und męrat/mārt, māt-linie nach dem bisher vorliegenden material leider nicht bis zum Rhein verfolgen. ${ }^{2}$ ) Für Krefeld und Homberg sind dertix und dęatex 'dreißig' belegt, andererseits hat Krefeld mārt. Jedenfalls gehen die linien von Viersen aus nicht mehr zusammen. Die $r$-linie schlägt Krefeld zum norden, greift dann über die vocalisierungslinie hinaus und weist Homberg noch dem gebiet mit $r$-schwund zu. ${ }^{3}$ ) Die $z e g a / z \bar{a} \gamma \partial-$ und die hoba, hębo, habə; $h \bar{a} n$, han, hāva-linie aber wenden sich zwischen Krefeld und Ürdingen der vocalisierungslinie $\mathrm{zu}$, mit der sie sich auf der oft genannten strecke Traar-Hohenbudberg decken: ${ }^{4}$ ) d. h. die niederfränkische normalgrenze fällt mit der normallinie des übergangsgebietes in unmittelbarer nähe des Rheins zusammen.

Kleine unregelmäßigkeiten, die sich für die mehrzahl der genannten linien nachweisen lassen, eröffnen uns einen einblick

1) Vgl. DDG. V \$\$ 206. 257. 258.

2) Uanenberg, DDG. VIIJ $\$ 24$ anm. belegt $m \bar{g} v t$ fiir Kalkar.

3) Röttsches, Krefelder ma. (in Frommanns Deutachen maa.), Halle 1877, s. 50; Meymen s. 23; Hanenberg belegt, $\$ \$ 135$. 225 fïr die nördlichste Rheinprovinz regelmäßig $r$.

•) Vgl. Raunisch, 1)D(1. I \&22 amm. 3. 
in die entstehung der normallinie des übergangsgebietes. Bereits DDG. V $§ 206$ ist nachgewiesen, daß die oben erwähnten schwankungen der $r$-linie in dem limburgischen zipfel jung sind. Die im zega-gebiet begegnenden $r$-losen grenzstrecken sind erst infolge junger durchbrechung der an dieser stelle

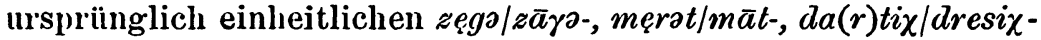
und $r$-linie entstanden. In gleicher weise ist der $r$-schwund nördlich der vocalisierungslinie zu beurteilen. Ein nördlicher grenzort der habo/han-linie hat neben dem inf. haba für die 1. sing. praes. bereits das südliche $h a \cdot n$. übernommen ${ }^{1}$ ); die damit erwiesene ausdehnungstendenz der südlichen hanformen wird auch in dem oben genannten limburgischen zipfel die hębə, høbə von einer ehedem mit zega, męrat, da(r)tix und $r$ vor dentalis gemeinschaftlichen linie abgedrängt haben. In einem kleinen grenzgebiet desselben districtes sowie an einer anderen, weit davon entfernt liegenden grenzstelle des zegəgebietes bei Dülken und Süchteln in der nähe von Viersen begegnet die form $z \bar{e} g a^{2}$ ), die den nördlichen umlaut mit der südlichen vocallänge verbindet, ein leises anzeichen eines in südnordrichtung erfolgenden druckes der $z \bar{a} \gamma \partial$-formen. Viersen, das nördlich der normallinie des übergangsgebietes liegt, ist diesem druck infolge besonders günstiger historischer verhältnisse bereits erlegen; es hat $z \bar{a}: \gamma^{\partial}$ und weist parallel dazu ein beträchtliches schwanken des $r$ vor dentalis sowie die form mārt 'markt' auf, während es andererseits treu an dartix und habə festhält. ${ }^{3}$ )

Es steht somit fest, daß infolge eines in nördlicher und nordwestlicher richtung erfolgenden druckes südlicher, ripuarischer formen die mehrzahl der linien, die mit der normallinie des übergangsgebietes ganz oder auf einer weiten strecke zusammenfallen und die wir zu einer dritten liniengruppe zusammenfassen können, eine allmähliche verschiebung erfahren oder erfahren haben. Die veränderungen liegen in derselben richtung, die wir für die $\bar{u}: / \bar{o}:-$ und wei/wer-, xei (jei)/er-linie erschlossen haben. Unter den linien der dritten gruppe nimmt nun die $d a(r)$ ti $\chi / d r e s i \chi$-linie eine besondere stellung ein. Sie

1) DDG. V s. 143 anm. 3.

2) DDG. V s. 144.

8) DDG. V $\S \S 206.258 .300$. 
wird ehedem zur Benrather linie in engerer beziehung gestanden haben; die form dresix hat einmal wie so mancher andere sproß der lautverschiebung an der normallinie des heutigen Benrather linienbündels halt gemacht und ist erst mit der weit verzweigten nördlichen auflösung der in älterer zeit einheitlichen verschiebungslinie nach norden gedrückt worden. Dann steht aber nichts im wege, die mit der $d a(r) t i \chi / d r e s i \chi$-linie heute an der normallinie des übergangsgebietes zusammenfallende dritte gruppe niederfränkischripuarischer grenzlinien für eine ältere epoche ebenfalls an die normallinie des Benrather lautverschiebungsbündels zurückzuweisen. Dadurch gewinnen wir aber gleichzeitig eine überraschende erklärung für den diagonalen verlauf, den wir für die $z e g a / z \bar{a} \gamma a$-linie oder die normallinie des übergangsgebietes beobachtet haben: gleich wie die stärkste auflösung der Benrather linie in der nähe des Rheins infolge eines hier besonders starken südnördlichen druckes stattgefunden hat, gleich wie die letzten ausläufer des Benrather bündels bis an die linie Traar-Hohenbudberg, also an die vocalisierungslinie getrieben worden sind, so sind auch die in der dritten liniengruppe vertretenen ripuarischen erscheinungen in einer gleichen, aber auf breiterem raume wirkenden entwicklungstendenz nach norden vorgestoßen und haben am Rhein die gleiche nordlinie wie die äußersten vorposten der lautverschiebung besetzt. Die absplitterungen von der normallinie des übergangsgebietes östlich Viersen, also wiederum in der nähe des Rheins, erscheinen dabei besonders bedeutungsvoll.

Eine bestätigung dieser auffassung bietet einmal die geographische verteilung der formen mit und ohne $r$-metathese in *breskan 'dreschen'. Im allgemeinen begegnen formen wie dorš̀, darša, doša, dęša, dèaša, die neuniederländischen und mittelniederländischen bildungen wie dors(ch)en, dars(ch)en, ders(ch)en entsprechen, nur nördlich der $z e ̨ g a / z \bar{a} \gamma a-l i n i e ~ b i s$ östlich Viersen. Doch begegnen an den rändern des drçšx, $d r \bar{c} \bar{s}$ o-districtes, der sich also im wesentlichen mit dem $\varepsilon \bar{a} \gamma^{a}$ gebiet deckt, hier und da noch bildungen, die auf $r$-metathese beruhen, und die einem ehedem zusammenhängenden gebiet angehören, das durch nöjdlich wandernde drs.s.)-formen besetzi worden ist. So erkliirt es sich denn anch, daß in dem gobiet 
zwischen Viersen, Krefeld und dem Rhein ein geographisch unentwirrbares nebeneinander von formen wie daša, døša, dęša,

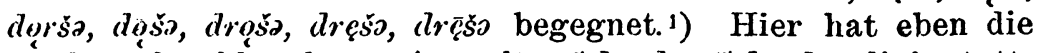
stïrkste durchbrechung einer alten *dersken/*dresken-linie stattgefunden, so daß sich eine neue linie nicht auskristallisieren komnte. Ähnliche beobachtungen ergeben sich aus der geographischen verteilung der stämme aft- und hint- in den mundartlichen entsprechungen der wörter 'hinten' und 'hinter'. Sie scheiden sich im großen und ganzen ebenfalls an der zegajzāajalinie. Doch lassen sich an der grenze des zega-gebietes hintund ebenso an der grenze des $z \bar{a} \gamma \partial$-gebietes aft-formen nachweisen. ${ }^{2}$ ) Im ripuarischen $z \bar{a} \gamma \partial$-gebiet erscheinen aft-formen nur noch in compositis wie eitarjaši a.r, äterjaši a.r 'geschirr des pferdes, das in der wagenschere geht', ātarfyrjęstar 'vorvorgestern', ātarwazsar 'wasser, welches schon abgelaufen ist, dann aber zurückkehrt und das mühlrad hemmt'. ${ }^{3}$ ) Sie sind relicte eines ehedem über die heutige grenze weit nach süden hinausreichenden aft-gebietes, das von nordwärtsdringenden hint-formen besetzt worden ist. Der umstand, daß die heutige nordgrenze des hint- mit der nordgrenze der $z \bar{a} \gamma \partial$ im wesentlichen zusammenfällt, weist auf ein gemeinsames vorrücken in gleicher richtung. So sind denn anch die heutigen aft-formen an der grenze des $z \bar{a} \gamma \partial$-gebietes als alte bodenständige formen, die hint-formen im $z e ̨ g$-gebiet aber als jüngere südliche eindringlinge zu betrachten; auch die aft-/hint-grenze erliegt also allmählich einem starken südlichen druck.

Die frage, in welchem verhältnis die an linien der zweiten und dritten gruppe beobachteten verschiebungen zueinander stehen, bleibe vorläufig unerörtert. Zunächst wäre noch eine vierte liniengruppe aufzudecken, die dieselbe diagonale richtung der dritten gruppe aufweist. Die zu ihr gehörigen einzellinien durchziehen das gebiet zwischen der $z e ̨ g a / z \bar{a} \gamma \partial-$ linie und der Benrather linie. Sie lehnen sich stellenweise an diese, stellen-

1) Vgl. DDG. V § 220, 5; Hanenberg, DDG. VIII $\$ 231$.

2) Vgl. Ramisch, DDG. I $\$ 22$ anm. 4; DDG. V § 228, 3.

3) Vgl. Münch, Rip. gramm., Bonn 1904, s. 92. Die bei W. Müller, Vocalismus der Kölner ma., Bonn 1912, s. 12 und bei J. Müller, Ma. von Aegidienberg, Bonn 1900 , s. 38 belegten ätor, äxtor, axtor 'hinter' sind wohl kaum lebendige formen. 
weise an jene an, so $\mathrm{da} \beta$ es vorkommen kann, $\mathrm{da} \beta$ eine im suidwesten an der Benrather linie einsetzende scheide auf ihrem nordostverlauf an die $z \varepsilon g \partial / z \bar{a} \gamma \partial-$ und in der nähe des Rheins an die vocalisierungslinie oder die Ürdinger linie herantritt. Die $v \bar{\imath} f / v \theta^{\prime} \cdot n . \partial f$ 'fünf'-linie ${ }^{1}$ ) z. b. setzt mit der $z e g \partial / z \bar{a} \gamma \partial-$ linie nördlich der Benrather linie an der reichsgrenze ein, läuft dann aber zunächst westlich und fällt auf einer kleinen teilstrecke sogar mit der Benrather linie zusammen. In schroff nördlicher richtung kehrt sie dann an die $z \varepsilon g \partial / z \bar{a} \gamma \partial-$ linie zurück und begleitet sie bis an die stelle östlich Viersen, wo die normallinie des übergangsgebietes zersplittert. Ihr genauer lauf zum Rhein läßt sich leider nicht weiter erkennen, da Ramischs material die linie nicht enthält. Doch läßt sich jedenfalls sagen, daß sie zunächst mit keiner linie der dritten gruppe zusammengeht, daß andererseits Krefeld parallel den dort belegten nfrk. dęrtix, hębə, zęgə ein viff aufweist. ${ }^{2}$ )

Vor allem aber gehören in diese gruppe die zahlreichen mouillierungslinien, die ebenso wie die lautverschiebungslinien ein weitschichtiges linienbündel darstellen. Keine von ihnen deckt sich ort für ort mit der normallinie der lautverschiebung; und auch miteinander kommen die varianten des mouillierungsprocesses nur in seltenen fällen auf einer längeren strecke überein. Und doch sind beide linienbündel in ihrer allgemeinen geographischen entwicklung wie in einzelheiten, z. b. dem nur durch unbedeutende abweichungen gestörten zusammenfall der $t \bar{t} t$, $t s \bar{t} t / t s i k$ 'zeit'-linie mit der lautverschiebungslinie des typus $k \bar{o} \partial l_{c} / k \bar{g} x \partial$, kquxa 'kochen'3), verwandt. Die durch die typen tīt, tsīt/tsitk 'zeit', krūt/krıık 'kraut'; - šnit/šnik 'schneidet',

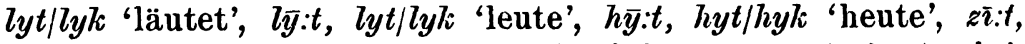
zit/zik 'seide, seite', min/min 'mein'; - win/win 'wein', brūn/brun 'braun'4) dargestellten linien verteilen sich geographisch so, daß die erste der drei gruppen die geringste, die letzte die größte nördliche entwicklung zeigt, wodurch auch gleichzeitig die entsprechenden abweichungen von der normallinie der lautverschiebung charakterisiert sind. Dieser

1) Vgl. Meyuen s. 24 fif; Hanenberg $\$ 143$ fif.

2) DJUG. V \$ 190; Röttsches s. 60.

3) DING. V \$ 176 .

-) DDG. V \$\$175. 177. 180. 191. 
iibergang aus einem horizontalen in einen diagonalen linienverlauf, der sich, wie immer wieder betont werden muß, für lautverschiebung und mouillierung in den dem Rhein zugewandten districten vollzieht, zeigt sich vor allem bei den fiillen, wo $n$ ursprünglich im silbenanlaut stand, also in der verbindung mhd. ine. Hier setzen die linien vom typus pĩ:n/piw. 'pein, schmerz' parallel aber nördlich der normalen lautverschiebungslinie ein, um dann gleich der linie $v \bar{\imath} f / v \theta^{\cdot} n . \partial f$ 'fünf' in stricter nördlicher richtung der zega/zāja-linie zuzustreben und sie bis östlich Viersen zu begleiten. Von hier

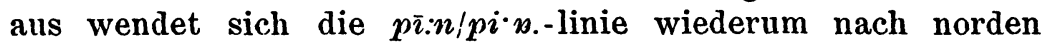
und geht sogar vertical über die vocalisierungslinie hinüber, so daß Krefeld und Aldekerk südlich Geldern noch pi·n., Homberg bei Mörs aber bereits pin hat; zwischen Geldern und Mörs wird sich die linie also wohl dem Rhein zuwenden. 1) Den charakteristischsten linienverlauf innerhalb der vierten gruppe bietet aber das zahlwort 'neun'. Die linie $n \bar{y} ә j ə / n y$ ' $\boldsymbol{}$. setzt im südwesten mit den hier zusammengehenden lautverschiebungs - und mouillierungslinien ein, trifft die $v \bar{\imath} f / v \theta^{*} n . \partial f$ linie und wendet sich mit ihr an derselben linie nordwärts; nach einer unbedeutenden abweichung treffen die beiden linien wieder an der $z \varepsilon g \partial / z \bar{a} \gamma \partial$-linie zusammen, wobei jetzt statt $n \bar{y} \partial j a$ ein $n \bar{\imath} \partial j a$ die niederfränkische form darstellt. ${ }^{2}$ ) In gemeinschaft mit der $p \bar{\imath}: n / p i \cdot n$.-linie begleiten dann die vĩf $/ v \theta \cdot n . \partial f$ und die nīaja/ny'n.-linie die zega/zāaja-linie bis östlich Viersen. Von hier aus geht die $n \bar{\imath} \partial j \partial, n \bar{j} j / n y \cdot n .-$ linie südlich KrefeldÜrdingen an den Rhein, ohne daß sie sich hier mit einer der bekannten linien deckte. Nachdem nun Beitr. 36, $362 \mathrm{ff}$. der nachweis erbracht worden ist, daß die heutige nördliche fächerung des Benrather linienbündels auf jüngerer auflösung einer ursprünglich einheitlichen linie beruht, wird man denselben vorgang für das verwandte mouillierungsbündel annehmen müssen. Sind an diese grenze aber die linien der $z e ̨ g)^{\prime} z \bar{a} \gamma \partial-g r u p p e$ zurückzuweiseu, dann um so mehr linien

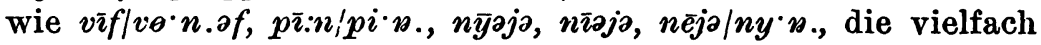

1) Meynen s. 19; Hanenberg, DDG. VIII §75 (pin); Ramisch, DDG. I $\S 25$ anm. 3; DDG. V $§ 192$.

2) Vgl. auch Meynen s. 17 nēgan; Hanemberg, DDG.VIII \$37 nèga. 
heute noch auf teilstrecken mit der normallinie der lautverschiebung zusammenfallen. Diese auffassung teilt auch Ramisch, wenn er DDG. I s. 25 fußn. 5 die form $n y \cdot r$. als einen aus dem süden vorgestoßenen eindringling bezeichnet. Und gerade die geographische entwicklung dieses wortes vermag alle bisherigen ergebnisse trefflich zu stützen: es bildet die einzige linie, die mit ihrer südweststrecke noch an der lautverschiebungslinie steht, in ihrem mittellauf die $z$ eqajzājalinie begleitet und nicht weit von der vocalisierungslinie den Rhein erreicht. Die alte linie ist noch nicht vollkommen verlassen, aber der vom Rhein her in nordwestlicher richtung erfolgende druck des ripuarischen hat die $n y \cdot v$.-formen doch schon an die normallinie des übergangsgebietes, ja sogar in die nähe der niederfränkischen normalgrenze getrieben. Und schließlich ist auch die alte südweststrecke nicht mehr ganz intact: $n \bar{y}$ ja - und $n y j$-formen - die letzteren am rande des $n \bar{y}$ aja-gebietes gegen den $n y \cdot r$. -bezirk - beherrschen das gebiet an der holländischen grenze, das westlich vom ny. gebiet und südlich der stelle liegt, an der die zęga/zāya-linie ins reich zurückkehrt; sie gelten also vor allem auch in dem limburgischen $z e g a$-zipfel. Nach dieser gruppierung wäre also das gebiet südlich der $z e g a / z \bar{a} \gamma \partial-$ linie von der stelle an, wo sie von der hölländischen grenze ins reich abbiegt, von $n \bar{y} a j$, $n y j$ j und $n y \cdot n$.-formen besetzt, während nördlich dieses teiles der $z e g a / z \bar{a} \gamma a-l i n i e ~ n e \bar{j} a$ und das daraus diphthongierte māaja herrschen. Die $n y \cdot w$.-formen haben also zu irgendeiner zeit auch ihre alte südwestlinie überschritten und die nach nordwesten liegenden gebiete überschwemmt; sie haben jedoch die bodenständigen nĩaja-formen nicht verdrängen können und sind daher mit ihnen ein compromiß $n \bar{\imath} a j a+n y \cdot \jmath .=n \bar{y} \cdot j a$ oder nyja eingegangen. Daß hierbei auch die limburgische zega $/ z \bar{a} \gamma^{\prime} a-$ linie überschritten wurde, kann nicht wunder geben, da sie für manche erscheinungen bereits als morsch und vielfach durchbrochen erwiesen ist. Und bedenkt man nummehr, daB der typus $p i \cdot r$. in der nähe des Rheins ebenfalls über die $z e g a / z \bar{a}$ - -linie, ja sogar über die niederfränkische normalgrenze. vorgedrungen ist, so wird man von diesem eroberungszuge der ripuarischen mouillierung auch wohl kaum den auf einem! gleichen phonetischen proceß beruhenden tyus howk 'hund' 
trennen kïmnen. J)ie heutige homk/hōnt-grenze ist somit jung. A uch sie hat einmal an einer für alle mouillierungserscheinungen gemeinsamen linie gestanden, die mit der normallinie des Benrather biindels im wesentlichen zusammenfiel. An dieser normallinie haben dann aber auch alle die linien halt gemacht, die mit der heutigen howk/hōnt 'linie' zusammenfallen oder doch verwandt sind, und das sind die als erste und zweite gruppe zusammengefaßten linien: ließen sich doch namentlich für die zweite gruppe verschiebungen beobachten, die mit der nordwärts erfolgten bewegung der in der dritten und vierten gruppe vereinten linien $\mathrm{zu}$ vergleichen sind. Damit wäre aber der nachweis geführt, daß die heutige niederfränkische normalgrenze ursprünglich mit der Benrather linie zusammenfiel; eine intensive ripuarische eroberung hat die alte niederfränkisch-ripuarische sprachscheide gesprengt und die südlichen formen in verschiedenen geographischen entwicklungsstadien nach norden gepreßt. Der kräftigste ripuarische stoß erfolgte vom Rhein her in nordwestlicher oder diagonaler, ein weniger kräftiger in nördlicher oder verticaler richtung. Das um die $z \ell g \partial / z \bar{a} \gamma \partial$-linie gruppierte linienbündel ist vorzugsweise das ergebnis des diagonalen stoßes, das gemeinsame ergebnis beider stöße ist die heutige niederfränkische normalgrenze. Nunmehr ist auch der streit um das verhältnis von Benrather und Ürdinger linie zueinander geschlichtet: die lautverschobenen formen, die bis zur Ürdinger linie reichen, dürfen nicht von den an der Benrather linie verschobenen wörtern getrennt werden. Sie sind nicht etwa das ergebnis einer lautveränderung in unbetonten wörtern, die mit der lautverschiebung schwerlich etwas $\mathrm{zu}$ tun hat' ${ }^{1}$, sondern in relativ junger zeit nach norden gedrängte ausläufer der Benrather linie.

Diese resultate ließen sich noch durch viele einzelbeobachtungen stützen. Nur zwei wichtige erscheinungen, die bereits gelegentlich erwähnt wurden, greife ich heraus: die compromißbildungen und die relicte. Bodenständige niederfränkişche bildungen wurden von entsprechenden ripuarischen formen über-

1) Franck, Altfrk. gramm. § 2; zu Wahlenbergs' (Lautverschiebungsstufe der niederrhein. ma., programm Köln 1871, s. 7) 'anticipierender stufe' und Behaghels auslautshypothese (Gesch. d. deutschen spr. ${ }^{8}$ s. 43) vgl. jetzt DDG. VIII § 20; beide erklärungsversuche werdeu dort abgelehut. 
flutet. Der ripuarische stoß war nicht immer so stark, daß er die niederfränkischen formen verdrängen konnte; infolgedessen bildete sich ein niederfränkisch-ripuarisches mischproduct. Diese compromißbildungen begegnen daher vor allem im westen des linksrheinischen übergangsgebietes, das von dem schwächeren verticalstoß getroffen wurde. Bildungen wie $\bar{\imath}:, \bar{u}:$ aus $\bar{\imath}:, \bar{u}$ : $+\bar{e}:, \bar{o}:$, bol aus $b u k+b \bar{o}: k, n \bar{y} \partial j a, n y j a$ aus $n \bar{\imath} \partial j \partial+n y \cdot \rightsquigarrow$. sind bereits gedeutet worden; auch $z \bar{e} g \partial$ aus $z \ell g \partial+z \bar{a} \gamma \partial$ gehört hierhin. Ein $p i \cdot n$. aus $p \bar{\imath}: n+p i \cdot n$. in Viersen $\left.{ }^{1}\right)$ fügt sich trefflich zu der an dieser stelle beobachteten durchbrechung der normallinie des übergangsgebietes. $\mathrm{Ob}$ auch bildungen wie hyt, lyt, zit, die am Rhein zwischen $h \bar{y}: t, l \bar{y}: t, z x: t$ und $h y l k, l y k$, zilk begegnen, als compromißformen zu gelten haben, bleibt zweifelhaft. ${ }^{2}$ ) Besonders wichtig erscheint aber das compromiß węt aus wat + jęt, das gerade an der stelle der vocalisierungslinie auftritt, wo die $e k_{i}^{\prime} e \chi-, \bar{o} k / \bar{o} x-$, wei/wer- und $x e i(j e i) / e r-l i n i e n$ die jüngere niederfränkische normalgrenze nicht erreichen, also ein erschlaffen des ripuarischen eroberungszuges stattgefunden hat. Am wichtigsten ist jedoch das compromiß habə aus hębə + han. Es erfüllt im ganzen das weite gebiet zwischen der vocalisierungslinie und der nordoststrecke der $z \varepsilon g \partial / z \bar{a} \gamma \partial$-linie. Der diagonaldruck hat also die ripuarische form weit nach nordwesten vorgetrieben; der verticaldruck ist jedoch im wesentlichen nur zu einem compromiß gelangt, dessen gebiet in Elmpt, Krüchten, Merbeck, Kaldenkirchen an der holländischen grenze sowie in Kempen und Krefeld ${ }^{3}$ ) dazu noch hębə als unberührtes niederfränkisches relict umschließt.

Die relicte finden sich wie die compromisse vor allem im westen des übergangsgebietes; stellenweise gehen sie sogar neben compromißbildungen einher, ein beweis, daß beide erscheinungen dem gleichen umstand, nämlich der abgeschwächten stoßkraft des ripuarischen ihr leben verdanken. Von diesem gesichtspunkt sind formen wie hont 'hand', u'ontar 'winter' in Viersen $z u$ beurteilen. ${ }^{4}$ So ist auch das um Heinsberg an der holländischen grenze gelegene gebiet zu erklären, das

1) IDG. V \$192.

2) DDG. V $\$ 180$.

8) Ramisch, DDG. I $\$ 22$ anm. 3; DI) $V \$ 257$.

•) $\mathrm{DDG} . \mathrm{V} \$ 200$. 
nur "1spriinglich inlautendes -nd-, das mundartlich in-oder

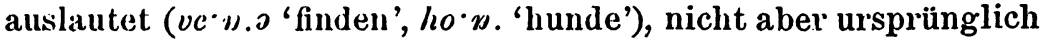
auslautendes -nd und -nt (kent 'kind', bont 'bunt') sowie ursprünglich inlautendes -nt-( (ventar 'winter') mouilliert. ') Es ist sicher, daß das heinsbergische und das nördlich der vocalisierungs- (bez. gutturalisierungs-) linie gelegene -nt-gebiet ehedem einem einheitlichen niederfränkischen sprachgebiet angehörten, das durch die ripuarische eroberung zerrissen wurde, ein vorgang, den das compromiß - skt aus -nt $+-n k$ (hovlct 'hand', kenkt 'kind', hoskt 'hund') an der -sk/-nt-grenze noch deutlich zu veranschaulichen scheint. Vielleicht wird sich in den holländisch-limburgischen dialekten einmal die beide gebiete verbindende sprachlinie wiederfinden. ${ }^{2}$ ) Nunmehr ist aber auch die erklärung für den -cht-streifen längs der reichsgrenze gefunden, der sich nach Anz. 21, 163 zwischen der Benrather linie und der Ǜdinger linie von Kaldenkirchen bis Gangelt erstreckt. Auch er hat einmal mit dem -cht-gebiet nördlich der vocalisierungslinie in directer geographischer beziehung gestanden; und noch heute zeigt er in der verteilung der aus einer ursprünglichen verbindung kurzvocal + cht möglichen mundartlichen entwicklungen von der art kurzvocal + spirans $+t$ (naxt 'nacht'), langvocal + spirans $\pm t(n \bar{\phi} x(t)$ 'nacht') directe analoga zu den verhältnissen der nördlichen Rheinprovinz. ${ }^{3}$ ) Auch hier veranschaulichen zahlreiche compromißbildungen, $\mathrm{z}$ : b. jaz $\bar{\phi} x+$ jazqut $=$ jazqux 'gesagt' in Bracht b. Kaldenkirchen ${ }^{4}$ ), die ripuarische überflutung. Die versprengten gebiete mit gutturaler spirantenarticulation, die sich längs der holländischen grenze beobachten lassen ${ }^{5}$ ), treten jetzt gleichfalls unter einen einheitlichen gesichtspunkt. Sie waren ehedem untereinander und mit dem gebiet nördlich der vocalisierungslinie verbunden; und die gutturalen spiranten südlich der vocalisierungslinie an der holländischen grenze weisen noch heute auf eine ehemalige verbindung mit den

1) DDG. V § 197.

2) Idg. forschungen 26, $262 \mathrm{f}$. finde ich für das holländisch-limburgische folgende -nt-belege: būnt 'bunt', vūnt 'fand', vīnts 'fanden'.

3) Ramisch, DDG. I § 21; DDG. V § 221; Hanenberg, DDG. VIII § 240.

•) Vgl. die zusammenstellungen DDG. V § 226 .

s) DDG. V \$§ 170. 171, s. 109 fußn. 2. 
südlichen relictgebieten hin. Auch für eine ältere periode ist daher eine strenge scheidung zwischen erhaltung der spirans in der verbindung cht und gutturaler spirantenarticulation einerseits und vocalisierung der spirans in der verbindung cht und vorwiegend palataler spirantenarticulation andererseits an der alten niederfränkisch-ripuarischen sprachscheide zu erschließen. Wenn in den westlichen relictgebieten heute die cht-formen ein größeres gebiet als die reste gutturaler spirantenarticulation einnehmen, so beruht das auf einem allgemeinen vordringen der palatalarticulation, das sich in den heutigen rheinischen maa. beobachten läßt.1) Die geographische verteilung der stämme wacht- und uard-für 'warten'2) ließe sich zur weiteren stütze dieser ausführungen insofern verwerten, als die niederfränkischen wacht-relicte im wardgebiet eine ähnliche verbreitung wie die gutturale spirans aufweisen.

Überhaupt haben die an der holländischen grenze gelegenen teile des übergangsgebietes, vor allem der district um Gangelt, Waldfeucht, Heinsberg, im allgemeinen ein echt niederfränkisches gepräge bewahrt. Hervorgehoben sei vor allem die erhaltung der kürzen vor altem - $h t^{3}$ ) (naxt 'nacht'), $\left.-h s^{4}\right)$ (das 'dachs'), -sk $\left.{ }^{5}\right)$ (fless, flęs 'flasche'), -st $\left.{ }^{6}\right)$ (fast 'fest') sowie das diminutivum nl. je nach altem $d$ und $t^{\top}$ ) (rę̧:tja, rętja 'rädchen'), erscheinungen, die das gebiet um Gangelt und Waldfeucht westlich der heinsbergischen $z \ell g a / z \bar{a} \gamma \partial$-linie mit dem äußersten nordwestzipfel der Rheinprovinz gemein hat. Auch der ersatz einer intervocalischen dentalis durch eine $j$-spirans ${ }^{8}$ ) (z. b. lëja 'leiten') sowie die dehnungen vor $n+$ dentalis ${ }^{9}$ )

1) DDG. V s. 110.

2) Vgl. Ramisch, DDG. I s. 20 fußn. 4; DDG. V § 228.

3) Ramisch, DI)G. I §21; Hanenberg, DDG. VIII $§ \S 178.190$; DIG. V' $\S 221 \mathrm{ff}$.

4) Hanenberg, DDG. VIII $\S \S 162.191,2 ;$ DNG. V § 235.

s) Hanenberg, DDG. VIII $\$ \S 165$. 239; DDG. V \$ 238.

e) Hanenberg, DDG. VIII $\S 13$; DDG. V § 237.

7) Ramisch, DDG. I § 31; DDG. V § 253. $\$ 244$ ff.

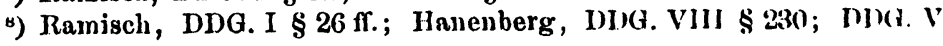

*) Ramisch, DDG. $1 \$ 24$; Hanenberg, 1DDG. VIII \$s 17. 38. 55. 2:37, 3; LUG. V \$ 215 . 
(". b. "'cht.)" 'winter') und $l+$ dental ') (z. b. alt 'alt') sind dem gebiet un Heinsberg und Cleve, Geldern gemein. Es muß der niederländischen dialektforschung vorbehalten bleiben, zwischen diesen getrennten gebieten den zusammenhang zu suchen. Ob dann die eroberung niederfränkischen sprachgebietes durch sïdliche erscheinungen sich in einem noch bedeutend weiteren umfange erweisen wird, wie z. b. der verlauf der -lik/-li $\chi$-linie von Gangelt an der holländischen grenze nach Rheinberg bei Mörs und die gelegentlich gestreiften durchbrechungen der niederfränkischen normalgrenze durch ripuarische formen vermuten lassen, das steht hier nicht zu untersuchen. Wir bescheiden uns vorläufig mit der feststellung, daß das ripuarische eroberungsgebiet zwischen der Benrather und der Ürdinger linie auf dem linken Rheinufer im allgemeinen in zwei hälften zerfällt: in ein stark mit ripuarischen erscheinungen durchsetztes $z \bar{a} \gamma \partial$-gebiet am Rhein und ein noch immer wesentlich niederfränkisches $z e g a-g e b i e t$ an der holländischen grenze. Man könnte daher geradezu versucht sein, die $z \ell g \partial / z \bar{a} \gamma e$-linie als niederfränkische normalgrenze statt Ramischs vocalisierungslinie zu fordern. Doch würde eine solche gruppierung an der noch näher zu erörternden tatsache scheitern, daß erst an der vocalisierungslinie der ripuarischen eroberung ein nur schwer zu überwindender historischer damm entgegengetreten ist.

\section{3.}

Auf die entstehung des rechtsrheinischen übergangsgebietes, dessen mischcharakter bereits von Lobbes energisch betont worden ist ${ }^{2}$ ), fällt nunmehr helles licht. Die verhältnisse dieses gebietes gestalten sich dadurch besonders schwierig, daß das ripuarisch-niederfränkische grenzbündel ständig in beziehung zur westfälischen -et-linie tritt. Deshalb schien es auch geboten, die entstehungsfrage zunächst vom linken Rheinufer aus zu beantworten.

Es wäre ideal, wenn sich die aufteilung des linksrheinischen übergangsgebietes in verschiedene linienbündel auf dem rechten

1) Ramisch, DDG. I $\S 32$; Hanenberg, DDG. VIII $\S \S 16.237,2$; DDG. V § 216.

2) Vgl. namentlich die tabelle DDG. VIII $\$ 80$. 
Rheinufer in entsprechender gruppierung wiederholen wollte. Aber vielleicht liegt gerade in dem umstande, daß linien, die linksrheinisch zusammengehören, sich rechtsrheinisch meiden und mit anderen linien in gemeinschaft treten, ein starker beweis für die vielgestaltige kraft, mit der das ripuarische die alte niederfränkische grenze durchbrochen hat.

Leider läßt die große zufälligkeit, mit der das dieser studie zugrundeliegende material zusammenkommt, nicht immer eine ununterbrochene beobachtung der scheidelinien von der holländischen bis zur westfälischen grenze zu. Die $m e ̨ r a t / m \bar{a}(r) t$ linie versagt dazu rechtsrheinisch vollständig: von Cronenberg bis Aldenrade sind uns merkwürdigerweise $a$-formen belegt. ${ }^{1}$ ) $r$ vor dentalis ist in demselben gebiete geschwunden oder vocalisiert, und nur selten läßt sich ein deutlicher $r$-laut wahrnehmen ${ }^{2}$ ); doch scheint es wichtig, daß unmittelbar nördlich der Benrather linie um Solingen, Gräfrath, Wald, Ohligs ein gebiet mit festem $r$-laut begegnet: ist es ein relictgebiet am nordrande der alten $r$-linie? Für 'dreißig' scheint zumindest zwischen Cronenberg und Wermelskirchen die Benrather linie grenzlinie zu sein ${ }^{3}$ ); und auch die $r$-metathese in 'dreschen' (dorš̌on, došon, dięšon gegenüber dręšon) fällt auf einer teilstrecke mit der Benrather linie zusammen.4)

Auch vollständig überlieferte linien, die wir auf dem linken Rheinufer für eine ältere epoche an die Benrather linie zurückverweisen mußten, finden wir rechtsrheinisch vielfach an dieser linie wieder. Schon bei den gleichzeitig für beide Rheinufer untersuchten linien der ersten gruppe zeigen sich gelegentliche anlehnungen an die Benrather linie. Die velaren spiranten in Cronenberg, Remscheid und Ronsdorf werden von

1) Maurmann $\$ 110$ mark; Leihener, DDG. II wörterbuch mat; Neuse, DDG. VIII § 12 mãt.

2) Maurmann $\S 93$; Neuse $\S \S 177$. 180. 181. 346; Leihener $\$ \$ 45$. 81.

s) Maurmann \$112 datax; Leihener, DDG. II wörterbuch d!tr $\chi$; Hasenclever $\$ \S 42.115$ dresa $\chi$. Dabei ist Wermelskirchen mit. Lobbes südlich der Benrather linie gedacht, während Hasenclever mul Jejhencr es zum norden schlagen. Diese unstimmigkeit verschlägt nichts, da es nur darauf ankommt, das verhältnis zur lautverschicbungslinie im allgemeineu $\mathrm{zu}$ bestimmen.

•) Leihener, DDG. II $\$ 81,5$; vgl. auch Maurmanu $\$ 24(1$ dasd; Nense $\$ 346$ VI $\operatorname{agrsa}(n)$, dęrso.

Beitrige zur geschichte der deutschen spraclic. 41. 
den palatalen spiranten der gemeinde Wermelskirchen durch die Benrather linie kurz vor ihrer vereinigung mit der Ürdinger

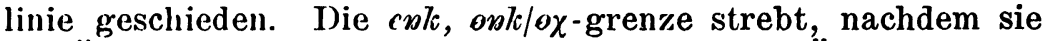
die Ürdinger linie verlassen hat, parallel der Ürdinger linie der Benrather linie zu, und vereinigt sich mit ihr ebenfalls an der grenze Remscheid/Wermelskirchen. Die rechtsrheinische grenze der rip. $\bar{e} ; \bar{o}$ : für westgerm. $\bar{c}, e o, \bar{o}$ ist uns leider nicht in allen einzelheiten verbürgt. Doch ist aus der bereits oben erwähnten angabe von Lobbes, DDG. VIII $\$ 36 \mathrm{zu}$ ersehen, daß sie, nachdem sie auf dem linken Rheinufer im großen und ganzen die Ürdinger linie erreicht hat, unmittelbar östlich des Rheins in strenger nordsüdrichtung zur Benrather linie abbiegt. Directe berührungen zwischen beiden linien lassen sich aus dem bisherigen material nicht belegen.

Ton den linien der zweiten gruppe deckt sich die rechtsrheinische fortsetzung der wei/wer-linie mit der Ürdinger linie bis auf eine kleine unregelmäßigkeit bei Ronsdorf, das mit den ortschaften außerhalb der Ürdinger linie geht.1) Dem linksrheinischen diphthongierten wei entspricht rechtsrheinisch ein $u \bar{\imath}$ oder $f^{\bar{\imath}^{2}}$ ), wobei das stimmlose labiodentale $f$ aus anlehnung des bilabial-labiodentalen $w^{3}$ ) an einen stimmlosen dentalen auslaut in fällen wie hant $\imath \bar{\imath}$ 'haben wir', zint wì 'sind wir' zu erklären ist. Den varianten des linksrheinischen wer stehen die rechtsrheinischen formen wìr, fĩar, wīr gegenüber. Sie stoßen nach süden und nach westen, in den Rheingegenden, auf ein mer-gebiet ${ }^{4}$ ), das Leihener, DDG. II $\$ 87,2$ für seinen engeren district von der Benrather linie begrenzt sein läßt. Zweifelhaft bleibt dabei nur die stellung von Wermelskirchen, das entsprechend seinen schwankenden lautverschiebungsverhältnissen $w \bar{\imath} r$ und mer zu haben scheint. ${ }^{5}$ )

1) Vgl. Leihener, DDG. II § 87,2; Lobbes, DDG. VIII $\S 60,1$.

$\left.{ }^{2}\right)$ Maurmann $\S 221$ vị $i$ mit diphthongiertem $\bar{\imath}$ und regulärem labiodentalem $v$; vgl. Mülheim vātor 'wasser' Maurmann $\$ 89$.

$\left.{ }^{3}\right)$ ' $w$ ist labiodental mit starker neigung zum bilabialen laut', Lobbes, DDG. VIII § 9, 4; vgl. Hasenclever § 13; Leihener, DDG. II s. XII.

4) So Lobbes, DDG. VIII $\S 60$.

5) So wird wohl die von Lobbes, DDG. VIII s. 38 fußn. 2 nachgewiesene unstimmigkeit zwischen Leihener, DDG. II \$ 87, 2 und Hasenclever $\$ 108$ zu überbrücken sein. 
Nun ist aber: auch DDG. V $\S 256$ für das linke Rheinufer ein mer nachgewiesen, das im westen die Benrather linie nicht erreicht, auf deren mittelstrecke jedoch mit ihr zusammenfällt und unmittelbar in der nähe des Rheins bis zum nördlichsten win 'wein'-, brun 'braun'-ort über sie hinausgreift. Leihener' und Lobbes sind darin einig, daß ihre wīar-, fĩar- und wīrformen nicht bodenständig, sondern auf compromiß zwischen nördlichem $w \bar{\imath}$ und südlichem mer beruhen. Überträgt man diese annahme auch auf das linke Rheinufer, so wäre - von allen abweichungen im einzelnen abgesehen - für das weite gebiet zwischen Ürdinger und Benrather linie und von der holländischen bis zur westfälischen grenze eine einheitliche compromißform vom idealtypus $w \bar{\imath} r=w \bar{\imath}+$ mer anzusetzen, und die anschauung von der ehemaligen identität der Benrather und Ürdinger linie und der jungen durchbrechung der alten niederfränkisch-ripuarischen grenze durch eine nordwärtsbewegung des ripuarischen hätte eine schöne bestätigung gefunden. Es scheint sicher, daß die $r$-losen formen des niederfränkischen einmal bis zur Benrather linie reichten. Aber es ist möglich, daß die wĩr-bildungen des übergangsgebietes einem vorsto $B$ älterer ripuarischer wīr, die mer (betont $m \bar{r} r$, die im westen die Benrather linie bis heute noch nicht ganz erreichen, einer jüngeren ripuarischen nordwärtsbewegung zu verdanken sind. Übrigens schwankt die grenze des aus bildungen wie hamar 'haben wir', zemar 'sind wir' 1) hervorgegangenen mer, mīr beträchtlich. Die linksrheinische xei (jei)/er-linie setzt sich auf dem rechten Rheinufer in der dual alts. git/ī $r$-grenze fort. Sie zeigt die gleichen abweichungen von der Ürdinger linie wie die enk, onk/ $\theta \chi$-grenze, so daß also auch hier die Benrather linie bei Remscheid/Wermelskirchen die grenze bildet. Die mundartlichen entsprechungen von alts. git sind recht mannigfaltig. Von den aus enklise hervorgegangenen at, jont (nasal unter dem einfuß von onk und der 2. plur. praes. in formen wie hant 'habt', zint 'seid') und dem nach den spirantenregeln wechselnden anlant abgesehen, begegnen wir wie bei $i n k$, enk, onk der dreifachen vocalgestalt $\left.i, s(c), a{ }^{2}\right)$

1) Münch \& 216, 3.

2) Vgl. zu den vorhergehenden ausfihrungen Maurmnnn $\$$ 221: N'use,

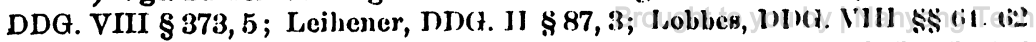


Von diesen qualitäten entsprechen die $i$ - und $e$-laute einem alten $i$. I)as $o$ in jot, yot stammt aus onte; das $\theta$ in owte aber ist bereits von Wenker als entlehnung aus dem südwestlich

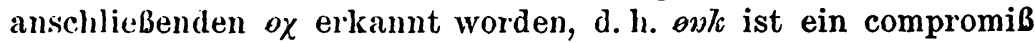
aus $e v k+\omega \chi$. Man hätte nur energischer betonen sollen, daß die jot $(\gamma \theta t)$, owli-formen im südosten den raum zwischen den

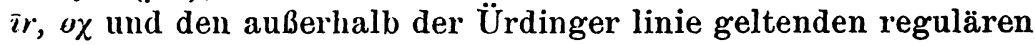
dualbildungen ausfüllen. ${ }^{1}$ ) Denn erst dadurch gewinnen die $o$-formen für die geschichte des rechtsrheinischen übergangsgebietes ihre volle bedeutung. Auch auf dem rechten Rheinufer erfolgte, wie schon der lauf der $\bar{e}$ :, $\bar{o}$ :-linie erkennen läßt, die stärkste durchbrechung der alten niederfränkisch-ripuarischen grenzlinie vom Rheine her in nordöstlicher oder diagonaler richtung, die schwächste auf der strecke zwischen dem Rhein und der heutigen vereinigungsstelle von Benrather und Ürdinger linie in verticaler oder nördlicher richtung. Das gemeinsame resultat aller ripuarischen stöße sind die an der rechtsrheinischen normallinie, d.h. an der Ürdinger linie stehenden linien. Die vom Rhein ausgehende stärkste durchbrechung hat die ripuarischen erscheinungen wie auf dem linken Rheinufer in möglichste nähe der Ürdinger linie gepreßt. Der östlich vom Rhein erfolgende durchbruch wird schon bald so schwach, daß erscheinungen, die am Rhein die Ürdinger linie erreicht haben, im osten an der grenze Remscheid/Wermelskirchen noch an der Benrather linie stehen; und schließlich bedeutet auch das plötzliche abbiegen der Ürdinger linie nach süden nichts anderes als ein erschlaffen der ripuarischen eroberung, die an der heutigen vereinigungsstelle von Benrather und Ürdinger linie ihren nullpunkt erreicht hat. So sind denn die schon im ersten abschnitt erwähnten wat westlich der Ürdinger linie bei Velbert, Neviges,

1) Die angaben Leiheners, DDG. II $\S 87,3$ über die verteilung der $e$ - und $\theta$-laute in den mundartlichen entsprechungen von alts. git widersprechen seinen eigenen angaben $\mathrm{s}$. XXVI fußnote 1 , wo er die $\theta$-form an der Ürdinger linie halt machen läßt, sowie den mit letzterer angabe übereinstimmenden beobachtungen von Lobbes, DDG. VIII §61. Die nach Leihener in dem oben genannten raume begegnenden $e$-laute sind wohl relicte, die außerhalb der Ürdinger linie vorkommenden $\theta$-formen junge südwestliche eindringlinge; vgl. hiermit das schwankende verhalten Elberfelds ( $j \theta t$ und $j e ̨ t)$. Die relicte erklären sich daraus, daß das $\theta$ von $\theta x k$ das bodenständige $\xi$ in jẹt, rẹt nicht vollständig verdrängt hat. 
die velaren spiranten in dem gebiet von Cronenberg, Remscheid und Ronsdorf und auch $f_{\bar{\imath}}$ 'wir' in Ronsdorf zu vergleichen mit den an der holländischen grenze südlich der vocalisierungslinie begegnenden parallelen erscheinungen: hier wie da haben die ripuarischen formen infolge des erschlaffenden druckes die bodenständigen formen nicht ganz verdrängt und die neue niederfränkische normallinie nicht ganz erreicht. Der eingeborenen anlautenden velaren spirans, die im ganzen übrigen übergangsgebiet verdrängt wurde, konnte das ripuarische in unmittelbarer nähe der normallinie zwar ihre stimmhaftigkeit, nicht aber ihre palatale natur aufdrängen ${ }^{1}$ ); und so konnten auch die im entk-gebiet vordringenden ripuarischen $\theta \chi$ nur ihre vocalqualität, nicht aber ihren consonanten bis zur niederfränkischen normalgrenze durchsetzen: das resultat $e x \jmath+o \chi$ $=$ ork im osten des rechtsrheinischen übergangsgebietes steht in parallele $\mathrm{zu}$ den resultaten $n \bar{\imath} \partial j \partial+n y^{\cdot} \cdot \boldsymbol{} .=n \bar{y} \partial j \partial, n y j \partial$, $w a t+j e ̨ t=w e ̨ t, h e ̨ b a+h a n=h a b a, p \bar{\imath} \cdot n+p i \cdot v .=p i \cdot n$. im westen des linksrheinischen übergangsgebietes, in denen die ripuarische vocalqualität ebenfalls mit dem bodenständigen niederfränkischen consonantenbestand verknüpft erscheint. Nur in $n \bar{y}$ əja spiegelt sich ein letzter rest niederfränkischer diphthongierung $\bar{\imath} \partial$ aus $\bar{e}$ wieder; doch stehen daneben die nyja mit ganz ripuarischem vocalismus. Und es ist kein zufall, daß die nyja nur in unmittelbarer nähe des $n y \cdot \rightsquigarrow$.-gebietes begegnen: die geographische abstufung $n y \cdot n .-n y j a-n \bar{y} \partial j \partial$ nördlich der Benrather linie veranschaulicht ein dreifaches ripuarisches eroberungsstadium. Auch die an der $-n t /-307$-linie im Heinsbergischen begegnende compromißbildung -rakt, in der sich bei übereinstimmung des wurzelvocals der in frage stehenden wörter ein schwächerer niederfränkischer mit einem stärkeren ripuarischen consonantismus vereinigt, tritt an der bergischen $-n t /-n z$-linie, und zwar in größerer geographischer ausdehnung als im westen hervor: ${ }^{2}$ ) Dabei herrscht sie vor allem anch in den gebieten außerhalb der Ürdinger linie, die durch das bestreben gewisser sprachlinien, eine anlehnumg an die westfälische -et-linie zu gewinnen, in jüngerer zeit mit ripuarischen

1) Die palatale spirans hat in Ronsdorf nach Lobhes, 1)I)(i. V'll \$ (i1 nur in jot vollstiindig gesiegt.

2) Lobbes, DDG. VIII \$33; Hasenclever \$. 72 
formen durchsetzt worden sind. $\mathrm{DaB}$ sie z. b. in dem zwischen der Ürdinger und der - et-linie gelegenen Vosnacken gilt, dessen typus nät 'nacht' bereits in abschnitt 1 als junge compromißbildung erwiesen ist, und dessen lautverschobene entsprechung von 'auch' nachweislich in jüngerer zeit eindrang ${ }^{1}$ ), ist ein sicherer beweis, daß sie nach ihrer entstehung aus $-n t+-n t$ als selbständige neubildung weiter vorrückte.

Nunmehr lösen sich auch alle schwierigkeiten, die das zahlwort 'fün' aus der vierten gruppe der westlichen linien zu bieten scheint. Schon aus der geographischen verteilung der

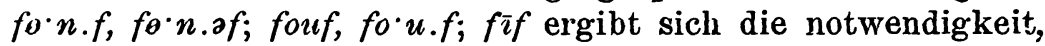
die fouf, fo'u.f als compromiß zwischen den niederfränkischen und ripuarischen extremen zu fassen; denn die fo'n.f, fo'n.of herrschen einmal südlich der Ürdinger linie längs des Rheins in einem schmalen streifen, der sich mit der ausdehnung des rip. $\bar{e}:, \bar{o}:$-gebietes vergleichen läßt, dann aber südlich der lautverschiebungslinie von östlich Benrath bis zur vereinigungsstelle von Ürdinger und Benrather linie; und die $f \bar{\imath} f$ stehen im allgemeinen außerhalb der rechtsrheinischen normallinie. ${ }^{2}$ ) Nur in unmittelbarer nähe des Rheins hat sich also bei der durchbrechung der alten niederfränkisch-ripuarischen grenzlinie die ripuarische form in reiner gestalt durchsetzen können. Im übrigen aber hat sie dem ursprünglichen $f \bar{\imath} f$ des eroberungsgebietes nichts als den labialen charakter ihres wurzelvocals aufgeprägt, so daß für das heutige fouf von einem ursprünglichen * $f \bar{f} f$ auszugehen wäre. Lobbes setzt demgegenüber ein altes *fonf a,n, dessen $n$ "in anlehnung an die $n$-losen formen des ostens und nordens und die zahlwörter 'fünfzehn' und

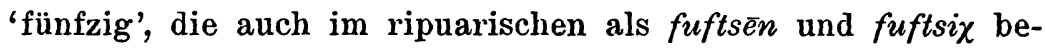
gegnen, ausfiel". Vor dem ausfall übte die verbindung - $n f$ eine ähnliche diphthongierende wirkung wie $l d, l t, m b, m p$ (z. b. hoult 'holz') aus. Diese ansicht stützt Lobbes durch die

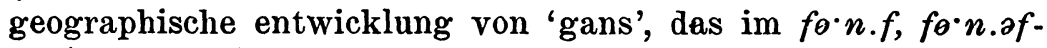
gebiet jans, im fouf, fo $u$.f-gebiet im ganzen jous, im $f \bar{\imath} f$ gebiet aber im allgemeinen $x \bar{\delta} s$ lautet; für jous erschließt er

1) Lobbes, DDG. VIII $\S 18$ anm. 2.

2) Leihener, DDG. II $\S 86,2$; Lobbes, DDG. VIII § 28; Maurmann $\S 219 ;$ Neuse, DDG. VIII § 189 (fif); Hasenclever $\S 115$. 
ebenfalls diphthongierung vor -ns.1) Etwas bestechendes gewinnt diese deutung dadurch, daß sich die diphthongierungsbezirke von 'fünf' und 'gans' tatsächlich mit dem diphthongierungsdistrict des typus hoult 'holz' decken. ${ }^{2}$ ) Aber dennoch enthält dieser interpretationsversuch viele schwächen. Das $n$ in ${ }^{*}$ fonf muß nach vollzogener diphthongierung vermittelst der angrenzenden niederfränkischen formen beseitigt werden; dem niederfränkischen lautstand wird damit eine geographische activität zugemutet, die sich mit der entstehung des übergangsgebietes und mit seiner in allen compromißbildungen zu tage tretenden passivität nicht vereinbaren läßt. Kann Lobbes' * fonf überhaupt als bodenständige $n$-form angesehen werden? Zumindest für die einem diphthongierten jous 'gans' angeblich zugrundeliegende -ns-form scheint er im übergangsgebiet altes heimatsrecht $\mathrm{zu}$ fordern. Aber dann muß dieselbe -ns-form auch für die echt niederfränkischen maa. von Mülheim a.d.Ruhr und Werden gefordert werden, die nach Lobbes' eignem zeugnis ebenfalls diphthong aufweisen. ${ }^{3}$ ) Es wäre gewiß sehr ansprechend, den diphthong in $x \varphi^{\cdot} u . s$ mit der Mülheimer diphthongierung vor $n d$, $n t$ (typus tount 'zahn') zusammenzustellen und einen jungen $n$-ausfall anzunehmen ${ }^{4}$ ); aber es ließe sich ebensogut an eine diphthongierung vor der spirans $s$ und somit an einen alten $n$-ausfall denken. Das bergiscse fouf wäre dann aus * $f o ̈ f$ durch diphthongierung vor der spirans $f$ entstanden. Der geographische zusammenfall der diphthongierungen vor $f, s$ mit denen vor $l d$, $l t$ wäre nicht zu verwundern, da die phonetischen voraussetzungen für beide diphthongierungsprocesse die gleichen sind. Jedenfalls würde diese erklärung den alten $n$-ausfall vor $s$ und $f$ fïr beide wörter an die Benrather linie verweisen und damit einen alten grenzgegensatz $-s,-f /-n s,-n f$ aufzeigen. $\left.{ }^{5}\right)$ Und schließt man jetzt die linksrheinische $v \tau f / v \theta^{\prime} n . \partial f-$ an die rechtsrheinische

1) Lobbes, DDG. VIII $\$ 29$.

2) Lobbes, DDG. VIII $\$ 46$; Leihener, DDG. II $\$ 70$ anm. 5.

3) Vgl. auch Maurmann ry $x_{\text {.s }}$ 'gans' \$ 97.

) Maurmann $\$ 160$.

•) Übrigens ist auch der accent in fou.f unter dem ninfluB des südlichen $f^{\circ} \cdot n . f$, fo'n.of (selten fonaf) in das diphthongierte fonf lineingetragen worden. 
fif, fouflfo'n.əf-linie an, so ergibt sich als resultat, daß die niederfränkische $-f$-form im westen zumindest noch an einer kleinen strecke, im osten in dem compromib fouf aber auf einer weiten linie der alten niederfränkisch-ripuarischen grenze treu geblieben, zu beiden seiten des Rheins jedoch bis an die Ürdinger linie zurückgedrängt worden ist.

$\mathrm{Zu}$ demselben resultat führt die verknüpfung der linksrheinischen winn/win mit der rechtsrheinischen win, win/win, we»s - und brūn, brun/brun, bron-linie ${ }^{1}$ ), deren grenzverlauf mit der fif, fouflfo'n.of-linie verwandt ist und die auch in den compromißbildungen $w_{\bar{n} n}+w_{i n}=w_{i n}, b r \bar{u} n+b r u n=b r u n$ ein analogon $\mathrm{zu}$ dem proceß $f \bar{\imath} f+f \boldsymbol{t}^{\cdot} \cdot \boldsymbol{n} . \partial f={ }^{*} f \bar{o} f>$ fouf aufweisen. Nur gestaltet sich hier das resultat insofern günstiger, als n!ouillierungslinie und Benrather linie auch links des Rheiıs eine größere gemeinschaft haben. Von den übrigen mouillierungslinien, die in der vierten gruppe für das linke Rheinufer zusammengestellt worden sind, trifft die mouillierung: eines $d(t)>g(k)$ die Benrather linie nur nördlich Wermelskirchen ${ }^{2}$ ), während die mouillierung des typus $p \bar{\imath}: n$, pi・色, dem sich auf grund der flectierten formen auch der typus min, min, $m i \cdot n ., m i \cdot r$. anschließt, rechtsrheinisch dieselbe unregelmäßige geographische entwicklungsfähigkeit wie linksrheinisch zeigt. ${ }^{3}$ ) Auch das zahlwort 'neun' fügt sich diesem bilde trefflich ein. Die auf altes nigun zurückgehenden formen sind bis auf einen district um Velbert, Neviges, der sich mit dem im ersten capitel erwähnten wat-bezirk vergleichen läßt, an die Ürdinger linie zurückgedrängt; das mouillierungsgebiet greift etwas über das wirs-gebiet hinaus; der rest zwischen Benrather und Ürdinger linie wird nach dem zeugnis von Lobbes, DDG. VIII \$ 34 anm. 1 von nyn-formen erfüllt, während Leihener, DDG. II $\S 86,2$ für einen teil dieses winkelgebietes $n y \cdot n$. belegt. Diese auffällige unstimmigkeit zwischen den beiden forschern kann nicht beunruhigen. Lobbes belegt die aus einem compromiß zwischen ältestem, heute überall geschwundenem rip. ${ }^{*} n \bar{y} n$, und jüngerem, nordwärts stoßendem rip. ny' . gebildete form, die

1) Leihener, DDG. II § 83,1. 3; Lobbes, DDG. VIII $§ 34$.

$\left.{ }^{2}\right)$ Lobbes a. a. O.; Hasenclever $\$ 82$.

3) Leihener, DDG. II § 83, 2; Lobbes, DDG. VIII $§ 35$. 
einen sieg des jüngeren ripuarischen vocalismus, nicht aber des consonantismus darstellt $\left({ }^{*} n \bar{y} n+n y \cdot n .=n y n\right)$, während Leiheners $n y^{\prime} \boldsymbol{n}$. einen letzten, aber endgültigen sieg des südlichen lautstandes bedeutet. Jedenfalls lassen auch die ny' formen durch ihr entschlossenes nordwärtsstreben den Rhein entlang bis zur Ürdinger linie die besonders starke activität der ripuarischen eroberung an dieser stelle erkennen. Daß der ripuarische typus *niun im übrigen aber das ganze rechtsrheinische übergangsgebiet bis auf die erwähnte ausnahme besetzt hat, stellt ihn neben die beiden linien der linksrheinischen dritten gruppe, die sich allein auf dem rechten Rheinufer genau verfolgen lassen: die 'haben'- und 'sagen'linie. Die han und $z \bar{a} \gamma \partial n$ haben im gegensatz zu ihrer linksrheinischen entwicklung die Ürdinger linie erreicht; die hęwan und zeyan decken sich im wesentlichen mit dem bereich der $\left.e k, \overline{o k} .{ }^{1}\right)$ Und auch der stamm hint- ist im norden an die niederfränkische normalgrenze vorgedrungen. Bei Kettwig hat er sie bereits durchbrochen, und im osten steht er sogar an der -et-linie. Auch rechtsrheinisch liefert die verteilung der aft- und hint- den beweis für die ripuarische eroberungstätigkeit: einmal läßt sich im übergangsgebiet ein eitarboks 'hintergeschirr des pferdes'2) belegen, andererseits findet sich ein eitar für unverbundenes 'hinter' nur noch in dem oft erwähnten dorfe Wanheim. ${ }^{3}$ ) Es gehört $\mathrm{zu}$ den beiden am Rhein gelegenen grenzdörfern, die zwar $e \chi, \bar{o} x$ aufweisen, im übrigen aber nördlich der niederfränkischen normalgrenze liegen. Ihr bodenständiger niederfränkischer stamm axt- ist zwar von der ripuarischen behandlung der spirans in der verbindung cht getroffen worden, d. h. die vocalisierungslinie und die Ürdinger linie sind an dieser stelle über die niederfränkische normalgrenze hinausgerückt; aber die verdrängung des stammes aftdurch den stamm hint- ist nur in Angerhausen, nicht in Wanheim geglückt. Die tatsache endlich, daß hint- im osten die Ürdinger linie mit der -et-linie vertauscht hat, erhebt es zur gewißheit, daß die abweichungen in den angaben Leiheners

1) Leihener, DDG. II $\$ 88$; Lohbes, DDG. VIII $\$ 53$ anm. 1. 2; Hnsenclever $\$ \S 128.131$; Maurmann $\$ \$ 102.276$.

2) Lobbes, JIJG. VIJI s. 80 (nachtriige).

3) Lobbes, JDDG. VIII $\$ 48$ amm. 1. 
und Lobbes', die ich mehrfach hervorgehoben habe und die sich noch hier und da vermehren ließen (z. b. stärkere anlehnung der *nigun/*niun 'neun' - an die -et-linie bei Leihener, stärkere anlehnung der fouflfif - an die -ct-linie bei Lobbes), auf einer tiefen erschütterung des östlichen teiles der Ürdinger linie beruhen. Daß sich in Voßnacken die verschobene 'auch'form nachweislich seit ausgabe der fragebogen des SA einzubürgern pflegt, beweist, daß diese phase der ripuarischen eroberung zumindest für einzelne erscheinungen allerjüngsten datums ist. Je inniger sich die anlehnung der ripuarischen formen an die -et-linie vollzogen hat, um so älter ist sie. Aber immerhin ist sie jünger als jene phase, in der mit der herausbildung der jungen niederfränkischen normalgrenze auch die compromißbildungen erwuchsen. Denn niederfränkisch-ripuarische compromißformen können nur innerhalb der Ürdinger linie entstanden sein. Ihr erscheinen zwischen Ürdinger linie und -et-linie, z. b. jot, ovk, fouf in Elberfeld, beruht auf mechanischer ausbreitung durch junge historische verschiebungen, deren centrum namentlich die beiden städte Elberfeld und Barmen bilden.

Man könnte versucht sein, von dem rechtsrheinischen material aus noch einige andere grenzlinien aufzustellen. Neben

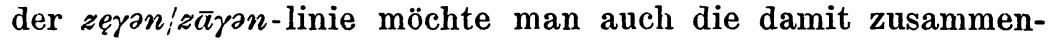
fallenden lijan/lījan 'liegen'- und lę̧an/lęjan 'legen'-linien 1) heranziehen. Die verteilung der mundartlichen entsprechungen von 'mir, mich, dir, dich', die dem gebiet außerhalb der Ürdinger bez. -et-linie für beide casus die $r$-losen dativformen (Mülheim a.d. Ruhr mii, dịi Maurmann § 221), dem gröBten teil des übergangsgebietes aber für beide casus die accusativ-

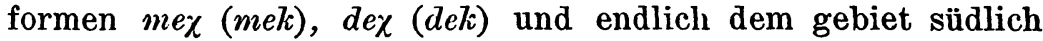
und unmittelbar nördlich der Benrather linie in regulärem

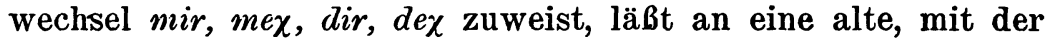
Benrather linie zusammengehende ${ }^{*} m \bar{\imath}, d \bar{\imath} / m i r, m i \chi, d i r$, dixlinie denken, die von den ripuarischen formen durchbroehen wurde, so da $\beta$ das übergangsgebiet durch compromi $\beta$ zwischen dem ursprünglichen dativischen einheitscasus und dem süd-

1) Lobbes, DDG. VIII §54 anm. 1; Maurmann \$§ 248. 276 (lijo, leyə), Hasenclever §§ 122. 131. 
lichen doppelcasus einen neuen einheitscasus aus dem südlichen accusativ bildete. ${ }^{1}$ ) Aber für diese linien fehlen in dem linksrheinischen material die genaweren angaben, oder ihr lauf führt über die Ürdinger linie hinaus; vgl. unten.

\section{4.}

Fassen wir, ohne uns in einzelheiten $\mathrm{zu}$ verlieren, die beobachtungen zur heutigen niederfränkischen grenzlinie (abschnitt 1) sowie zu den grenzlinien des übergangsgebietes links (abschnitt 2) und rechts (abschnitt 3) des Rheins zusammen, so steht nunmehr fest, daß die heute vielfach auseinandergerissenen scheidelinien ehedem eine einheitliche niederfränkisch-ripuarische grenzlinie darstellten, die mit dem heutigen normalverlauf der Benrather linie im wesentlichen zusammenfiel. Die durchbrechung dieser alten niederfränkischen grenzlinie durch ripuarische formen zeigt ein allmähliches erschlaffen vom Rheine her zu den an der holländischen und westfälischen grenze liegenden flügeln des übergangsgebietes, so $\mathrm{daB}$ im westen und osten noch breite niederfränkische zonen südlich der heutigen niederfränkischen normalgrenze liegen bleiben. Vom standpunkte der deutschen maa. erscheinen diese zonen an der holländischen grenze als relictgebiete; doch wird die holländische dialekterforschung sie sicher einmal in geographischen zusammenhang mit den nördlich der vocalisierungslinie gelegenen deutschen gebieten bringen. Die niederfränkisch-ripuarischen grenzlinien werden dann als weite bogen erscheinen, die der Benrather linie mit der öffnung nach süden und dem geographischen höhepunkt bei Ürdingen am Rhein aufgesetzt sind. Der äußerste dieser bogen würde dann das gesamte gebiet der ripuarischen eroberung umschließen. Nach den angaben Schrijnens Tijdschrift 21, 249 will es scheinen, $\mathrm{daß}$ diese rolle der Ürdinger linie, die vom standpunkte der deutschen maa. allein nicht dazu geeignet erscheint, zufallen wird. Daß dieser bogen allerdings die endgültige grenze des südlichen einflusses bedeutet, dürfte man bereits nach den ergebnissen von abschnitt 2 bezweifeln. Schon die fest gefïgte

1) Leihener, DDG. IJ $\$ 87,3$; Lobbes, II)(G.VI11 $\$ 63$. 
niederfränkische normalgrenze zeigt bei Gelinter-Wachtendonk auf dem linken, bei Angerhausen-Wanheim und Kettwig auf dem rechten Rheinufer bedenkliche durchbruchsstellen, und das ständige schwanken gewisser grenzen zwischen Ürdinger und -ct-linie verkündet bis in die jüngste zeit ein ewiges vorwärts der südlichen formen. Der geltungsbereich der schärfung, des $r$-ausfalls vor dental sowie von formen wie - $l i \chi$ und $p i \cdot n$. scheint auch für eine ältere epoche ripuarischen einfluß nördlich der Ürdinger linie $\mathrm{zu}$ verraten. Vielleicht weisen auf dem rechten Rheinufer auch das weit nach norden reichende $-n$ in $m y: n$ 'muhme, tante', sowie die durchgehenden $a$-formen in 'markt' in dieselbe richtung. Auch die tatsache, daß auf dem linken Rheinufer einige linien von der holländischen grenze bis südwestlich Mörs mit der niederfränkischen normalgrenze gehen, dann aber nach norden abbiegen und ebenso auf dem rechten Rheinufer diese oder jene erscheinung im südosten an der Ürdinger linie einsetzt, sie jedoch später verläßt, scheint hierhin zu gehören. Für den ersten fall sei auf den $j$-ersatz für geschwundenes intervocalisches - $d$ - verwiesen, der sich im anschluß an die linksrheinische $j$-linie, die Mörs zum süden schlägt ${ }^{1}$ ), rechtsrheinisch nördlich Duisburg-Mülheim ${ }^{2}$ ) vollzieht,

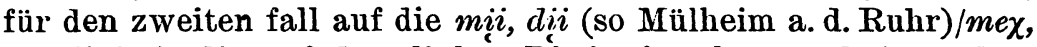

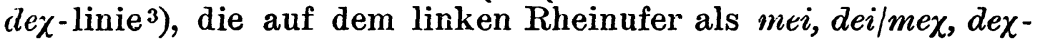
linie ${ }^{4}$ zwischen Rheinberg-Mörs und Goch-Geldern wiederkehrt. Aber überlassen wir die frage nach dem alten verhältnis dieser grenzen zur Benrather linie oder der alten niederfränkisch-ripuarischen grenze einer späteren einteilung des niederfränkischen, so verlockend es auch scheinen mag; dem durch das heinsbergische $j$-gebiet an der holländischen grenze gebotenen fingerzeig zu folgen. Es bleibt sicher, daß die vocalisierungslinie das gebiet der intensivsten ripuarischen eroberung abschließt. Will man ihr auf grund der weiter nach norden reichenden südlichen erscheinungen den titel einer niederfränkischen grenzlinie schlechthin versagen, so mag man, übrigens auch mit rücksicht auf die noch südlich der

1) Ramisch, DDG. I $\S 31$; Hanenberg, DDG. VIII $\S 230$.

2) Neuse, DDG. VIII $\$ 355$.

3) Lobbes, DDG. VIII $\S 63$.

4) Hanenberg, DDG. VIII § 242. 
vocalisierungslinie stehenden niederfränkischen erscheinungen, die bereits ständig verwandte bezeichnung niederfränkische normalgrenze wählen.

Aber ist der alten niederfränkisch-ripuarischen grenze außer den an der normallinie des Benrather bündels verschobenen formen auch nicht eine einzige linie treu geblieben? Die ihr linksrheinisch am nächsten stehende wīn/wi»-, brīn/brun-linie versagt unmittelbar am Rhein und vollends rechtsrheinisch. Ähnlich verhält es sich mit den linien $j \bar{g} n$, jōon/jon 'gehen', štōn, stōan/ston 'stehen', jadōn, jadōan/jadon 'getan', dōn, dūan/ don 'tun' '), deren formen mit kurzvocal im ripuarischen wohl kaum mit Müller-Aegidienberg $§ 39$ aus unbetonter satzstellung, sondern aus anlehnung an formen mit auslautender doppelconsonanz (jont 'gehen' 1. 3. plur.) zu erklären sind. Auch sie biegen frühzeitig nach norden ab und scheiden sich rechtsrheinisch sogar an der Ürdinger linie ${ }^{2}$ ), wobei übrigens Cronenberg, Ronsdorf und Remscheid neben den jungen kürzen auch noch die alten bodenständigen längen aufweisen. Bleibt nur eine besonderheit der nördlichen diminutivbildung. Dem südlichen diminutivconsonanten $-\chi$ aus $-k$ [neben dem $-l$ äußerst selten ist (Münch $\S 136$ ) und im allgemeinen nur in der verbindung $\partial l_{\chi} \partial(n)$ nach auslautendem guttural auftritt z. b. bęrojkalxan 'kleine bank'] entspricht, wenn man alle schwankungen beiseite läßt, nördlich der Benrather linie von der holländischen bis zur westfälischen grenze neben dem regulären $-k$ ein $-s k$ nach guttural und ein $-\check{s}$ nach dental ( $d$ und $t$, zumeist auch $l$ und $n)$; neben letzterem steht in dem bereits am ende von abschnitt 2 erwähnten limburgischen zipfel des übergangsgebietes, im niederländischen und im äußersten norden der Rheinprovinz ein $j .^{3}$ ) Die kleinen abweichungen von der normalen lautverschiebungslinie im westen und die compromißbildungen im osten sind ripuarische erfolge, denen keine weitere bedeutung zukommt. Wrede hat in dem $-\check{s}$ eine juingere entwicklung aus $-j$ erkannt. ${ }^{4}$ ) Die tatsache, daß wir damit von

1) DDG. V § 257.

2) Ieihener, DDG. II $\S 25$ anm. 1; Lobbes, DNG. VIII $\$ 65$.

3) Vgl. Ramisch, DDG. I \$31; DDG. VIII \& $253 \mathrm{f}$.; Neuse, DI)( VIII §\$ 235. 372; Jeibener, DDG. II \$ 85; Lobbes, DJ)( k. VIII \$70 ff.

๖) DDG. I $\S 86$. 
ciner hcutigen $-j,-5 /-\chi$ - zu einer älteren $-j \mid-\chi$ - oder $-j \mid-k$-linie gelingen, stellt die richtigkeil dieser erkenntnis außer zweifel. Auch IVredes ansicht, daß das $-j$ durch die 'einst in diesen gegenden des nordens viel weiter verbreitete friesische palatalisierung des $-k^{\prime}$ ') entstanden ist, erhebt sich zur gewißheit. Nimmt man weiter noch mit Wrede an, daß das $-s$ in $-s l c$ ebenfalls ein rest der alten palatalisierung, im übrigen aber die $-k$ des heutigen $-j,-s$-gebietes eindringlinge aus gebieten ohne $-k$-erweichung sind, so ergibt sich für die diminutivsuffixe nördlich der Benrather linie folgende genesis: in $-j(s)$ nach dental lebt die alte palatalisierung weiter; in -sk nach guttural ist ein product der palatalisierung aus altem $-k$ mit neu suffigiertem $-k$ verbunden; in allen übrigen fällen ist keine spur alter palatalisierung erhalten. Von einer palatalisierungsgrenze $(-j /-k)$ nach dental gelangen wir damit zu einer alten, nach jedem stammesauslaut gültigen palatalisierungsgrenze. Die alte niederfränkisch-ripuarische grenze fiele darnach mit der südgrenze eines alten ing wäonischen sprachprocesses zusammen.

Von neuem scheint sich damit die möglichkeit zu eröffnen, in einer heutigen sprachlinie eine alte stammesgrenze wiederzufinden. Aber schon sprachgeographische erwägungen verbieten uns, die alte niederfränkisch-ripuarische grenze, d. h. die Benrather linie, in die zeit der germanischen stammesgeschichte hinaufzurücken. Südlich der normalen lautverschiebungslinie steht noch eine reihe unverschobener formen; und auch die ripuarische mouillierung hat in den fällen ehemalig inlautender -d- die Benrather linie nur an einzelnen stellen erreicht. ${ }^{2}$ ) Zumindest für lautverschiebung und mouillierung ist also die Benrather linie eine in späterer zeit entstandene grenze. Und selbst $z e g \partial / z \bar{a} \gamma \partial$ und hębə/han, deren geographische verteilung ursprünglich einmal durch stammesverhältnisse bestimmt gewesen sein mag, müssen über die für sie zu erschließende Benrather linie hinaus für eine frühere epoche noch weiter nach süden verlegt werden. Es scheint mir noch nicht endgültig erwiesen zu sein, daß die südlich der $z \ell g \partial / z \bar{a} \gamma \partial$-linie im ripuarischen, moselfränkischen und rheinfränkischen be-

1) DDG. I § 81 .

2) Vgl. DDG. V § 180 'leute, heute, seile, seite'. 
gegnenden $s \bar{e}: s, s \bar{c}: t, s \bar{l} s, s \bar{e} t$ für die 2. 3. sing. praes. durchgehends analogische neubildungen sind ${ }^{1}$ ); zumindest für den bis zum moselfränkischen $s \bar{o}: n$-gebiet reichenden $s \bar{a} \gamma \partial n$-bezirk ist eine ableitung von segis, segit sehr wahrscheinlich. Jedenfalls aber hat hębo einmal südlich der Benrather linie gegolten. Nach DDG. V § 257 setzt mit der $v \bar{\imath} f / v \theta^{\prime} n$. $\partial f^{\prime}$ 'fünf'-linie an der holländischen grenze die hę:s, hęs/has-, hẹ:t, hęt/hat-linie ein; sie wendet sich, von der $v \bar{\imath} f / v \theta \cdot n . \partial f$-linie abbiegend, der Benrather linie $\mathbf{z u}$, schlägt $\mathbf{z w i s c h e n ~ E r k e l e n z ~ u n d ~ L i n n i c h ~}$ eine reihe von dörfern, die südlich der lautverschiebungslinie liegen, zum hęs, hęt-gebiet, kehrt an die Benrather linie zurück, wendet sich dann ähnlich der vīfivo'n.əf 'fünf'- und $n \bar{y} a j \partial$, $n \bar{\imath} \partial j \partial / \varkappa y ' \rightsquigarrow$. 'neun'-linie nach norden an die $z e ̨ g \partial / z \bar{a} \gamma \partial$-linie und kommt schließlich in südlichem lauf wieder an die Benrather linie zurück. ${ }^{2}$ ) Da somit die hęs, hęt/has, hat-linie bedeutend südlicher als die hębo, habə, han-linie verläuft, so ist ein weiterer beweis für die verlegung der hębə/han-linie nach norden erbracht; es ergibt sich ferner aus der noch heute nachweisbaren verwandtschaft der hęs, hęt/has, hat-linie mit der Benrather linie, daß die scheide zwischen den typen heblijan und habēn zur lautverschiebung einmal engere geographische beziehungen gehabt haben muß. Und das hęs, hęt-gebiet südlich der Benrather linie beweist, daß auch diese beziehungen nicht auf einer alten dialektgruppierung beruhen. Dazu lautet der infinitiv in dem genaunten hęs, hęt-gebiet hęn, das als compromiß zwischen einem bodenständigen hębben und einem nordwärts rückenden han aufgefaßt werden muß. I)a das gleiche hęn östlich des Rheins bei Gimborn (südlich Wermelskirchen) in der nähe der lautverschiebungslinie und der han/hęu'anlinie nachgewiesen ist ${ }^{3}$ ), so ist damit für das gebiet südlich der Benrather linie ein ehemaliger typus hebljan erschlossen. Es steht dann aber nichts im wege, auch diejenigen niederfränkisch-rijuarischen grenzen, die der grenze helljan/halı̄n sprachhistorisch gleichwertig sind, über ihre bereits erschlossene.

1) Hasenclever $\$ 132$; K.Schwarz, Das intervocaliscbe $-g$ - im Frünkischen, Strablourg 1914, s. $53 \mathrm{f}$.

2) DDG. V \$ 257; der weitere verlauf der linie östlich des Rheins ist nicht belegt.

3) Hasenclever s. $71 \mathrm{f}$. 
ehemalige geographische entwicklung an der Benrather linie noch weiter nach siiden zu verlegen.

Damit wird eine sprachhistorische scheidung unseres linienmaterials notwendig. Neben hęba, hoba, hęwon (haba)/hāva, hān,

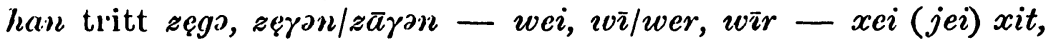
jęt $(j o l) / e \cdot, \bar{\imath} r-o u, c \cdot n k(o n k) / o \chi-v \bar{\imath} f, f \bar{\imath} f(f o u f) / v \theta^{\cdot} n . \partial f, f \theta^{\cdot n . \partial f-}$

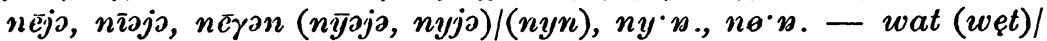
jęt ${ }^{1}$ ), die auf alte grenzen der typen hebljan/habēn - seggjan/

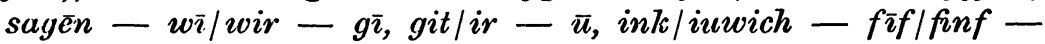
niguniniun - vat,iowicht zurückgehen. Die $j$-bildungen bei 'haben' und 'sagen', die $r$ - und $k$-losen pronominalformen, die duale sowie $f \bar{f} f$ und nigun sind gemeinsame eigenheiten einer westgermanischen sprachgruppe, die das niederfränkische, angelsächsische, friesische und altsächsische umschließt. An der ältesten südgrenze dieser erscheinungen hat auch einmal die palatalisierungslinie gestanden. Wie weit sie über die Benrather linie hinaus nach süden $\mathrm{zu}$ verlegen ist, wage ich nicht zu sagen. Es ist schon mehrfach darauf hingewiesen worden, daß die ripuarisch-moselfränkische Eifellinie von der zukünftigen einteilung des fränkischen einmal als wichtigste grenzscheide gefordert werden wird. Man will in ihr die auch in der späteren territorialgeschichte weiter lebende südgrenze der Germania inferior, die Vinxtbachgrenze, wiedererkennen. Es ist möglich, daß die ingwäonismen des niederfränkischen ehedem bis zu dieser grenze gereicht haben. Sicher ist nur, daß sie aus irgendwelchen gründen durch südliche, meinetwegen 'deutsche' formen nach norden gedrängt worden sind, zu irgendeiner zeit die Benrather linie erreicht haben, aber auch diese wieder verlassen mußten und schließlich an der Ürdinger linie einen letzten halt fanden. Bremer hat Grundr. III'2 s. 862 eine reihe von möglichkeiten zusammengestellt, die die anglofriesischen eigentümlichkeiten des altniederfränkischen erklären könnten. Überlassen wir es einer besonderen arbeit, diese historischen einzelheiten mit der ehemaligen und heutigen geographischen entwicklung der ingwäonismen zu verknüpfen, und begnügen wir uns vorläufig mit dem resultat, dab die bis

1) Nur wichtige mundartliche varianten sind verzeichnet; compromisse in klammern. 
in die heutige mundartengeographie $\mathrm{zu}$ verfolgende verdrängung der ingwäonismen schon zu einer recht frühen zeit begonnen haben muß, und zwar jedenfalls bevor die lautverschiebung die mittlere Rheinprovinz im 9. jahrhundert erreichte. ${ }^{1}$ ) Denn nur so läßt sich die verdrängung des palatalisierten $-k$ durch unberïhrtes $-k$ und die alte ingwäonisch-dentsche compromißbildung -sk erklïren. Auch die vielleicht nie lösbare frage, ob die ingwäonismen genau gleichweit nach süden reichten und zu gleicher zeit und in stets gleicher geographischer entwicklung nach norden gedrängt wurden, scheiden wir hier aus. Das diminutive $-z(-\chi)$ ist jedenfalls $z u$ verschiedenen zeiten verschieden weit nach norden vorgestoßen; am frühesten und weitesten in den fällen, wo heute keine spur der palatalisierung erhalten ist, sowie nach guttural, am spätesten nach dental. Die verdrängung des $-j$ nach dental ist überhaupt erst durch verschobenes $-\chi$ erfolgt. I)ieses $-\chi$ hat auch die eiumal südlich der Benrather linie anzusetzenden $-s \chi$, die DUG. V $\$ 254$ als nur gelegentliche erscheinungen nachgewiesen sind, verdrängt. Uns kommt es hier vor allem darauf an festzustellen, wann die ingwäonismen an der Benrather linie gestanden haben und wann die weitere zurückdrängung bis zur Ürdinger linie, d. h. die herausbildung des ingwäonischen linienbïndels erfolgte. Es darf als sicher gelten, daß die in dem heutigen Bemrather linienbündel als normallinie weiter lebende einheitliche lantverschiebungslinie des 13. jh.'s auf einer großen strecke mit der nordgrenze der alten grafschaft Jülich zusammenfiel, die ihrerseits im 12., spätestens im anfang des 13. jh.'s vorhanden war, und die sich seit frühestens 1029 herausgebildet und seit frühestens 1386 wieder aufgelöst hat..2) Nach 1029 haben also die deutschen formen das unmittelbar siidlich der Benrather linie gelegene gebiet besetzt. Die heutige $-j,-5 /-\chi$-linie des diminutivums ist in ibereinstimmung mit der normalen lantverschiebungslinie genauer 11 rund 1250 entstanden ${ }^{3}$ ), nachdem bereits in einer älteren, vorterritorialen epoche der eroberungszug des -ls stattgefunden hatte. Seit, irgendeinem zeitpunkte vor dem 9. jh. bis um rund 1250 steht also eine allmähliche

1) Vgl. Beitr. 1, 4:s.

e) Vyl. Beitr. 399, 374.

2) V gl. Heitr. 39, 374 f.

Beiträge zur geschichte der deutschen eprache. 41. 
verdrängung der ingwäonismen nach norden fest. Keine der heutigen ingwïonisch-deutschen grenzen setzt somit eine alte stammesgrenze fort.

Gegenüber dem ingwäonisch-deutschen linienbündel des übergangsgebietes, dessen nördliche und südliche typen einer iiltesten, heute verschobenen und vorläufig nicht sicher erkemnbaren stammesgruppierung entsprechen mögen, sei ein zweites linienbündel herausgehoben, dessen nördliche und südliche typen sich dadurch auszeichnen, daß der eine aus dem andern in der literarischen epoche der deutschen sprache hervorgegangen ist. Ich denke, um nicht alle einzelheiten zu berücksichtigen, vor allem an die lautverschiebung, mouillierung, gutturalisierung und vocalisierung. Sie sind, von der lautverschiebung abgesehen, an irgendeiner stelle des südlichen oder mittleren Ripuarien entstanden. ${ }^{1}$ ) Sie dehnten sich aus irgendwelchen gründen nach norden aus, ohne daß die einzelnen phonetischen processe und wörter zu stets gleicher zeit eine gleiche geographische linie entwickelt hätten; gegen eine solche annahme würden $z$. b. bei der mouillierung die noch heute südlich der normalen lautverschiebungslinie begegnenden unmouillierten formen sprechen. Aber immerhin haben sie doch entsprechend den die ingwäonismen verdrängenden deutschen formen im großen und ganzen das nördliche Ripuarien besetzt und zu irgendeiner zeit in der Benrather linie ihre nördliche grenze gefunden. Für die lautverschiebung ist nun Beitr. 39, 374 die nordwärtsentwicklung innerhalb Ripuariens vom 9., 10. jh. bis rund 1250 beobachtet worden. Es ist nicht nötig, die frühesten anfänge der mouillierung, gutturalisierung und vocalisierung in die zeit der ersten ripuarischen spiranten und affricaten zu verlegen. Jedenfalls können sie, wenn sie damals schon vorhanden waren, Nordripuarien erst nach 1029 erreicht haben. Für den typus tīt, tsīt/tsik 'zeit', also für die mouillierung von auslautender dentalis, ist es bei der engen geographischen verwandtschaft mit der Benrather linie ${ }^{2}$ ) immer-

1) Vgl. Müller, Aegidienberg §§ 35. 20; vgl. Anz. fda. 20, 212 'braune', 19, 279 'wein'; 19, 104 'pfund', 107 'hund', 108 'winter', 111 'kind'; 21, 163 'recht', 19, 278 'luft'.

2) Vgl. DDG. V § 176. 
hin sicher, daß - von jüngeren ausbuchtungen abgesehen seine heutige linie um 1250 entstanden ist. Damit fällt also auf grund geographisch-historischer erwägungen den mouillierungsund gutturalisierungsprocessen ein verhältnismäßig hohes alter $\mathrm{zu}$, eine feststellung, die um so wertvoller erscheint, als uns literarische belege für die erscheinung bisher fehlen. Für die vocalisierung, die man gewöhnlich als $h$-schwund zu bezeichnen pflegt, sind nach Franck (Altfrk. gramm. § 113) und Weinhold (Mhd. gramm. ${ }^{2} \S 241$ ) aus alter und mittlerer zeit belege erbracht; speciell fürs ripuarische ist auf Westd.zs. 21, $291 \mathrm{f}$. und Dornfeld, Hagens reimchronik (= Germ. abhandlungen 40) $\S 107 \mathrm{zu}$ verweisen.

Drei sprachhistorisch so verschiedene linien wie die normale lautverschiebungslinie, die ingwäonisch-deutsche $-j /-\chi$-linie und die niederfränkisch - ripuarische mouillierungslinie für auslautendes $d>t$ sind also um die gleiche zeit, um die mitte des 13. jh.'s, nach einer voraufgehenden nordwärtsbewegung der südlichen formen entstanden. Es läge somit nahe, die verschiebung des ingwäonisch-deutschen linienbündels, die herausbildung der mouillierungs-, gutturalisierungs- und vocalisierungslinien oder des niederfränkisch-ripuarischen linienbündels im engeren sinne, und die entstehung der normalen lautverschiebungslinie einer gleichen epoche und gleichen, aus der politischen geschichte Ripuariens näher zu erschließenden ursachen zuzuweisen. Für die entscheidung dieser frage fehlen aber zurzeit noch die genauen sprachlichen und historischen vorarbeiten; auch könnte sie nur in ständigem hinblick auf die ripuarisch-moselfränkische Eifelgrenze gelöst werden, über deren sprachliche und historische bedeutung wir ebenfalls noch keine untersuchung besitzen. Aber die allgemeine erkenntnis von bedeutenden nordwärtsbewegungen südlicher formen auf ripuarischem boden in der zeit vom 9. bis 13. jh. genügt vorläufig für unsere zwecke. Wer sie übrigens noch bezweifeln möchte, der sei auf die vocalgestalt der mouillierten formen im nördlichen Ripuarien bez. im übergangsgebiete verwiesen. Es erscheinen gegenüber der sonst allgemein geltenden senkung von $i, u, y>e, o$, o kurze $i, u, y$ (typus win 'wein'), die sich, wie schon DJGG. V § 176 vermutet, wurde und jetzt, anch von Lobbes, DDG. VIII § 34 anm. 2 bestätigt wird, nur aus einem 
compromiß zwischen bodenständigem $\bar{\imath}, \bar{\imath}, \bar{y}$ (typus win 'wein') und nordwärtsdringendem, regulärem $c, o, \theta$ (typus wcn 'wein' 1)) erklïren, so daß also die nordripuarischen wis ähnlich den compromibbildungen des übergangsgebietes aus einer addition win + vev $=$ win hervorgegangen sind.

Fïr die frage nach der entstehung des niederfränkischripuarischen übergangsgebietes ergibt sich nunmehr ein grundlegender anhaltspunkt. Nachdem die dialekt-geographischen beobachtungen gezeigt haben, daß die heutigen niederfränkisch ripuarischen grenzlinien ehedem einmal alle an der normalen Benrather linie gestanden haben, nachdem im anschluß an die untersuchungen über das alter der Benrather linie Beitr. 39, $362 \mathrm{ff}$. als entstehungszeit einer ingwäonisch-deutschen und einer niederfı̈̈nkisch-ripuarischen grenzlinie im engeren sinne das 13. jh. gewonnen ist, werden wir für die verschiebung des niederfränkisch-ripuarischen gesamtbündels von der normalen Bemrather linie nach norden auf dieselbe zeit und die gleichen ursachen verwiesen, die für die nördlichen abzweigungen von der normalen lautverschiebungslinie nachgewiesen worden sind. Von diesen aber ist a.a. o. s. 375 gesagt, daß sie infolge kurkölnischer territorialverhältnisse des ausgehenden 13. und jülichischer territorialverhältnisse des ausgehenden 14. jh.'s entstanden sind. Also in der territorialgeschichte Jülichs und Kurkölns wäre auf dem linken Rheinufer die entwicklung des heutigen niederfıänkisch-ripuarischen linienbündels aus der ehedem für alle grenzen einheitlichen Benrather linie zu suchen.

\section{5.}

Nach der karte von 1789 im Geschichtlichen atlas der Rheinprovinz gruppiert sich um den westen der normalen lantverschiebungslinie jülichisches, um den osten kurkölnisches gebiet. Aber der jülichische besitz unmittelbar nördlich dieser linie wurde erst seit dem 14. jh. erworben. Die späteren jülichischen ämter Randerath, Heinsberg, Wassenberg, an deren südgrenze sich die linie bewegt, waren ehedem selbständige territorien, deren südgrenze sich bereits im 12., 13. jh. deutlich

1) So bei Münch und Müller-Aegidienberg. 
aus der historischen überlieferung erkennen läßt. Obgleich nun die südlich dieser territorialgrenze gelegenen ortschaften sich zum teil erst im 14. jh. als jülichisch belegen lassen, so müssen wir sie aber doch bereits für das 13. jh. zumindest als jülichische interessensphäre ansetzen. ${ }^{1}$ ) Damit gelangen wir also spätestens für das 13. jh. zu einem festen grenzgegensatz $z$ wischen der nordgrenze der alten grafschaft Jülich und den nördlich anschließenden territorien. Diese grenze wurde durch die erwerbungen Jülichs seit dem 14. jh. gesprengt. Randerath kam 1392, Heinsberg 1484, Wassenberg 1493 an Jülich; als jülichische ämter erscheinen die ehemalig selbständigen territorien 1445, 1555, 1555.2) Mit Heinsberg wurde auch das südlich anschließende und im osten an Randerath grenzende terıitorium Geilenkirchen, sowie ein teil des westlich Héinsberg und Geilenkirchen gelegenen Millen gekauft. Der rest von Millen wurde 1499 durch tausch erworben. Als jülichische ämter sind Geilenkirchen und Millen 1556 und 1578 zu belegen. ${ }^{3}$ ) Ende des 15. jh.'s ist also die um die Roer gruppierte nordwestecke Jülichs, die bis zur heutigen niederländischen grenze reicht, abgerundet.

Nach osten legt sich vor diese von 1392-1499 nördlich der alten grafschaftsgrenze erworbenen gebiete eine alte politische barriere. Sie erstreckt sich nach der karte von 1789 zungenförmig, und zwar von westen nach südosten in jülichisches gebiet hinein und besteht aus drei, in eben dieser richtung aufeinander folgenden teilen: dem ehedem geldernschen, später spanisch-österreichischen gebiet mit den hauptorten Elmpt, Brempt, Krüchten und Wegberg (links der Schwalm), dem ort Schwanenberg, der zu dem 1288 von Geldern erworbenen, später als reichsherrschaft erscheinenden Wickrath gehört, und dem ehedem ebenfalls geldernschen, später pfälzischen territorium Erkelenz, dessen südostecke an der scheide Erkelenz-Baal auf die alte jülichische grafschaftsgrenze stößt. ${ }^{4}$ )

Nördlich und östlich dieser barriere hat Jülich schon frïhzeitig fuß gefaßt. Die ersten nachrichten über territorialbesitz

1) Beitr. 89, 366 .

2) J3eitr. 39, 367 und die dort nach I)](t. $V$ angegebenen belege.

s) DDG. V $\$ \$ 274.275 .276$.

) DDG. V \$\$ 284. 286. 
der grafen von Jülich im bereich des späteren amtes Brüggen, als dessen hauptorte Brüggen, J)ülken, Dahlen und Süchteln erscheinen, stammen aus dem anfang des 14. jh.'s. Ende, vielleicht auch schon mitte des 14. jh.'s ist der umfang des im jahre 1500 genauer umschriebenen antes sicher zu erkennen. Das südlich und östlich an Brüggen-Dahlen anschließende, später grevenbroichische unteramt M.-Gladbach kam nach dem tode des letzten grafen von Kessel laut schiedsspruch zwischen Köln und Jülich 1307 an Jülich; mit M.-Gladbach auch die spätere herrschaft Rheydt, die ausdrücklich jedoch erst 1388 in ein schutz- und schirmverhältnis zu dem mächtigen Jülich trat und erst im lauf des 16. jh.'s ihre selbständigkeit endgültig einbüßte. 1) Ende des 14. jh.'s ist also die zwischen Maas und Niers gelegene nordostecke Jülichs abgerundet.

Öfters hat Jülich versucht, das zwischen der nordwestund nordostecke gelegene gebiet zu erlangen. Nach vergeblichen jülichischen bemühungen um den besitz der herren von Brempt zu ende des 13. und anfang des 14. jh.'s, erscheinen Brempt und Niederkrüchten 1340 in festem besitz der herzöge von Geldern. Die seit anfang des 14.jh.'s erworbene herrschaft über Erkelenz hat Geldern nach langwierigem streit mit Jülich 1545 fest behauptet. ${ }^{2}$ )

Es liegt nahe, die sprengung der alten niederfränkischripuarischen linie mit der verschiebung der jülichischen nordgrenze zu verknüpfen. Schon die untersuchungen von DDG. V weisen darauf hin, daß die übereinstimmung zwischen sprachlicher und politischer grenze in der jungen jülichischen nordwestecke nicht etwa auf der alten territorialgeschichte, sondern auf der jüngeren geschichte der ämter, in denen die territorien weiterleben, basiert. Untereinander weisen nämlich die territorien dieses gebietes mannigfache gemeinsame schicksale auf. Heinsberg hatte schon vor 1170 Geilenkirchen ${ }^{3}$ ), und vor 1120, vor 1282 und endlich 1342 die einzelnen teile des späteren jülichischen amtes Millen erworben ${ }^{4}$ ), sich also nach westen erweitert. $\mathrm{Zu}$ dem östlich gelegenen Wassenberg weist es nur

1) DDG. V $\S \S 269.270$.

3) DDG. V \& 275 .
2) DDG. V $\$ \$ 284.286$.

4) DDG. $\ \$ 276$. 
unbedentende beziehungen auf. Und doch liegen die meisten und bedeutendsten heutigen sprachgrenzen nicht etwa zwischen Heinsberg und Wassenberg, deren grenze dazu durch eine natürliche scheide, die Roer, gestützt wird, sondern zwischen Millen im westen, und Heinsberg-Geilenkirchen im osten, also inmitten von gebieten, die seit früher zeit miteinander vereinigt waren.1) Den beweis, daß diese sprachlichen grenzgestaltungen sich nach der erweiterung der alten jülichischen grafschaftsgrenze auf grund der jülichischen amtsgeschichte regulieren, liefert die geographie des wortes 'neun'. Das rip. $n y \cdot$ ' . steht noch heute an der südgrenze von Randerath, Heinsberg, Wassenberg, also an der nordgrenze der alten grafschaft Jülich. Die compromißform $n \bar{y} a j a, n y j a$ gilt in Randerath, Geilenkirchen, Millen, Heinsberg, Wassenberg, also in der von 1392-1499 erworbenen jungen jülichischen nordwestecke sowie in dem bis 1545 von Jülich umworbenen südteil der geldernschen barriere (Erkelenz). Jülich trug also mit seiner politischen eroberung das rip. $n y^{\prime} \not$. nach 1392 in das gebiet des nfrk. nīaja, woraus dann $n \bar{y} a j a, n y j a$ als compromiß resultierte. Für das alter der ehemaligen niederfränkischripuarischen grenze ergibt sich daraus, daß sie schon vor 1392 vorhanden war, also zwischen 1029 und 1392 entstanden sein muß, was $\mathrm{zu}$ der auf grund der lautverschiebungslinie erworbenen datierung 1029-1386²) stimmt, für das alter der mouillierung $n>n$, daß sie Nordripuarien schon vor 1386 erreicht haben muß, was wiederum mit der datierung der mouillierung $(d>) t>k$ in einklang steht.

Die einordnung der übrigen niederfränkisch-ripuarischen grenzlinien, die über die alte scheide nach norden drängten, ohne die äußerste nordgrenze des ripuarischen eroberungsgebietes $\mathrm{zu}$ erreichen, also die einordnung von linien aus der dritten und vierten liniengruppe in die neuen politischen verhältnisse, vollzog sich folgendermaßen. Von den ingwäonisch deutschen linien der alten niederfränkisch-ripuarischen grenze

2) Vgl. die tabellen DDG. V \& 264 J. II. VII und die in zahlen berechneten grenzstärken DDG. V s. 146. Über dic belentungslose Rorrgrenze. vgl. auch DDG. V \$260.

2) Beitr. 39, 873 und oben (datierung von $-j,-z /-x$, $n t$, tsit/(sil) 
rück te vif/\%'n.of 'fünf' an die südgrenze von Millen, Heinsberg (von dem jelloch ein kleiner, nach süden vorspringender zipfel ebenfalls von $v \cdot n$.of besetzt wurde), Wassenberg; während $z \bar{a} \gamma \partial$ und han die ganze jülichische nordwestecke außer Millen und den siidteil der geldernschen zunge besetzte. Die mouillierungslinien blieben an dieser stelle der alten jülichischen nordgrenze trel; nur der typus $p i \cdot n$. 'pein' besetzte den südosten der neuen jülichischen eroberungen, ohne sich einer festen grenze anzupassen.

Dieses etwas dürftige bild gewinnt ein volleres leben, wenn wir die linien heranziehen, die rechtsrheinisch auf grund besonderer entwicklungen oder aus mangel an belegen nur gelegentlich herangezogen wurden. Der $\boldsymbol{r}$-ausfall

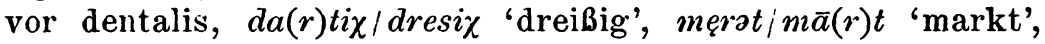
*dersken ${ }^{*}$ dresken 'dreschen', *aft-/*hint-, grenzen, die alle den limburgischen zipfel des regierungsbezirks Aachen abschneiden, rückten wie $z e g \partial / z \bar{a} \gamma \partial$, hębrihan gleichfalls an die ostgrenze des amtes Millen. Da nun Millen von Jülich erst 1499 abgerundet wurde und erst 1578 als jülichisches amt erscheint, so kann diese sprachgrenze und damit der südwestverlauf der normallinie des übergangsgebietes erst nach ca. 1500 entstanden sein; da ferner Wassenberg erst 1493 erworben wurde und erst 1555 als jülichisches amt $\mathrm{zu}$ belegen ist, so kann sich auch das stück der normallinie des übergangsgebietes, das mit der grenze zwischen aint Wassenberg und der geldernschen barriere an der holländischen grenze zusammenfällt, erst nach ca. 1500 entwickelt haben.

Veitere datierungen ergeben sich bei berücksichtigung der an der holländischen grenze liegenden relictgebiete. Das heinsbergische nt-gebiet (7ent 'kind', bont 'bunt', wentar 'winter') wird im wesentlichen von den grenzen des amtes Heinsberg gegen die ämter Geilenkirchen, Randerath, Wassenberg bestimmt. Der von süden vorwärtsschreitende gutturalisierungsproceß, der im falle eines intervocalischen -nd- auch amt Heinsberg besetzte, kann an dieser stelle des übergangsgebietes also erst nach dem erwerb Heinsbergs 1484 und seiner einordnung als jülichisches amt (also solches 1555 belegt) aufgetreten sein. Dieselbe datierung ergibt sich auf grund ähnlicher geographischer verhältnisse für die vocalisierung der 
spirans in der verbindung ch.t. Die grenze zwischen gutturaler und palataler spirantenarticulation, die mit der linie Millen/ Geilenkirchen-Heinsberg zusammenfällt, entstand analog zegวi $z \bar{a} \gamma \partial$, hębə/han nach ca. 1500. Dieselbe datierung ist für die entstehung der linien zwischen kurzem und langem vocal vor altem $h . t, h s, s 7, s t$, die alle an der ostgrenze des amtes Millen stehen, und damit für das auftreten der dehnungsprocesse im westlichen übergangsgebiet anzusetzen.

Für die immerhin merkwürdige tatsache, daß die jülichische nordwestecke so weitgehend an ihren alten bodenständigen formen festhielt, scheinen in den westlichen beziehungen dieses gebietes vor der jülichischen eroberung einige anhaltspunkte zu liegen. Heinsberg und Geilenkirchen gingen seit 1367 von Geldern zu lehen. Millen wurde mit den städten Gangelt und Waldfeucht 1363 an Geldern verpfändet, 1378 rom herzog von Brabant gekauft, und 1423 dem bischof von Lüttich überlassen. Wassenberg kam vor 1139 an Limburg, erscheint 1276 als geldernsche interessensphäre und fällt 1289 an Brabant. ${ }^{1}$ ) Vor allem hat also Geldern im anschluß an die geldernsche barriere die alten territorien umworben. Diesen geldernschen einfluß hat das von Jiilich nach norden getragene ripuarische nie ganz verwinden könnell. Und die bekannte sprachliche verwandtschaft $z$ wischen dem limburgisch-heinsbergischen zipfel und dem noch heute Geldern genannten teil der Rheinprovinz wird in einem anf holländischem boden zu suchenden directen sprachgeographischen zusammenhang begründet sein, der sich seinerseits auf eine alte politische gemeinschaft stützt. Es ist möglich, daß auch die zugehörigkeit einzelner teile zur diöcese Lüttich mitgewirkt hat, den niederfränkischen charaktej zu wahren. ${ }^{2}$ )

Als erstes ergebnis dieser verküujfung von dialektgeographie und geschichte steht somit fest, daß die ursache des in den sprachgeographischen kapiteln erwähnten ripuarischen verticalstoßes in der erweiterung der alten jülichischen grafschaftsgrenze $\mathrm{zu}$ suchen jst. Der verticalstoB kann mithin frühestens im 15. jh. eingesetzt haben. Die einsclıränkung der

1) DDG. V § $273 \mathrm{ff}$.

2) Doch $\nabla$ gl. DDG. $V \$ 301$. 
stoßkraft, die sich in relicten und compromissen dartut, beruht auf alten niederfränkischen beziehungen der neu erworbenen gebiete. Das erste wichtige resultat des verticalstoßes ist die herausbildung der $z \ell g \partial / z \bar{a} \gamma \partial$-linie, die seit frühestens 1500 entstanden sein kann. Ihr verlauf reflectiert sprachlich das niederfränkisch-ripuarische, politisch das ringen Gelderns und Jiilichs um die vorherrschaft.

Bevor wir die beziehungen zwischen politik und sprachgeschichte für die jülichische nordostecke aufzeigen, ist die allmähliche erweiterung des kurkölnischen machtbereiches darzulegen. Gleichwie im westen der linksrheinischen Rheinprovinz die jülichische eroberung nordwärts Jülich vorstieß, so im osten die kurkölnische nordwärts und westwärts Neuß. Neuß wurde unter Heinrich IV., also im 11. jh., kölnisch. Das nördlich Neuß und südlich Ürdingen am Rhein gelegene ursprünglich clevische amt Linn, in dem Köln schon im 12. jh. fuß faßte, wurde 1392 erworben, nachdem es in der ersten hälfte des 14. jh.'s als kurkölnisches lehen und 1378 in kölnischer pfandschaft erscheint. Das zwischen amt Linn und der grafschaft Mörs gelegene amt Ürdingen, in dem kölnischer besitz sich seit ende des 13. jh.'s nachweisen läßt, muß vor 1400 kölnisch geworden sein. ${ }^{1)}$ Im bereich des spätern amtes Kempen-Ödt zeigen sich die ersten festen ansätze kölnischer herrschaft im 13. jh.; 1349 werden Kempen und Ödt mit allem, was dazu gehört, endgültiger kölnischer besitz, nachdem Kempen 1314 an Cleve verpfändet worden war. Da auch die innerhalb des amtes Kempen gelegenen herrlichkeiten Anrath und Neersen vor 1381 an Köln gekommen sind, so ist die im osten an den Rhein und im westen an die jülichische nordostecke (amt Brüggen, unteramt M.-Gladbach) stoßende kölnische nordecke (amt Linn, amt Ürdingen, amt Kempen-Ödt) im 14. jh. abgerundet. ${ }^{2}$ )

Südwestlich von Neuß gelangen wir in ein gebiet, das auf der karte von 1789 eine reiche politische buntscheckigkeit aufweist, das in früheren jahrhunderten aber noch bedeutend

1) Ramisch, DDG. I $\$ 55$ und DDG. V § 280.

2) Ramisch, DDG. I $\$ 54$. 
zerklüfteter gewesen ist. Es ist die zone des jülich-kölnischen interessengegensatzes. Zwar sind die Neuß zunächstliegenden teile des amtes Hülchrath-Erprath 1314 (Glehn, Büttgen) und 1405 (Grefrath) als unumstrittenes kölnisches eigentum gesichert ${ }^{1}$ ); aber schon Liedberg, das 1369 als amt erscheint, befindet sich, bevor es 1279 an Köln kommt, im besitz Jülichs; nur der westlichste teil von Liedberg, die herrschaft Odenkirchen, die im westen an die jülichische nordostecke grenzt, ist seit 1153 in ununterbrochenem kölnischen besitz. ${ }^{2}$ ) Das lang gezogene jülichische amt Kaster stellt die verbindung zwischen Odenkirchen und der stelle der alten jülichischen grafschaftsgrenze her, welche nach norden durch Wassenberg und Erkelenz begrenzt wird. Seine nordgrenze von 1789 ist eine erweiterung der alten jülichischen grafschaftsgrenze. Letztere ist an dieser stelle schon für das 12. jh. zu erschließen und lebt heute in der normalen lautverschiebungslinie weiter. Eine erweiterung läßt sich für 1386 fest datieren; damals ging Wanlo nach einem seit $1251 \mathrm{zu}$ verfolgenden streit mit Köln in den endgültigen besitz Jülichs über. ${ }^{3}$ )

Zwischen dem östlichsten punkte des jülichischen machtbereiches und der süd- und westgrenze der kölnischen ämter Liedberg und Hülchrath-Erprath liegt die grafschaft Dyck. Ihre nordgrenze setzt die normale lautverschiebungslinie nach osten fort. Sie ist bereits 1166 in der südlichen begrenzung des liedbergischen besitzes gegeben und wird durch eine urkunde von 1334, die Aldenhoven für Dyck sichert, bestätigt. ${ }^{4}$ ) Dadurch, daß Kurköln mit dem erwerb Liedbergs, das schon vorher von Jülich umworben worden war, 1279 nördlich um Dyck herumgreift, wird die sprachscheidende kraft der Dycker grafschaftsgrenze gefährdet.

Mit den daten 1386 und 1279 ist im osten des linksrheinischen übergangsgebietes die möglichkeit einer durchbrechung der alten niederfränkisch-ripuarischen grenzlinie gegeben. vo'n.əf 'fünf' besetzte das ganze gebiet östlich der geldernschen barriere bis zur nordgrenze des unteramtes

1) DIAG. V \$ 282, wo es 1314 statt 1342 heißen muß.

2) DDG. V \& 281 .

s) DDG. V \$ 277 und Beitr. 39, 367.

) DDG. V $\$ \S 281.287$. 
M.-Gladbach, d. h. die nördlichen teile des jülichischen amtes Kiaster, das als solches 1394 zuerst erscheint 1), das zu amt Briiggen gehörige und in seiner amtszugehörigkeit 14932) bestimmte Vemrath, die seit 1338 genau erkennbare reichsherrschaft Wickrath ${ }^{3}$ ), das gericht Beeck, das schon $1283 \mathrm{zu}$ Wassenberg gehörte und wohl 1493 mit Wassenberg an Jülich kam ${ }^{4}$ ), das seit spätestens $1352 \mathrm{zu}$ amt Brüggen gehörige Dahlen ${ }^{5}$ ), das 1307 von Jülich erworbene M.-Gladbach, sowie den größten teil der kurkölnischen besitzungen einschließlich der reichsherrschaft Mylendonk. ${ }^{6}$ ) Amt Kempen und die mörsische enclave Krefeld bleiben unberührt; wie sich die $v \bar{\imath} f$ lvo.n.əf-grenze zu der grenze Ǘrdingen/Linn oder gar Mörs/Ürdingen verhält, ist bei dem fehlen der sprachlichen belege nicht zu ersehen. Da jedoch die Kempener amtsgrenze erst 1349 fest wird und Linn erst 1392 an Köln kommt, so hat die $v \bar{\imath} f / v v^{\prime} n . \partial f$-grenze frühestens seit anfang des 15. jh.'s ihre heutige linie erreicht. Ähnliches gilt für $z e g \partial / z \bar{a} \gamma \partial$ und die übrigen mit der normallinie des übergangsgebietes verwandten grenzen.

Von den mouillierungslinien hat tīt, tsīt/tsik 'zeit' ähnlich den affricatalinien ${ }^{7}$ ) die westliche nordgrenze von amt Kaster erreicht, und ebenso wie ein großer teil der spiranslinien das gebiet um Liedberg-Glehn besetzt. Die übrigen typen haben nichts mehr mit der noch heute erkennbaren strenge der spiranslinien gemein. Sie sind gleich den affricatalinien verwildert, erreichen aber, von 'neun' und dem typus $p i \cdot \boldsymbol{r}$. abgesehen, niemals das gebiet der jülichischen nordostecke oder der geldernschen barriere. Greift man das dem typus tìt, tsīt/tsik 'zeit' gegenüberstehende extrem win/win 'wein' heraus, so zeigt sich auch hier zunächst die anlehnung an die westliche nordgrenze von amt Kaster; auch Wanlo hat wir; dann folgt die linie im wesentlichen der westgrenze des kö]nischen gebietes und läuft endlich östlich Viersen quer durch kölnisches

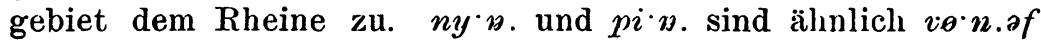
verteilt; nur reicht $p i \cdot \rightsquigarrow$. nordwärts noch über das kölnische

1) DDG. V § 277.

3) DDG. V § 278.

5) DDG. V § 269.

7) Vgl. Beitr. 39, 370 f.
2) DDG. V § 269.

4) DDG. V § 273.

6) DDG. V § 279 . 
gebiet hinaus Die mouillierungslinien liefern also vor allem den beweis, daß das vorwärtsdringen der ripuarischen formen im osten in directem zusammenhang mit der kölnischen gebietserweiterung steht. Daß weder die mouillierungslinien noch die ïbrigen linien der dritten und vierten gruppe auf kölnischem boden zu einer neuen festen grenzgestaltung kommen konnten, liegt darin begründet, daß sich die kurkölnischen ämter im allgemeinen nicht auf so einschneidenden territorialgrenzen wie die ämter der jülichischen nordwestecke aufbauen konnten.

Damit steht also fest, daß die ursache des in den sprachlichen kapiteln erwähnten ripuarischen diagonalstoßes in der planmäßigen erweiterung des kurkölnischen herrschaftsbereiches im 13. 14. jh. zu suchen ist. Der diagonalstoß kann mithin frühestens im 14. jh. begonnen haben. Er bildete mit dem verticalstoß, den wir für den äußersten westen frühestens seit dem 15. jh., in der mitte nach 1386 anzusetzen haben, zunächst die normallinie des übergangsgebietes heraus, wobei ihm, infolge seines besonderen territorialen bereiches, der hauptanteil an der diagonalen entwicklung der $z \varepsilon g \partial / z \bar{a} \gamma \partial$-linie von Gangelt bis Ürdingen zufiel. Gleichwie sich nun im westen dem sowieso durch niederfränkische gegenströmungen geschwächten verticalstoß die geldernsche barriere vorlegte, so traf der diagonalstoß nördlich M.-Gladbach auf die geldernsche enclave Viersen 1), östlich Kempen auf die mörsischen enclaven Krefeld und Hüls. ${ }^{2}$ ) Ihre niederfränkischen beziehungen, die sich bis heute in sprachlichen besonderheiten äußern (Viersen hont, wontar, Krefeld hęba), scheinen dem vorwärtsdringenden ripuarischen ein kräftiges halt geboten $\mathrm{zu}$ haben. Viersen ist seit 1359 als geldernsche, Krefeld seit 1259 und der nördliche teil von Hüls seit ende des 16 . jh.'s als mörsische enclave nachzuweisen ${ }^{3}$ ); und da trotz aller besonderheiten der einzellinien die grenze Kempen, Krefeld/Linn den wesentlichen rückhalt für die herausbildung der wichtigsten linien auf kurkölnischem boden abgegeben lıat, jene grenze aber erst seit 1349, 1392 erscheint, so kann der nordöstliche teil der normallinie des übergangsgebietes seit frühestens 1400 entstanden sein;

1) DIG. V $\$ 285$.

2) Ramiscb, 1)IDG. I \$ 53 .

-) Vgl. außer fußnote 1 und 2 Rnmisch, 1)I)(1. I $\$ 5.4$. 
d. h. für die auflösung der alten niederfränkisch-ripuarischen grenze und die entstehung einer ersten neuen linie war im osten infolge kurkölnischer territorialverhältnisse (13. 14. jh. bis ca. 1400) rund 100 jahre eher die moglichkeit gegeben als im westen, wo die jülichischen territorialverhältnisse (14. 15. jh. bis ca. 1500) verantwortlich $\mathrm{zu}$ machen sind.

Da nun die $z e g a / z \bar{a} \gamma \partial$-linie im äußersten nordosten an der oft erwähnten strecke Traar-Hohenbudberg mit der Ürdinger linie zusammenfällt, so ist auch der ostteil dieser linie, an den die linien der ersten und zweiten gruppe sich in besonderer strenge anlehnen, nach 1400 entstanden. Diese datierung stimmt auch mit der tatsache überein, daß wir für die südgrenze der grafschaft Mörs, die das kurkölnische amt ÜrdingenLinn im norden begrenzt, 'am ende des 14. jh.'s den umfang voraussetzen dürfen, den zuerst rechnungen aus der ersten hälfte des 16. jh.'s und dann besonders ausführlich ein bericht vom jahre 1643 ort für ort angeben'.1)

Es wäre zu ideal, wenn auch weiter westlich das auswirken des vertical- und diagonalstoßes mit dem ende des kurkölnischen und jülichischen machtbereiches zusammenfiele, und wie Mörs im osten so Geldern im westen den äußersten damm gegen das vordringende ripuarische errichtet hätte. Aber - westgerm. $\bar{e}, \bar{o}$, eo schalten vorläufig ganz aus - die linien der zweiten gruppe erreichen nicht den norden von amt Kempen: wei/wer und $x e i(j e i) / e r$ bleiben an der südgrenze dieses amtes stehen, $e k / e \chi$ und $\bar{o} k / \bar{o} x$ durchschneiden südlich Kempen das amt von westen nach osten, und im äußersten westen laufen sie in der gleichen querrichtung durch das geldernsche amt Krieckenbeck; einmal wird also die nordgrenze des kölnischen bezirkes nicht erreicht, und das andere mal das jülichische gebiet überschritten. Die linien der ersten gruppe sind meistens an den nordrand von amt Krieckenbeck vorgedrungen und schlagen stellenweise sogar das geldernsche amt Wachtendonk zum gebiet des ripuarischen einflusses; sie haben also gegenüber den linien der zweiten gruppe wenigstens eine geschlossene historische stütze gefunden. Die gründe für diese verhältnisse hat bereits Ramisch, DDG. I $\$ 59$ beigebracht.

1) Ramisch, DDG. I $\$ 53$. 
Betreffs der niederfränkischen elemente in amt Kempen, und umgekehrt der ripuarischen einflüsse in amt Wachtendonk, weist er darauf hin, daß Wachtendonk zwar 1434 an Geldern kam, der südliche teil auf grund seiner alten zugehörigkeit zum amte Kempen jedoch bis zu anfang des 17. jh.'s von Köln zu lehen ging. Auch die 'kirchliche zugehörigkeit Wachtendonks zum decanat Süchteln (bis 1559) und (von 1559 an) zur christianität Krieckenbeck, jedenfalls also zum süden, war wohl nicht ganz bedeutungslos'. Demnach reflectieren die abweichungen der sprachgrenzen von der politischen grenze Wachtendonk, vogtei Geldern/Kempen bis heute das an dieser linie nach $1434 \mathrm{zu}$ beobachtende ineinanderspielen geldernscher und kurkölnischer interessen. Die ripuarischen einflüsse in amt Krieckenbeck sind im wesentlichen wohl darin begründet, daß Krieckenbeck 'mit dem gleichfalls geldernschen amt Wachtendonk bis 1559 zum decanat Süchteln, also zum süden gehörte, während amt Straelen und die vogtei Geldern zum decanat Geldern, also zum norden gehörten. Auch von 1559 an wurde Krieckenbeck nicht etwa mit dem decanat Geldern vereint, sondern bildete mit Wachtendonk die selbständige christianität Krieckenbeck'. Immerhin beweist der äußerste westverlauf einiger linien der ersten und zweiten gruppe (vgl. z. b. die $e k / e \chi, \bar{o} k / \bar{\partial} x$-linie), daß sie sich nur widerwillig von der grenze Brüggen (Jülich)/Krieckenbeck (Geldern) abdrängen ließen, und es bleibt also im grunde genommen dabei, daß die grenze des jülichischen und kurkölnischen machtbereiches die grenze des ripuarischen vertical - und diagonalstoßes angegeben hat. Das datum 1434 verrät, daß der mittlere teil der neuen niederfränkischen normalgrenze erst nach dieser zeit entstanden ist. Für den äußersten westen wäre daran zu erinnern, daß Brüggen von 1421-1494 als pfand in mörsischem besitz war, und erst. seitdem wieder ununterbrochen ein jülichisches amt bildete. 1) Auch hier könnte also der ripuarische einfluß frühestens mit ca. 1500 eingesetzt haben, die neue niederfränkisch-ripuarische grenze mithin erst nach ca. 1500 entstanden sein. $O b$ in dem nachwirken dieser niederfränkischen bezichungen auch die erklärung der relicte (z. b. hębo in kaldenkirchen, der

1) Vgl. Ramisch, DI)(1. I \$57; J)DG. V \$269. 
district mit erhaltener spirans südlich Kaldenkirchen an der hollïndischen grenze) zu suchen ist, oder ob für diese erschcimmgen eher auf die zugehörigkeit des westens von amt Brüggen zur diöcese Liittich zu verweisen ist, mag dahingestellt bleiben. Die form habo aus hęlı + han, die, von den relicten algesehen, das gebiet zwischen der zega/zāja-linie und der vocalisierungslinie oder - historisch gesprochen amt Brüggen (außer Rheindahlen) und amt Kempen umfaßt, ist jedenfalls aus dem widerstand der in diesen beiden jülichischen und kırkölıischen gebieten fortlebenden niederfränkischen beziehungen gegen die neue südliche form zu begreifen. Und vielleicht liegt in dieser sonderstellung der Brüggener und Kempener lande ein weiterer grund für die herausbildung der $z \xi g \supset / z \bar{a} \gamma \partial-$ linie. Einen terminus ad quem für die entstehung der neuen niederfränkisch-ripuarischen grenze liefern ebenfalls die kölnisch-geldernschen beziehungen des amtes Wachtendonk. Mit anfang des 17.jh.'s hörte die jurisdiction und lehnsherrlichkeit Kölns über den südteil des amtes auf. Die ripuarische eroberung muB also vor diesem zeitpunkt in Wachtendonk gewirkt haben, mit anderen worten, die ripuarischen formen haben die heutige niederfränkische normalgrenze vor rund 1600 erreicht.

Stellen wir nunmehr die wichtigsten daten nebeneinander:

a) Historische voraussetzungen für die auflösung der alten niederfränkisch-ripuarischen grenze (Benrather linie): 1392 (Randerath, Jülich), 1484 (Heinsberg, Jülich), 1493 (Wassenberg, Jülich), 1386 (Wanlo in Kaster, Jülich), 1279 (Liedberg, Köln). Auflösungsmöglichkeit seit dem 13. 14. 15. jh.

b) Historische voraussetzungen für die herausbildung der $z e ̨ g \partial / z \bar{a} \gamma e$-linie: 1499 (Millen, Jülich), 1493 (Wassenberg, Jülich), 1392(Linn, Köln), 1349 (Kempen, Köln). Entstehungsmöglichkeit seit ca. 1500 im westen, seit ca. 1400 im osten.

c) Historische voraussetzungen für die herausbildung der jungen niederfränkisch-ripuarischen grenze (niederfränkische normalgrenze, vocalisierungslinie, Ürdinger linie): 1392 (Linn, Köln), 1349 (Kempen, Köln), 1434 (Wachtendonk, Geldern Köln), 1494 (Brüggen, Jülich). Entstehungsmöglichkeit seit ca. 1400 im osten, seit ca. 1500 im westen; terminus ad quem ca. 1600 (Wachtendonk, Geldern-Köln). 
Man darf wohl annehmen, daß die sprachlichen verschiebungen den politischen unmittelbar gefolgt sind. Dann ergibt sich für die entstehung des übergangsgebietes folgendes endresultat: Die alte niederfränkisch-ripuarische linie wurde auf dem linken Rheinufer in westen im 15., im osten im 14.jh. durchbrochen. Eine aus der fülle der neuen einzellinien heraustretende normale übergangslinie entstand etwa gleichzeitig mit der neuen niederfränkischen normalgrenze, und zwar im westen im 15. 16., im osten im 14. 15. jh.; vor 1600 ist die bildung der übergangszone abgeschlossen.

Aber warum verschoben sich die einzelnen grenzlinien in ungleichmäßiger geographischer entwicklung nach norden? Auf diese frage läßt sich keine befriedigende antwort finden. Wir müssen die tatsache ebenso hinnehmen, wie die bereits früher erwähnte, daß auch die auf ripuarischem boden erschlossene nordwärtsentwicklung sich nicht in zeitlich und geographisch gleichen phasen vollzogen hat. Das jahr 1250, das für einzelne, noch heute im großen und ganzen an der alten grenze stehende linien als entstehungszeit angesetzt wurde, braucht keineswegs als generaldatum der alten niederfränkisch-ripuarischen scheide betrachtet zu werden. Es wurde gewonnen auf grund der erwägung, daß die linien, die den auflösungsproceß des 14. 15. jh.'s überstehen konnten, schon verhältnismäßig fest eingewurzelt sein mußten. ${ }^{1}$ ) Von diesem gedanken könnten wir dann zu der schlußfolgerung gelangen, $\mathrm{da} \beta$ die linien, die dem jülich-kölnischen stoß erlagen, nicht allzu tief mit den alten territorialgrenzen des 13. jh.'s verwachsen waren, mit andern worten nach 1250 aber vor dem auflösungsproceß des 14. 15. jh.'s der alten niederfränkischripuarischen grenze zugesellt wurden, so daß die linien, die heute nordwärts der Benrather linie stehen, ehedem zcitlich am kürzesten mit ihr verknüpft gewesen wären. Aber das sind nur speculationen, und es wäre besser, bei der nackien tatsache zu bleiben, daß eine alte, aus verschiedenen elementen gemischte nordwärtsbewegung südlicher sprachformen an territorialen linien, die im 12. 13. jh. bereits deutlich aus der 
historischen überlieferung heraustreten, für geraume zeit halt machte, und erst mit der geographischen erweiterung des politischen bezirkes im 14. 15. jh. weiter nach norden schritt, so daß ein teil der sprachlichen erscheinungen des südens bis an die iußerste grenze der neuen politischen gebilde getrieben wurde: in diese etwas allgemeine formel läßt sich die geschichte der Benrather und Ürdinger linie im weiteren siune und des von ihnen umgrenzten gebietes westlich des Rheins am besten zusammenfassen. Neben dieser sprachgeographischen einsicht ergibt sich das bereits gelegentlich gestreifte weitere resultat, $d a B$ alle die als speciell ripuarisch bezeichneten sprachprocesse, die an der alten niederfränkischripuarischen grenze beteiligt sind, bereits lange vor dem beginn der auflösung in Nordripuarien vorhanden gewesen sind. Diese erkenntnis ist für die geschichte von westgerm. $\bar{e}, e o, \bar{o}$ von besonderer wichtigkeit. Denn damit ergibt sich, daß der ersatz der nach gemeindeutscher regel entwickelten $\bar{\imath}, \bar{u}(\bar{y})$ durch die infolge besonderer accentuierung erhaltenen $\bar{e}:, \bar{o}:(\bar{\theta}:)$ und auch die übertragung des südlichen accentes auf die nördlich anschließenden $\bar{\imath}: \bar{u}:(\bar{y}:)$-districte sich vom 14.-16. jh. vollzogen hat. Für Nordripuarien ist vor der allgemeinen nordwärtsbewegung wohl ebenfalls der gemeindeutsche entwicklungsstand anzusetzen. Wann und wo die ripuarischen formen in Mittel- oder Südripuarien entstanden sind, geht uns hier nichts an. Nur ist sicher, daß ihre heutigen nördlichsten ausläufer in keinen directen phonetischen zusammenhang mit dem ripuarischen entstehungsherd zu bringen sind. Zumindest die vorwärtsbewegung im übergangsgebiet beruht auf mechanischer sprachübertragung: es hat sich ein ähnlicher proceß vollzogen, wie wenn der eroberer dem unterworfenen seine sprache aufzwingt. Die compromißbildungen sind das ergebnis dieses processes und damit seine besten zeugen.

Aber nicht alle compromißbildungen sind das ergebnis großer politischer bewegungen. Neben einem so classischen beispiel wie $n \bar{y} a j a$, wo das gebiet der politischen eroberung mit der sprachlichen compromißbildung dorf um dorf zusammenfällt, stehen formen wie $p i \cdot n$. und $z \bar{e} g a$, die auf der niederfränkischen seite der $p \bar{\imath}: n / p i \cdot n .-$ und $z e g a / z \bar{a} \gamma a-l i n i e$ in schmalen grenzstreifen auftreten. Gewiß reflectieren auch sie 
im letzten grunde die richtung der alten politischen eroberung, aber sie sind im übrigen von ihr zeitlich unabhängig, junge bildungen, die in allerkleinsten politischen oder gar kirchlichen beziehungen zwischen ort und ort begründet und dadurch entstanden sind, daß den südlichen formen noch immer die durch ehemalige politische verhältnisse geschaffene sprachgeographische ïberlegenheit innewohnt. Wrede pflegt solche erscheinungen von den compromißbildungen abzuscheiden und als schwellenformen zu bezeichnen. Wie weit das sprachgeographische entwicklungsbedürfnis der südlichen formen unabhängig von politischen verhältnissen und doch als deren letzte folge überhaupt in jüngerer zeit auf niederfränkischem boden gewirkt hat, ist hier nicht näher zu untersuchen.

6.

Rechts des Rheins ist die geschichte der niederfränkischripuarischen grenze mit der geschichte der grafschaft Berg verknüpft. Wie Jülich ging auch Berg aus der zertrümmerung der gauverfassung am ende des 11. und $\mathrm{zu}$ anfang des 12. jh.'s hervor. Hier wie dort erwuchsen die grafenrechte aus der alten gaugrafenwürde, hier wie dort vollzog sich eine allmähliche ausdehnung des grafschaftsbesitzes von süden nach norden, vom Deutzer gau über den Keldachgau und Ruhrgau. ${ }^{\text {) }}$ Wenn somit der Deutzer gau auch die wiege der grafschaft Berg darstellt, so ist über die identität ihrer grenzen damit nichts gesagt. Außerdem dürfte es schwer fallen, ein einigermaßen exactes bild von der nordgrenze des Deutzer gaues zu zeichnen. Schönneshöfers beschreibung des Deutzer galles ${ }^{2}$ ) basiert auf der oft gerïgten gleichsetzung von gau- und decanatsgrenze. Aber selbst wenn sie richtig wäre, so würde sie doch nur beweisen, daß unsere heutigen sprachgrenzen nicht auf alte gaugrenzen zurückführen; denn Solingen, das zum Deutzer gau gehören soll, liegt nördlich der normalen lautverschiebungslinie, die somit an dieser stelle den Deutzer gau durchschneiden würde; Monheim, das dem närdlich an-

1) Schönneshöfer, Geschichte des Bergischen landes ${ }^{2}$, Elberfeld 1908 , s. 59 ff.; Lobbes, DDG. VIII $\$ 88$.

2) A. a. 0. s. 60 . 
schließenden Keldachgau zugewiesen wird, liegt umgekehrt südlich der normalen lautverschiebungslinie, die also an dieser stelle den Keldachgau durchschneiden würde: ein zusammenhang zwischen der grenze Deutzer gau/Keldachgau und der normalen lautverschiebungslinie wäre also $\mathrm{zu}$ verneinen.

Nach der karte von 1789 deckt sich die normale lautverschiebungslinie mit der grenze der südlichen bergischen ämter Monheim und Miselohe gegen die nördlichen ämter Düsseldorf, Mettmann, Solingen. Östlich hiervon durchschneidet sie sowohl nach Lobbes, der Wermelskirchen zum süden, als auch nach Leihener, der es zum norden schlägt, das bergische ant Bornefeld. Die schwierigkeiten, die dieser punkt bietet, können nur im zusammenhang mit der südlich anschließenden sprach- und territorialentwicklung gelöst werden. Die nordgrenze der ämter Monheim und Miselohe scheint die alte nordgrenze der grafschaft Berg fortzusetzen. Jedenfalls erscheinen nördlich dieser ämter in dem später bergischen territorium zunächst noch eine reihe kleinerer, durch den verfall der gauverfassung emporgekommener grafen und edelherren. ${ }^{\text {) }}$ Die abrundung der grafschaft Berg vollzog sich im verlauf des 12. und 13. jh.'s. 1176 wurden Hilden (im amte Solingen) und Elberfeld, haupthöfe der kölnischen kirche, in erblichen pfandbesitz genommen. $\left.{ }^{2}\right) 1189$ wurde Düsseldorf, das allode der edelherren von Tyvern, erworben und 1288 zur stadt erhoben $^{3}$ ), nachdem Lennep und Ratingen schon ca. 1230 und 1276 als bergische städte gegründet worden waren.4) Die höfe Barmen, Mettmann und Rath kamen 1244, 1248, 1248 an Berg. ${ }^{5}$ ) Vor 1247 ging die zwischen 1167 und 1191 vom erzstift Köln erworbene allodialherrschaft Angermund als kölnisches lehen an Berg über. Obgleich schon 1303 und 1327 ansätze zur bildung eines amtes Angermund zu beobachten sind, wird die lehnsabhängigkeit von Köln noch 1399 ausdrücklich betont, geriet aber nachher in vergessenheit. ${ }^{6}$ ) 1260 wurde Hückeswagen endgültig erworben, nachdem schon Engelbert I. († 1189) den erwerb der hoheit über dieses gut

1) Schönneshöfer s. 68 .

3) Schönneshöfer s. 80. 127.

5) Schönneshöfer s. 107. 110.

•) Lobbes, DDG. VIII $§ 90$; Schönneshöfer s. 136 .
2) Schönneshơfer s. 79.

4) Schönneshöfer s. 108. 118. 
angebahnt hatte. $\left.{ }^{1}\right) 1355$ folgte die grafschaft Hardenberg ${ }^{2}$ ), und 1363 finden wir in der bei Leihener, DDG. II s. LXXIV fußnote 4 im auszug wiedergegebenen urkunde das gebiet zwischen der Benrather linie und dem westostlauf der Ürdinger linie in städten und ämtern abgerundet: Düsseldorf, Lennep, Ratingen; amt Mettmann, amt Solingen mit der späteren herrschaft Schöller, amt Angermund, amt Bornefeld. Es ist wohl zu beachten, daß in dieser urkunde die unmittelbar am südostverlauf der Ürdinger linie gelegenen bezirke, die zur grafschaft Mark hinüberführen, nämlich Hardenberg, das amt Elberfeld und das amt Beyenburg (mit Barmen) fehlen. Hardenberg hat wohl nie ein festes verhältnis $\mathrm{zu}$ dem übrigen bergischen territorialbesitz gefunden; schon 1496 ging die ehedem selbständige grafschaft als bergisches lehen käuflich an Bertram von Gevertzhain über; seitdem erscheint sie als bergische unterherrschaft. ${ }^{2}$ ) Elberfeld ist vor 1264 wieder von Köln eingelöst worden, wird aber in der folge an die verschiedensten geschlechter in erblichen pfandbesitz gegeben; dabei blieb Cronenberg ständig unter bergischer verwaltung; erst 1427 fielen beide endgültig an Berg. $\left.{ }^{3}\right)$ Beyenburg war nach einer vermutung Schönneshöfers verpfändet ${ }^{4}$ ); es erscheint jedenfalls um 1400 in clevisch-märkischer pfandschaft. ${ }^{5}$ ) Bemerkenswert ist ferner, daß 1397 das herzogtum Berg für kurze zeit geteilt wurde. In diesem jahre tritt herzog Wilhelm von Berg seinen söhnen Gerhard, Adolf und Wilhelm in einem vertrage Hückeswagen, die stadt Lennep mit dem amte Bornefeld (Dhünn, Wermelskirchen, Lüttringhausen, Remscheid und Dabringhausen) sowie die stadt Wipperfürth mit dem amte Steinbach ab.6) Im 14. jh. erscheint also der um den südostverlauf der Ürdinger linie westlich der märkischen grenze gruppierte besitz in keinem oder doch gelockertem zusammenhang mit den nördlich amt Monheim und amt Miselohe liegenden neuerwerbungen des 12. 13. jh.'s. Der durch die

1) Schönneshöfer s. 80. 112.

2) Lobbes, DDG. VIII § $102 \mathrm{ff}$.

8) Leihener, DDG. II s. LXXVIJ fußnote und $\$ 124$.

4) A. a. o. 8. 553.

๖) Schø̈nueshofer s. 152.154 .

") Leihener, DDG. III s. IJXXXII. 
urkunde von 136:3 gesicherte zustand wird durch eine weitere urkunde von 1387 sowie durch hebelisten aus dem ersten drittel des 15. jh.'s bestäitigt. 1)

I)er westostverlauf der Ürdinger linie von AngerhausenWanhein gegenüber Ürdingen-Hohenbudberg am Rhein bis Velbert deckt sich mit der südgrenze des herzogtums Cleve, der bergischen unterherrschaft Broich (Mülheim) und der reichsabtei Werden. Die südgrenze von Cleve und Werden ist für das 13. jh. sicher nachweisbar. ${ }^{2}$ ) Die entfremdung der bergischen unterherrschaft Broich (Mülheim) von amt Angermund, dem es in der urkunde von 1363 noch zugeteilt ist, vollzog sich im laufe des 14. jh.'s und vollendete sich mit dem jahre 1399, wo Mülheim an Cleve verpfändet wird. ${ }^{3}$ )

Seit ende des 14. jh.'s wird also der westostteil der Ürdinger linie oder der jüngeren niederfränkisch-ripuarischen grenze östlich des Rheins entstanden sein. Die für diesen proceß vorauszusetzende auflösung der Benrather linie oder der älteren niederfränkisch-ripuarischen grenzlinie ist eine folge der bergischen nordwärtsentwicklung im 13.jh.; denn die bergischen erwerbungen des 12. jh.'s waren wohl kaum geeignet, eine großzügige sprachliche eroberung einzuleiten. Die Benrather linie muß ihrerseits vor 1248 (erwerb von Mettmann und Rath) und vor der erhebung Düsseldorfs zur stadt 1288, wodurch dieser ort zum mittelpunkt der neuen bergischen territorien wurde, vorhanden gewesen sein. Setzen wir die anfänge der grafschaft Berg mit rund 1100 an ${ }^{4}$ ), so ergibt sich als terminus a quo und ad quem 1100-1248. Der terminus ist günstiger als der Beitr. 39, $372 \mathrm{f}$. für den linksrheinischen teil der Benrather linie gewonnene, da hier die extreme (1029-1386) weiter auseinanderklaffen. Von dem rechtsrheinischen terminus aus würde man die entstehung der Benrather linie mit rund 1200 ansetzen. Es scheint nicht nötig, das linksrheinische datum 1250 hiernach $\mathrm{zu}$ corrigieren; die bestimmung 1. hälfte

1) Schönneshöfer s. 143.

2) Lobbes, DDG. VIII §§ 92. 96.

3) Lobbes, DDG. VIII $\S 94$.

4) Vgl. Schönneshöfer s. $65 \mathrm{ff}$; für das hohe alter der amtsgrenze Solingen/Miselohe, die sich mit dem Wupperlauf deckt, vgl. auch Leihener, DDG. II § $118 \mathrm{f}$. 
des 13. jh.'s mag beide resultate in sich vereinigen. Jedenfalls hatte sie zum festwurzeln rechtsrheinisch nicht soviel zeit wie linksrheinisch. Darin mag es denn auch zum teil begründet sein, $d a ß$ sich dort eine reiche nördliche fächerung ${ }^{1}$ ) der lantverschiebungslinie findet, die an die linksrheinischen verhältnisse auf kurkölnischem terrain erinnert. ${ }^{2}$ )

Die schwächung des für das 14. jh. anzusetzenden verticalstoßes, die sich z. b. in den dualcompromissen sowie in den compromißbildungen fouf 'fünf' und -nt $+--\eta \jmath k=-\imath k t$ äußert, zeigt sich in dem nordostknie der Ürdinger linie, in der gegend von Wülfrath. Schon Wenker hatte deshalb dem Wülfrather platt eine besondere stellung unter den bergischen maa. eingeräumt, und Lobbes hat in den rechtlichen und kirchlichen beziehungen jenes districtes zur abtei Werden die erklärung für diese sonderstellung ${ }^{3}$ ), nach unserer darstellung also für die schwächung des ripuarischen verticalstoßes, gefunden. Niederfränkische beziehungen der neu erworbenen gebiete haben also wie auf dem linken Rheinufer die durch politische entwicklungen eingeleitete ripuarische eroberung gehemmt; die niederfränkisch-ripuarischen compromisse reflectieren zum teil das politische ineinandergreifen von Berg und Werden. Auch der ripuarische einfluß in Kettwig (reichsabtei Werden) ist damit erklärt. Die kräftige durchstoßung der alten niederfränkisch-ripuarischen grenzlinie in unmittelbarer nähe des Rheins, die sich in diagonaler richtung entwickelt, und die sich z. b. in der ausdehnung der formen $f \theta^{\prime} n . f$, fo'n.of 'fünf' und $n y \cdot n$. 'neun' sowie des mouillierungstypus win 'wein', brun 'braun' bis zur Ürdinger linie sowie in den rechtsrheinischen $\bar{e}: \bar{o}$ : für westgerm. $\bar{c}, e o, \bar{o}$ äußert, scheint in den kölnischen beziehungen des amtes Angermund begründet, die sich von 1167 bis 1399 verfolgen lassen. Die kurkölnische territorialpolitik zwischen Ürdingen im norden und NeußDüsseldorf im süden ist für jene merkwürdigen ausbuchtungen niederfränkisch-ripuarischer grenzlinien verantwortlich $z$ machen, die der normalen lautverschiebungslinie hutförmig.

1) Vgl. Leihener, DDG. II \&82; lobhes, DIIG. VIII \$ $17 \mathrm{ff}$; fiir sonstige gründe Lobbes a. a. o. und 13eitr. 39, 365.

2) Vgl. Beitr. 39, $371 \mathrm{f}$.

s) DDG. VIII $§ 124$. 
mit, dem Rhein als achse und der spitze bei Ürdingen, aufgesetzt sincl. Nach osten mubte der diagonalstoß an denselben politischen einflüssen wie der verticalstoß erlahmen; auch in dieser bezichung ergibt sich mithin eine den linksrheinischen verhältnissen entsprechende parallele. Die tatsache, daß die einordnung der grenzlinien inuerhalb des von der Benrather und Ürdinger linie umschriebenen raumes sich nur schlecht den ämtern von 1363 anpaßt, stimmt gleichfalls zu den linksrheinischen erscheinungen auf kurkölnischem gebiet: die ausbildung der bergischen und kurkölnischen ämter erfolgte ohne die alten traditionen, die die jülichische amtsbildung vorfand.

Für das plötzliche abbiegen der Ürdinger linie östlich Velbert, für die historische grundlage dieses südostteiles sowie für sein verhältnis zu der parallel verlaufenden -et-linie konnte bisher keine sichere erklärung gegeben werden. Aber beobachten wir auch hier einmal die kleinen und kleinsten

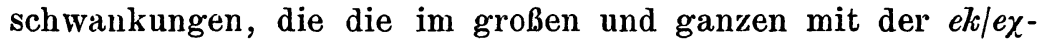
linie zusammengehenden scheiden zeigen. wat und die entsprechung von altem nigun 'neun' zeigen an der stelle, wo sie ins $e \chi$-gebiet hinübergreifen, eine anlehnung an die westgrenze der unterherrschaft Hardenberg, die im übrigen von dem niederfränkisch-ripuarischen linienstrang zwischen Neviges und Langenberg von norden nach süden durchschnitten wird. Das gebiet von Cronenberg, Remscheid, Ronsdorf, also das centrum der untersuchungen Leiheners, zeichnet sich vor allem durch die aus compromiß zwischen bodenständigem stimmlos gutturalen und eindringendem stimmhaft palatalen anlaut hervorgegangene stimmhafte gutturale spirans aus; und außerdem hat das unmittelbar westlich der $e k / e \%$-linie gelegene Ronsdorf $f^{\bar{\imath}}$ 'wir'. Legen wir westlich dieser eigentlich östlich der Ürdinger linie zu erwartenden erscheinungen eine grenze, und fügen wir ihr zwischen Neviges und Cronenberg das zwischen Elberfeld und Sonnborn verlaufende stück der Ürdinger linie ein, so ergibt sich eine historische linie, die die unterherrschaft Hardenberg, das amt Elberfeld und das amt Bornefeld im westen begrenzt. Und diese linie schließt, wenn wir amt Beyenburg mit Ronsdorf und Barmen noch hinzufügen, nach westen das westlich der märkischen grenze gelegene gebiet $\mathrm{ab}$, das im 14. jh. in keinem oder doch gelockertem zusammen- 
hang mit den bergischen neuerwerbungen stand. Als nun das ripuarische infolge der bergischen nordwärtsentwicklung des 13. jh.'s vorstieß, fand es an dieser linie widerstand, und hier wird sich zunächst der von der Benrather linie abgetriebene linienstrang entwickelt haben. An der linie Sonnborn/Elberfeld hielt er sich im allgemeinen bis heute ${ }^{1}$ ); der ripuarische einfluß, der sich in Elberfeld bemerkbar macht, kann seit frühestens 1427, wo Elberfeld endgültig an Berg fiel, datiert werden; daß auch Westbarmen ihm erlag, erklärt sich aus den kirchlichen beziehungen zu Elberfeld ${ }^{2}$ ), daß Ostbarmen ihm aber andererseits zu trotzen suchte, ist in den kirchlichen und politischen beziehungen dieses districtes zu Schwelm und der grafschaft Mark begründet. ${ }^{3}$ ) Vor 1427 ist die Ürdinger linie westlich Elberfeld vorhanden gewesen; da nun das nördlich anschließende Hardenberg erst 1355 an Berg kommt, so könnte man weiter folgern, daß die Ürdinger linie vor 1355 an der westgrenze dieser grafschaft stand und seit 1355 nach osten verschoben wurde. Sie erreichte zunächst die grenze, die die grafschaft in zwei politisch und kirchlich geschiedene bezirke, Neviges und Langenberg, trennte ${ }^{4}$ ); da der politische einfluß Bergs aber 1496 abgeschwächt wurde, konnte ein€ ausdehnung der ripuarischen formen über den gesamten alten grafschaftsbereich nicht erfolgen, und die Ürdinger linie blieb an der grenze Neviges/Langenberg stehen, müßte sich somit an dieser stelle zwischen 1355 und 1496 verschoben und nach 1496 neu befestigt haben. Aber es ist wohl eher anzunehmen, daß die ripuarischen formen später als 1355 ihre nördlichste zone erreichten, also zu einer zeit, als Hardenberg schon zu Berg gehörte, $d a \beta$ sie aber in ihrer ausbreitung über das hardenbergische gebiet einmal durch die alte nordsüdgrenze zwischen Neviges und Langenberg, andererseits durch das erlahmen des bergischen einflusses 1496 behindert wurden. Es bliebe dann immerhin dabei, daß dieses stück der Ürdinger linie sich nach 1496 endgültig festgesetzt hätte. Die verschiebung, die die Ürdinger linie quer durch das amt Elberfeld trieb, und damit. die seit alter zeit politisch zusammengehörigen orte Elberfeld

1) Lobbes, DDG. VIII $\$ 110$.

8) Lobbes, DDG. VIII $\S 114$.
2) Lobber, DNG. VIII $\$ 113$.

‘) Lobbes, DJAG, VIII \$10.4. 
und Gronenberg anseinanderriß, muß in die zeit fallen, wo Wherfeld von geschlecht zu geschlecht wanderte, Cronenberg aber trotzdem unter ständiger bergischer verwaltung blieb, also in die zeit von vor 1264--1427. Es ist sehr wohl möglich, daß die grenze von 1397, die Berg für kurze zeit in eine west- und osthälfte teilte, einen vorläufigen anhalt für die vorstoßenden linien geboten hat, und daß mit der auflösung der historischen grenze die ripuarische eroberung nach osten innerhalb des amtes Bornefeld fortschritt; die ursache für die neue festlegung der linie muß im zusammenhang mit der südlich und östlich anzuschließenden dialektgeographischen und historischen untersuchung, für die vorläufig das material fehlt, aufgedeckt werden; auch die strittige stellung Wermelskirchens, das eine weitgehende mischung alter und junger bestandteile aufweist, kann nur in diesem zusammenhang richtig gewürdigt werden. Vor 1397 müßte dann der Ürdinger linienstrang an der grenze Solingen/Bornefeld gestanden haben, was der für die grenze Elberfeld/Sonnborn gewonnenen datierung (vor 1427) durchaus entspräche. Die eroberung Ronsdorfs durch ripuarische formen scheint jüngeren datums $\mathrm{zu}$ sein; sie hat erst stattgehabt, als amt Beyenburg nach dem ersten drittel des 15. jh.'s in festeren verband mit den übrigen bergischen besitzungen getreten ist; daß die ripuarischen formen im übrigen vor Barmen halt machten, daß also der Ürdinger linienstrang das alte amt Beyenburg heute zwischen Barmen und Ronsdorf durchschneidet, liegt in den bereits oben erwähnten märkischen beziehungen Barmens begründet; an dieser stelle reflectiert somit die sprachscheide den politischen gegensatz zwischen Berg und Mark.

Am südostverlauf der Ürdinger linie läßt sich also eine allmähliche ostwärtsverschiebung der ripuarischen formen beobachten, die sich in unmittelbarer anlehnung an bergische territorialbewegungen vollzog. Eine folgerichtige weiterentwicklung dieses processes müßte schließlich den ganzen Ürdinger linienstrang an die westfälisch-märkische -et-linie gedrängt liaben. Ansätze zu diesem proceß, der einmal in einem frühneuzeitlichen bedürfnis nach sprachlichem und politischem ausgleich, andererseits in den modernen ausgleichsbewegungen des industriegebietes begründet scheint, sind in den beschreibenden teilen 
aufgezeigt worden. In Vosnacken hat der proceß in der allerjüngsten vergangenheit tatsächlich zu einer anlehnung der $k / x$-linie des wörtchens 'auch' an die -ct-linie geführt; die differenzen zwischen Lobbes und Leihener sind in ihm begründet; und damit ergäbe sich, daß seit dem 15. jh. bis heute ein ständiges vorwärtsdringen der ripuarischen formen stattfindet, wobei ihre geographische entwicklung immer noch der durch die bergische territorialpolitik angegebenen richtung folgt.

Damit wird aber ein dogma erschüttert, das sich noch bei Lobbes, DDG. VIII $\S 122$ findet. Er weist nach, daß zwar die elc/e $\chi$-linie eine genauere beziehung zur ehemaligen gauoder stammesgrenze nicht erkennen läßt; behauptet dann aber, daß 'die -et-linie sich seit den tagen Chlodewigs unverändert erhalten hat, mithin auch schon die fränkischen und sächsischen gaue schied'.1) Westlich des gebietes mit 1.2.3. plur. praes. -ət liegt ein district mit 1.2. 3. plur. praes. -ə(n). Er deckt sich ort für ort mit dem dualbezirk westlich der -et-linie, schließt also auch Werden und Mülheim a.d. Ruhr ein. ${ }^{2}$ ) So wie nun die dualformen innerhalb der Ürdinger linie einen compromißvocal besitzen, so ist auch 1.2. 3. plur. praes. -ə(n) eine compromißbildung zwischen bodenständigem 1.2. 3. plur. praes. - $\partial t$ und vorrückendem ripuarischen 1.2. 3. plur. praes. $-\partial(n),-\partial t,-\partial(n)$. Der eingesessene einheitstypus übernahm die im ripuarischen typus am häufigsten begegnende form und entwickelte aus ihr einen neuen einheitstypus. Demnach ist die alte fränkisch-sächsische sprachgrenze bedentend weiter westwärts zu verlegen, als man bisher anzunehmen pflegte. Es wird aufgabe eines nächsten aufsatzes sein, die damit aufgeworfene frage nach der ehemaligen fränkisch-sächsischen grenze und ihrem verhältnis zur alten niederfränkisch-ripuarischen sprachgrenze zu erörtern. Zunächt genügt das resultat, daß die heutige -et-linie mit dem Ürdinger linienstrang eine verschiebung erfahren hat, in einer vorneuzeitlichen epoche an dem heutigen südostverlauf der Ürdinger linie stand, und mit. den weiteren ausgleichsbewegungen seit der frïhen neuzeit

1) Vgl. hingegen Lobbes $\S 125$, wo das fränkisch-süchsische grenzproblem in anschluß an T'ümpel, Behaghel, Brnme, Crecelius richtig erfnBt wird; vgl. unten.

2) Vgl. Lobbes, DDG. VIII § 27. 
all die bergisch-märkische grenze gedrückt wurde. Somit ist die frage nach dem verhältnis der $e \% / c \%$ - zur -ct-linie mit hilfe der bergischen territorialentwicklung gelöst; und es ist nicht nötig, die Hattuarier, Brukterer und gar die Engern zu hilfe zu rufen. Auch was Behaghel, Eraune und Tümpel iiber den ehemalig sächsischen charakter der Elberfelder ma. und im besonderen Tümpel, Crecelius und Leithäuser über das vordringen des fränkischen in der Elberfelder gegend im 15. 16. jh. und im 18. 19. jh. beigebracht haben ${ }^{1}$ ), stimmt zu dieser darlegung ausgezeichnet. Die rechtsrheinische aft-/hintlinie hat allein die geographische unstimmigkeit zwischen der Ürdinger und der -et-linie überbrïckt. Sie folgt auf ihrem westostverlauf der Ürdinger, auf ihrem südostverlauf der -etlinie, umschließt also, von Mülheim-Broich abgesehen, genau die nordostgrenze der grafschaft Berg gegen Cleve, Werden, Mark.

Auch für das rechtsrheinische gebiet darf man annehmen, daß die sprachlichen verschiebungen den politischen unmittelbar gefolgt sind. Dann ergibt sich für die entstehung: des rechtsrheinischen übergangsgebietes folgendes endresultat: Die alte niederfränkisch-ripuarische (und fränkischsächsische) grenzlinie wurde im 14. jh. durchbrochen. Die neue niederfränkische normalgrenze entstand im norden und osten im 14. jh., jedenfalls vor 1427. Seit dem 15. jh. ist eine bewegung im gange, die den südostteil des Ürdinger linienstranges weiter nach osten an die bergisch-märkische grenze drängt.

Es ist nicht nötig, die allgemeinen gesichtspunkte, die am ende des vorhergehenden abschnittes gewonnen wurden, durch rechtsrheinische beobachtungen weiter zu stützen. Ich erwähne nur noch die interessanten schwellenformen wie win 'wein', brun 'braun' im gebiet von Solingen, Gräfrath, Ohligs als parallelen zum linksrheinischen typus $p i \cdot n$. 'schmerz', und betone noch einmal, daß - nach ausweis der compromißbildungen - auch östlich des Rheins die nordwärtsbewegung der ripuarischen formen mechanisch, und nicht in consequenter

1) Vgl. Lobbes $\S 125$ und Leithäusers nachweis, Rheinische geschichtsblätter 2, 298, daß die gutturalisierung von $n$ vor dental in der Wuppertaler ma. erst eiu ergebnis jüngerer zeit ist. 
phonetisch-articulatorischer entwicklung vom entstehungsherde aus erfolgte. Mechanisch vollzog sich auch die verschiebung des siidoststückes der Ürdinger linie von einem früher westlicheren zu einem heute östlicheren verlauf; mechanisch wurden endlich die im allgemeinen innerhalb der Ürdinger linie entstandenen compromißbildungen bei den verschiebungen jüngerer

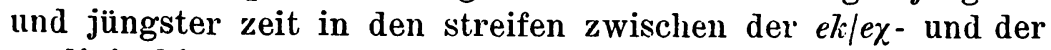
-et-linie hineingetragen. Auch datierungen für die entstelıung und ausbreitung ripuarischer sprachprocesse östlich des Rheins können nach den principiellen ergebnissen des vorhergehenden abschnittes ohne schwierigkeit aus den daten der territorialgeschichte gewonnen werden. Nur sei auch hier noch einmal betont, daß kirchlichen grenzen im allgemeinen keine ausschlaggebende bedeutung zukommt. Kirchliche verhältnisse mögen der allerkleinsten dialektgeographie hier und da eine stütze gewährt haben, sie besaßen aber nicht die kraft, große sprachliche bewegungen $\mathrm{zu}$ veranlassen, $\mathrm{zu}$ dirigieren und $\mathrm{zu}$ begrenzen. Nur großzügige territoriale bewegungen trieben die sprache des politischen ausgangspunktes bis an die grenzzone der politischen interessensphäre, wo dann die kirchliche und territoriale kleingeschichte, aber auch hier wieder vor allem die letztere, die festlegung der linien im einzelnen bestimmte. So ist Leihener im recht, wenn er vom standpunkte seines kleinen gebietes den kirchlichen verhältnissen eine besondere bedeutung zuschreibt; und doch kommt andererseits für diese von den großen politischen bewegungen aus gesehene zusammenfassung seine untersuchung der kleinen kirchspielpolitik kaum zur verwendung. Es ist nicht richtig, wenn Lobbes ${ }^{1}$ ) auch der modernen kreis - und provinzialgrenze die kraft zusprechen will, sprachgrenzen zu gestalten. Wo die moderne kreis- und provinzialgrenze dialektscheide ist, da setzt sie alte historische traditionen fort; um dialektscheide werden zu können, niißte eine ohne traditionen entstandene junge kreisgrenze im volksbewußtsein zunächșt als trennende barriere empfunden werden. Und auch das unverkennbare bestreben des Ü'rdinger linienstranges, die westfälische provinzialgrenze zu erreichen, beruht. nicht auf einem gegensatz Rheinland : Westfalen, also auf der

2) DIJG. VIII $\S 126$. 
tenden\%, den sprachlichen ausgleich den modernen politischen verhïlnissen anzupassen, sondern auf dem alten gegensatz Berg: Mark und der bis heute durch die territorialpolitik Bergs bestimmten entwicklungsrichtung der fränkischen formen.

\section{\%.}

Ich fasse die ergebnisse der untersuchung in einer skizze zusammen. Diese sucht die entwicklung des niederfränkisch ripuarischen ïbergangsgebietes nur in den allergröbsten zügen zu veranschaulichen. Alle einzelheiten lassen sich auf grund der beschreibungen von abschnitt 1-6 und mit hilfe der karten in Wredes Dialektgeographie I, II, V, VIII unschwer einordnen.

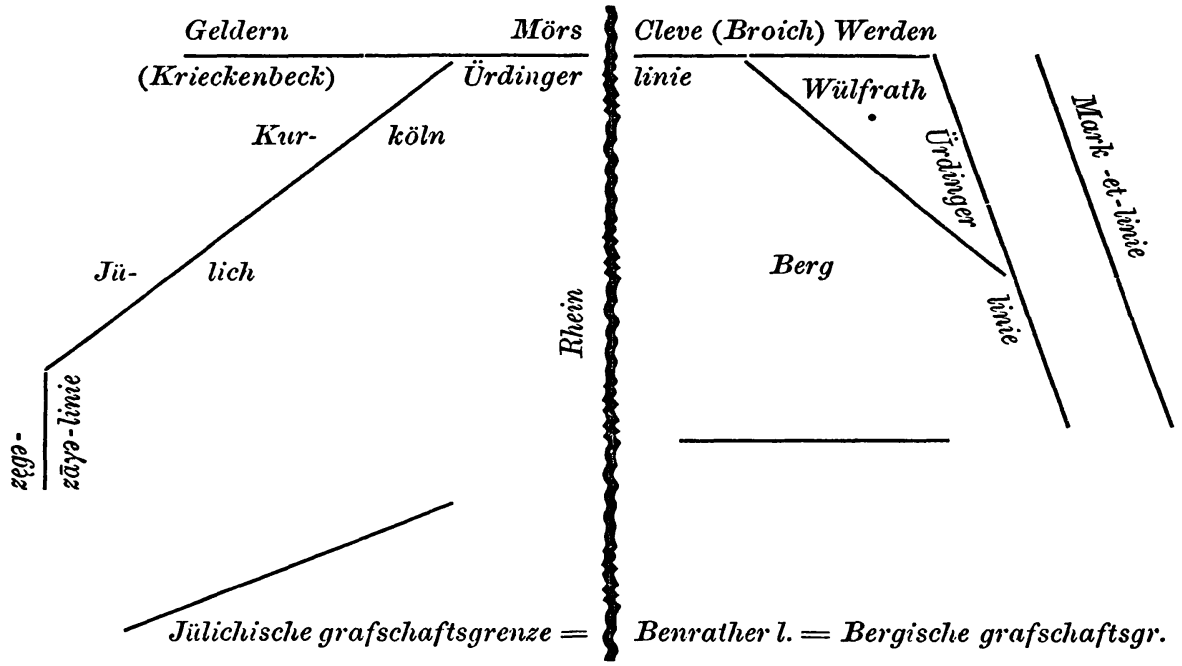

Jülich, Kurköln und Berg haben somit die alte niederfränkisch-ripuarische grenze, zu der östlich des Rheins eine noch näher zu bestimmende fränkisch-sächsische grenze hinzukam, durchbrochen, und die junge niederfänkische und fränkisch-sächsische grenze an der endzone ihres neuen politischen interessengebietes entstehen lassen. Geldern, Mörs, Werden und Mark bauten den damm, an dem sich die fränkisch-ripuarischeleroberung 
brach. Alte traditionen und kleine neubildungen auf dem eroberten boden haben eine alles nivellierende tätigkeit der südlichen formen verhindert; aus stoB und gegenstoß entwickelte sich vom 14. bis 16 . jh. das reich gegliederte übergangsbündel, das heute den raum zwischen der Benrather und Ürdinger linie erfüllt. Die örtlich eng begrenzte historische und sprachliche forschung hatte die Benrather linie als einschneidende sprachliche grenze gestrichen und die Ürdinger linie nur östlich des Rheins und auch hier nur deshalb geduldet, weil sie sich mit der vocalisierungslinie deckte; eine neue linie, die $z \ell g a / z \bar{a} g \partial-$ grenze, beanspruchte endlich einen hohen dialektscheidenden wert. Aber eine von allen kleinigkeiten losgelöste synthese des in tausend fetzen zerschlagenen übergangsgebietes führt zu den lautverschiebungslinien als praktischen begrenzungen ehemaliger und moderner verhältnisse zurück. Ob freilich auch zu den begriffen niederfränkisch und ripuarisch, ist zunächst zweifelhaft. Es wurde zwar von einer alten niederfränkisch-ripuarischen linie, von einer jungen niederfränkischen normalgrenze und von einem niederfränkisch-ripuarischen linienbündel, das sich aus ingwäonisch-deutschen, niederdeutschhochdeutschen und niederfränkisch-ripuarischen grenzen im engeren sinne zusammensetzt, gesprochen. Aber die tatsache, daß sich die alte niederfränkisch-ripuarische grenze an der alten nordgrenze von Jülich und Berg, die junge niederfränkische normalgrenze an der neuen nordgrenze von Jülich, Köln und Berg orientiert, gibt doch der frage raum, ob jene von alten stammesgruppierungen hergenommenen begriffe noch weiterhin geltung haben können. Die antwort hierauf muß im zusammenliang mit einer bewertung der ingwäonismen und der festlegung der alten fränkisch-sächsischen grenze gegeben werden.

\section{BONN.}

THEODOR FRINGS. 